\title{
Tropical Cyclone Motion and Surrounding Parameter Relationships
}

\author{
By \\ John E. George- Captain, USAF \\ Department of Atmospheric Science \\ Colorado State University \\ Fort Collins, Colorado
}

Preparation for this report has been financially supported by NOAA Grant 04-5-022-14.

Principal investigator: William M. Gray

December 1975

\section{Department of Atmospheric Science}



TROPICAL CYCLONE MOTION AND SURROUNDING PARAMETER RELATIONSHIPS

\author{
BY \\ John. E. George \\ Preparation of this report \\ has been financially supported by \\ NOAA Grant 04-5-022-14 \\ Principal Investigator: William M. Gray
}

\author{
Department of Atmospheric Science \\ Colorado State University \\ Fort Collins, Colorado \\ December 1975
}

Atmospheric Science Paper No. 241 

Ten years of rawinsonde data for 30 stations in the Western North Pacific have been compsited relative to tropical cyclone center positions. This information is used to study tropical cyclone motion and surrounding parameter relationships. Tropical cyclone motion and lower troposphere surrounding actual and geostrophic flow fields from 1-70 radius are very well correlated. This general correlation of surrounding flow features applies equally well for cyclones with different directions of motion, speeds of propagation, intensities, or intensity changes. The $700 \mathrm{mb}$ level best specifies cyclone speed. The $500 \mathrm{mb}$ best specifies direction. It is suggested that an operational short range forecasting scheme could be developed using the wind-height relationships presented in this paper.

This composite data set has also been used to study prior (12 to 72 hours) differences in surrounding environmental fields between tropical cyclones which recurved and those which did not. Basic differences out to $21^{\circ}$ radius in the wind, height, and temperature fields between these separate classes of storms are presented. A strong recurvature correlation is found in the $200 \mathrm{mb}$ wind and height fielcis at large radii. It is suggested that an operational long-range (2-3 days) tropical cyclone forecast recurvature scheme can be developed using upper: tropospheric data. 
TABLE OF CONTENTS

Page

ABSTRACT .............................. 1

PART I - TROPICAL CYCLONE MOTION AND SURROUNDING WIND-HEIGHT

RELATIONSHIPS . . . . . . . . . . . . . . . . . . . 1

1. INTRODUCTION .................... . . . . 2

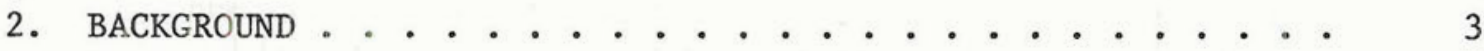

2.1 Steering Flow Track Prediction. . . . . . . . 3

2.2 Statistical Track Prediction. . . . . . . . . . 7

2.3 Numerical Track Prediction. . . . . . . . . . 9 9

2.4 Climatology-Persistence Track Prediction. . . . . . 11

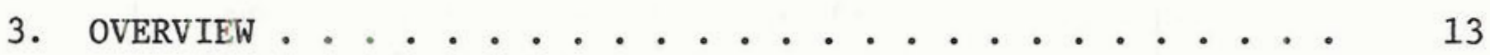

4. DATA SET AND COMPOSITE ANALYSIS. . . . . . . . . . 15

4.1 Compositing Philosophy. . . . . . . . . . 15

4.2 Data Composite Technique. . . . . . . . . . 15

4.3 Data Portrayal. . . . . . . . . . . . 19

4.4 Parameters Composited ............. . 20

4.5 Storm Motion Analysis Coordinate System . . . . . . 20

4.6 Definitions... . . . . . . . . . . . 22

5. MOTION COMPOSITE RESULTS . . . . . . . . . . . 26

5.1 Storm Asymmetry ................ 26

5.2 Relative Surrounding Flow Normal and Parallel Wind Components ................. 28

5.3 Horizontal Radial Band Vectors. . . . . . . . 31

5.4 Vertical Radial Band Vectors. . . . . . . . . 31

5.5 Storm Motion vs. Actual Surrounding Mean Wind Direction and Speed (Horizontal Multiple Radial Bands). . . .. 31

5.6 Storm Motion vs. Actual Surrounding Mean Wind Direction and Speed (Vertical Multiple Radial Bands). . . . . . 39

5.7 Comparison of Composite Wind Components vs. Calculated
Geostrophic Components. . . . . . . . . . . . 44

5.8 Cyclone Motion Relation to Right Octant Winds . . . . 51

6. DISCUSSION . . . . . . . . . . . . 53

PART II - SURROUNDING ENVIRONMENTAL DIFFERENCES BETWEEN

RECURVING AND NON-RECURVING TROPICAL CYCLONES. . . . . . . 55

1. INTRODUCTION . . . . . . . . . . . . . 56 


\section{TABLE OF CONTENTS}

Page

2. METHODOLOGY ..................... 58

3. RECURVATURE COMPOSITE RESULTS . . . . . . . . . . . 68

3.1 Depiction. . . . . . . . . . . . 68

3.2 Wind Direction and Speed . . . . . . . . . . 68

3.3 Zonal Wind .................. 76

3.4 Meridional Wind. . . . . . . . . . . . . 79

3.5 Height ................... 86

3.6 Temperature. .. . . . . . . . . . . . . . 86

3.7 Recurvature Minus Non-Recurvature Zonal and Meridional
Geostrophic Wind Components. . . . . . . . 87

4. DISCUSSION. . . . . . . . . . . . . . 9 90

SUMMARY OF PARTS I AND II . . . . . . . . . . . . . . 91

ACKNOWLEDGEMENTS. . . . . . . . . . . . . . . . . 94

BIBLIOGRAPHY . . . . . . . . . . . . . . 9 95

APPENDIX. . . . . . . . . . . . . . . . . 99 

PART I

TROPTCAL CYCLONE MOTION AND SURROUNDING WIND-HEIGHT RELATIONSHIPS 


\section{INTRODUCTION}

One of the most challenging problems in tropical meteorology is that of forecasting the movement of tropical cyclones. ${ }^{1}$ The relation of tropical cyclone movement to its surrounding flow has been previously examined by a number of meteorologists, but their data sources have usually been limited. The exact relation of cyclone movement to the surrounding flow has yet to be quantitatively established. Because tropical cyclones can be so devastating, it is important to try to better understand their movement so that improved forecasts can be made. With all the concentrated research and sophisticated forecasting techniques, the 24-hour prediction error of the National Hurricane Center (Atlantic) and the Joint Typhoon Warning Center (Pacific) remains at 100-125 nautical miles (nm). 48 and 72 hour vector forecast errors are approximately 250 and $375 \mathrm{~nm}$, respectively. Because the 24-hour forecast is the most critical in terms of lives and dollars, it is imperative that more research be attempted to improve this forecast. This may be possible by a more thorough quantitative investigation of cyclone motion and environment parameter relationships. This has been the purpose for this research.

$1_{\text {Throughout this paper tropical cyclone refers to all tropical }}$ storms regardless of their standard classification of typhoon, hurricane or tropical storm. Cyclone or storm motion is defined as the movement of the tropical cyclone center of circulation. 


\section{BACKGROUND}

Tropical cyclone prediction methods can be classified in four categories. These are:

1.) steering flow track prediction,

2) statistical track prediction,

3) numerical track prediction, and

4) climatology-persistence track prediction.

The steering concept hypothesizes that tropical cyclones are vortices embedded in the basic environmental flow, and thus, should move with the so called "steering current". This is an established forecasting concept. The statistical forecast approach numerically screens various meteorological parameters for motion related correlations and then uses these correlations to develop regression prediction equations. The numerical method uses primitive equation model prediction of the largescale flow surrounding the cyclone and more recently a crude simulation of storn structure to dictate its future track. Climatology and/or persistence of storm track relies upon empirical relationships related to the cyclone tracks of previous storms.

Table 1 lists the past 30 years' major contributions to the field of tropical cyclone motion forecasting. The type of cyclone prediction method is listed along with the primary pressure levels employed.

\subsection{Steering Flow Track Prediction}

From earlier work, the steering concept evolved because it was seen that tropical cyclones do respond to the environmental flow in which they are embedded. Rieh1 and Shafer (1944) related the movement of hurricanes to the middle level (i.e., 700 and $500 \mathrm{mb}$ ) wind and height fields, especially the changes in height of the base of the polar westerlies. Simpson (1946) deduced that the best steering level of a tropical storm 
TABLE 1

SUMMARY OF PAPERS ON TROPICAL CYCLONE TRACK FORECASTING

\begin{tabular}{|c|c|c|}
\hline Author (s)/Year & $\begin{array}{l}\text { Type of Prediction } \\
\text { Method/Concept }\end{array}$ & Primary Levels Used \\
\hline Rieh1 and Shafer (1944) & Steering & $700,500 \mathrm{mb}$ \\
\hline Simpson (1946) & Steering & Top of vortical circ. \\
\hline Rieh1 and Burgner (1950) & Steering & Sfc. to $300 \mathrm{mb}$ \\
\hline Gentry (1951) & Steering & Top of vortical circ. \\
\hline E. Jordan (1952) & Steering & Sfc. to $300 \mathrm{mb}$ \\
\hline Colón (1953) & Climatology & -- \\
\hline Riehl et al. (1956) & Steering/Statistica1 & $500 \mathrm{mb}$ \\
\hline L. Hubert (1956) & Numerical & $500 \mathrm{mb}$ \\
\hline W. Hubert (1957) & Numerical & $500 \mathrm{mb}$ \\
\hline Kasahara (1957) & Numerical & $500 \mathrm{mb}$ \\
\hline Miller (1958) & Steering & $500-200 \mathrm{mb}$ \\
\hline Veigas et a1. (1959) & $\begin{array}{l}\text { Statistical/ } \\
\text { Climatology }\end{array}$ & Sfc. \\
\hline Miller and Moore (1960) & Steering/Statistical & $700,500,300 \mathrm{mb}$ \\
\hline Wang (1960) & Statistical & $700 \mathrm{mb}$ \\
\hline Birchfield (1960) & Numerical & $\begin{array}{l}\text { Sfc. } 1000,700,500 \\
200 \mathrm{mb}\end{array}$ \\
\hline Veigas (1961) & Statistical & Sfc., $500 \mathrm{mb}$ \\
\hline Arakawa (1961) & $\begin{array}{l}\text { Statistical/ } \\
\text { Climatology }\end{array}$ & Sfc., $700 \mathrm{mb}$ \\
\hline Vanderman (1962) & Numerical & $850,700,500,300 \mathrm{mb}$ \\
\hline Tse (1966) & Steering & $700 \mathrm{mb}$ \\
\hline Miller and Chase (1966) & Statistical & Sfc., $700,500 \mathrm{mb}$ \\
\hline Miller et a1. (1968) & Statistical & $\begin{array}{l}\text { Sfc., } 1000,700 \\
500 \mathrm{mb}\end{array}$ \\
\hline
\end{tabular}


TABLE 1 (cont.)

\begin{tabular}{|c|c|c|}
\hline Author (s)/Year & $\begin{array}{l}\text { Type of Prediction } \\
\text { Method/Concept }\end{array}$ & Primary Levels Used \\
\hline Sanders and Burpee (1968) & Numerical & Sfc. $-100 \mathrm{mb}$ \\
\hline Renard (1968) & Steering/Numerical & $700 \mathrm{mb}$ \\
\hline Hope and Neumann (1970) & C1imatology & -- \\
\hline $\begin{array}{l}\text { Jarre1 and Somerve11 } \\
(1970)\end{array}$ & Climatology & -- \\
\hline Chin (1970) & Steering & $700,500 \mathrm{mb}$ \\
\hline Hope and Neumann (1970) & Climatology & -- \\
\hline Neumann et al. (1972) & $\begin{array}{l}\text { Statistical/ } \\
\text { Climatology }\end{array}$ & $\begin{array}{l}\text { Sfc., } 1000,700, \\
500 \mathrm{mb}\end{array}$ \\
\hline Neumann (1972) & Climatology & -- \\
\hline Renard (1973) & Steering & $700 \mathrm{mb}$ \\
\hline $\begin{array}{l}\text { Neumann and Lawrence } \\
\text { (1973) }\end{array}$ & $\begin{array}{l}\text { Statistical/ } \\
\text { Climatology }\end{array}$ & $1000,700,500 \mathrm{mb}$ \\
\hline
\end{tabular}


is determined by the height to which the storm's vortical circulation extends. He also formulated the idea that a tongue of warmer lighter air is oriented along the axis of the storm and thus gives indication of the storm's ensuing 24-hour motion. Later, Rieh1 and Burgner (1950) examined the relation between the motion of tropical cyclones and the steering current quantitatively. They defined the steering current as a zonal belt of $5^{\circ}$ wide extending $2 \frac{1}{2}^{\circ}$ north and south and $45^{\circ}$ east and west of the storm center and vertically from sea level to $300 \mathrm{mb}$. Gentry (1951) discussed how the Cedar Keys hurricane could have been best forecast by the use of the "steering level" winds at the top of the storm. Sherman (1950) stated that the steering current accounted for only a little more than half of the variability in the movement of hurricanes. From a limited data set, E. Jordan (1952) deduced that hurricanes move with a steering current from the surface to $300 \mathrm{mb}$ extending over $8^{\circ}$ latitude in width centered on the storm.

The most comprehensive study of this type was accomplished by Miller (1958a). His data indicated that the best cyclone steering level was from $500 \mathrm{mb}$ to $200 \mathrm{mb}$ integrated over a doughnut-shaped ring 2-6 ${ }^{\circ}$ from the center of the storm. Except in the upper layers, the storm motion was found to be faster than the mean environmental flow and, for most cases, the storms moved to the right of the mean flow. In another paper, Miller (1958b) presented a mean composite of the three-dimensional wind structure around a tropical cyclone. Miller and Moore (1960) further looked for steering levels by computing geostrophic components around tropical cyclones at the 700,500 , and $300 \mathrm{mb}$ levels. The components were then compared with the subsequent 24-hour motion. The 700 and 500 $\mathrm{mb}$ charts appeared to indicate cyclone motion with equal merit. 
Tse (1966) looked to the $700 \mathrm{mb}$ chart for height values at $10^{\circ}$ radius north, east, south, and west of the cyclone center for predictors of the next 24-hour movement. Chin (1970) showed that the wind at 700 and 500 $\mathrm{mb}$ and $4-6^{\circ}$ radius to the right of storm movement is often a good indicator of steering. Renard (1973) developed an objective cyclone forecast scheme from a sample of North Atlantic storms. This study attempted to relate the cyclone center motion with surrounding geostrophic winds derived from heavily smoothed isobaric height fields. The $700 \mathrm{mb}$ level was established as the optimum steering level, but a fully operational test in 1971 suggested that the $850 \mathrm{mb}$ level was better for forecast intervals beyond 36 hours.

Summary. As described above, the past efforts of the steering method for tropical cyclone track prediction vary in their approaches. Different levels were found as the optimum for steering by the various researchers. Most of these studies lacked sufficient data for precise quantitative specification of the surrounding flow. Past data samples were usually small, and in some studies single storm samples were employed. Thus, there presently is no agreement on the "steering flow" or level, although the majority of the steering method schemes use lower and middle level data (surface - $500 \mathrm{mb}$ ).

\subsection{Statistical Track Prediction}

The statistical approach to the forecasting of tropical storms came naturally as an off-shoot of the steering concept, in that certain parameters were compared quantitatively to the storm motion. Riehl, et al. (1956) developed one of the earlier objective schemes which gave regression equations and a prediction diagram for forecasting purposes. 
They assumed that hurricanes moved with the general flow, and the E-W and $\mathrm{N}-\mathrm{S}$ components of geostrophic $500 \mathrm{mb}$ flow over a $15^{\circ}$ square were statistically related with the E-W and $\mathrm{N}-\mathrm{S}$ storm displacements. This scheme appeared to improve the forecasts slightly at that time. Veigas, et a1. (1959) developed an objective scheme based on motion statistics. The resultant regression equations used the present and past 24-hour positions of the storm and selected surface pressures as predictors. Wang (1960) developed a similar technique in the Pacific. He used the contour heights as selected points at the $700 \mathrm{mb}$ level and the intensity and orientation of the major axis of the subtropical high cell as predictors. Both of these new schemes were found to be of practical value. Veigas (1961, 1962) expanded on his earlier work and included the surface and $500 \mathrm{mb}$ pressure heights to develop a new set of prediction equations. Arakawa $(1961,1963)$ developed a scheme similar to Veigas' (1959) and concluded that the subsequent location of a typhoon can be better predicted without attempting to include persistence explicitly in the regression formula. The $700 \mathrm{mb}$ height values were used as the primary predictors.

Miller and Chase (1966) developed a complex statistical objective scheme known as NHC-64 (National Hurricane Center 1964). This scheme incorporated a set of prediction equations which had the best features of the earlier techniques. The predictors used included the sea level pressure, $700 \mathrm{mb}$ height, $500 \mathrm{mb}$ height, 1000-700 mb thickness, 700-500 mb thickness, $500 \mathrm{mb}$ height change, geostrophic wind components and past 12-hour movement. The accuracy of NHC-64 forecasts compared favorably with that of the official forecast for the sample cases. Miller et al. (1968) continued this work and revised the NHC-64 scheme with the 
addition of more predictors. The new scheme was labeled NHC-67 and added the following predictors: $u$ and $v$ components at 1000,700 , and $500 \mathrm{mb}$. The NHC-67 was slightly superior to the NHC-64 technique. Neumann, et al. (1972b) expanded this statistical approach by combining the NHC- 67 method with climatology and persistence to produce the NHC-72 scheme. In essence, NHC-72 combines synoptic and empirical data to make one forecast. An additional statistical model was developed by Neumann and Lawrence (1973) which used similar predictors as the NHC-72 scheme, but included regression techniques with the 'perfect-prog' concept to introduce numerically forecast upper-air data into the prediction equations. Today, the NHC-67 and NHC-72 schemes are run on an operational basis by the hurricane specialists at the National Hurricane. Center in Miani. Overall, the NHC-72 model seems to give a better forecast than the NHC-67. No synoptic/empirical technique of this type has been developed to this date in the western North Pacific.

Summary. The statistical schemes have aided the state-of-the-art forecasting of tropical cyclones. Different parameters or combinations of parameters are used as predictors. Again, technique accuracy is limited by the data set used in their development. Except for Bernuda, western Atlantic rawinsonde data is non-existent. Not many storms per year pass through the more dense West Indies network.

\subsection{Numerical Track Prediction}

Earlier work with predicting storm motion with numerical models had little success (L. Hubert, 1956, 1959; W. Hubert, 1957; Kasahara, 1957; Birchfield, 1960; Vanderman, 1962). The results of all these numerical schemes compared very unfavorably with the official forecast based on existing schemes. This, of course, must be attributed to both 
the inadequacy of the physical models used and the input data which was usually quite deficient. Sanders and Burpee (1968) developed a barotropic hurricane track forecasting numerical model. The barotropic prediction model was applied in a way such that it used the information available to describe the character of tropical circulations. It was thought that this concept could improve the current state-of-the-art forecast from 24-72 hours in regions of relatively dense rawinsonde data coverage. The initial tests of the barotropic track forecasts were encouraging. Sanders (1970) discussed the major hypothesis of barotropic track forecasting. He stated that the motion of a tropical cyclone is governed principally by advection of mean vorticity in the air column containing the storm, which is taken to be the entire tropical troposphere from 1000 to $100 \mathrm{mb}$. Tests on past hurricanes indicated a substantial improvement on extended forecasts. Operationally, Sander's scheme (SANBAR) does provide significant improved forecasts at the 48 and 72 hour forecast periods. Renard (1968, 1969) developed a numerical scheme for the U.S. Navy which uses a numerically derived forecast steering current and its bias. The $700 \mathrm{mb}$ level of steering was found to give best results. The National Hurricane Center (Miller, et al. 1972) and the NOAA research group under the direction of J. Hovermale in Washington D.C., are currently developing baroclinic P.E. models for track prediction. Initial indications are that these new numerical models will be much superior to all previous numerical schemes. In fact, it is hypothesized that these new models will not only improve the track prediction at all time periods but also predict storm precipitation. 
Summary. Except for the current barotropic model now being used, previous numerical models have had little success in predicting tropical cyclone motion. This can be attributed to the combined inadequacy of the physical models and the input data, which is usua1ly sparse. Diabatic processes and cumulus interaction are not well handled by any numerical mode1. Although extensive research is now being carried out on baroclinic prediction models, significant improvement in track predictions by these methods is not likely to occur until the basic physical processes between the tropical cyclone and its environment are observationally delineated.

\subsection{C1imatology-Persistence Track Prediction}

Climatology and persistence methods have greatly aided in cyclone forecasting. Colón (1953) performed an extensive study of the clinatology of hurricanes in the Caribbean-West Indies region. His study, based on data from 1887-1950 showed annual and monthly motion frequencies, probabilities of movement, regions of formation, and directions and speeds of motion. This massive climatology greatly aided the tropical storm forecaster. Hope and Neumann (1971) expanded on this original work with the use of the computer.

Hope and Neumann (1970) also developed an ingeneous objective motion scheme known as HURRAN. The HURRAN, which stands for hurricane analog, is a technique for selecting analogs for an existing tropical storm from past tracks of all Atlantic tropical storms since 1886 . Those that have designated characteristics of latitude, longitude, date, intensity, motion, etc. similar to an existing storm are selected and identified as to give possible insight in predicting the current storm's 
future track. Jarrell and Somervell (1970) developed a similar scheme for the Pacific Ocean. Neumann (1972) developed yet another scheme called CLIPPER, based on climatology and persistence. It reduces the shortcomings of the HURRAN system by providing forecasting guidance when insufficient analogs are available. The CLIPPER model uses a series of regression equations fitted to essentially the same predictors used in the analog sense by HURRAN. Thus, climatology and persistence are used extensively in tropical storm prediction. The HURRAN and CLIPPER models are run routinely on an operational basis at the National Hurricane Center, while the analog approach is used extensively for initial. guidance at the Joint Typhoon Warning Center.

Sumnary. Climatology and persistence techniques aid the forecaster in track prediction for "typical" storms for the earlier part of the forecast period. Typical refers to we11-behaved storms that move in an expected continuous track with little deviation. Storms with erratic or sudden changes in their tracks are handled poorly with the climatological approach. 


\section{OVERVIEW}

Combining all schemes and systems, it can be stated that no one objective technique is superior at all times to another. As can be deduced from the above discussion, there is no agreement on a specific outer steering current or level, although the majority of the schemes use lower tropospheric data. Some schemes work well for one storm, but poorly for another. The final forecast at the National Hurricane Center (Atlanti.c) and the Joint Typhoon Warning Center (Pacific) is a result of subjective modification of the multiple objective schemes. Although there has been improvement in the 48 to 72 hour forecast time frame, significant improvement of the 24-36 hour forecast has remained difficult to accomplish. This must be attributed to a basic lack of knowledge of the cyclone in its relation to its immediate environment and perhaps more importantly to the accuracy of measuring this environment.

With the recent availability of massive computer tape data storage, these data limitations can now be partially overcome. This study is so directed. It employs ten years of rawinsonde data around tropical cyclones in the western North Pacific. Approximately 20,000 soundings are ava:ilable for this composite study. The mean composite surrounding winds are examined in relation to the cyclone motion. This is done at all levels in the atmosphere as well as for various radial distances from the cyclone center. Another unique feature of this study is that the data set is broken down into a group of sub-sets or stratifications based on certain characteristics of the cyclones. This is done on the hypothesis that if, indeed, there are certain steering relationships between the cyclone motion and the surrounding wind flow, then these relationships should be consistent regardless of different storm 
characteristics such as speed, direction of movement, intensity, etc. Using the above mentioned data and the stratification approach, this composite study does indeed describe consistent relationships between the cyclone motion and the surrounding flow. It is concluded that new operational forecast schemes might be developed using the findings of this study and some improvement in track forecasting possibly obtained. 


\section{DATA SET AND COMPOSITE ANALYSIS}

\subsection{Compositing Philosophy}

The merit and requirement of rawinsonde compositing has been discussed previously by Williams and Gray (1973) and Ruprecht and Gray (1974). Basically, at one time period there are simply too few rawinsonde stations in proximity to a tropical cyclone to give enough data for a reasonable accurate surrounding analysis. This is true for all cyclone regions except possibly within the West Indies network. In the western North Pacific there is one region where many typhoons traverse that no rawinsonde station is available within a $600 \mathrm{~nm}$ radius circle. The surrounding observations that are available at regular time intervals are often not representative of the inner cyclone circulation. By compositing the rawinsondes from many cyclones with similar characteristics over nany parts of the ocean, many of the data limitations can be overcome and the basic physical processes and relationships involved with the tropical storm better understood.

\subsection{Data Composite Technique}

The data used in this composite study comes from ten years of rawinsonde reports (1961-1970) in the western North Pacific. Fig. 1 shows the locations of the 30 stations available for that period. The western North Pacific has approximately 20 well developed tropical cyclones per year within the rawinsonde network (Gray, 1971). Thus, over this ten year period there are approximately 200 cyclones on which this data sample is based. If each storm has approximately 6 days or 12 time periods of observations and 8 rawinsonde stations surrounding it each time period (within $25^{\circ}$ radius), then over a 10 year period approximately: 10 (yr) $x \sim 20$ (storms per year) $x \sim 12$ (time periods for each storm) $x 8$ (stations available 


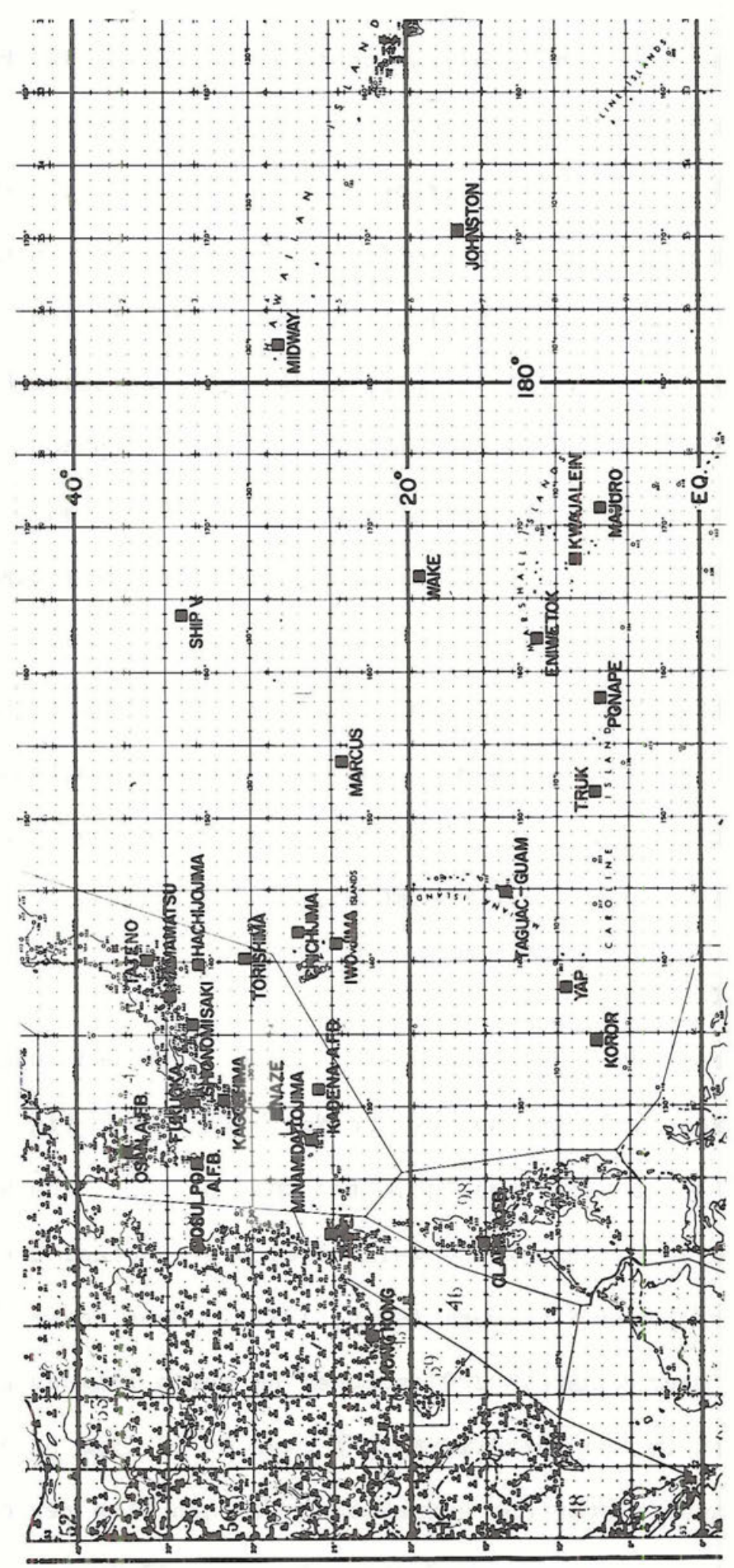

Dే 
for each time period) $=\sim 20,000$ rawinsonde reports are available for the entire data set. Within $15^{\circ}$ radius there are about 9,000 reports available around the storms as shown in Figure 2. The Appendix lists the number of rawinsonde reports which are contained in each octant of each radial band for each storm stratification. As can be seen for the complete data set, the azimuthal distribution of rawinsonde reports is quite symmetrical at radii greater than $1^{\circ}$, and the number of rawinsonde reports in each outer averaging area is quite large.

A $15^{\circ}$ circular radius grid is used for the compositing - see Figure 2. Each sounding for each storm is recorded by latitude and longitude for each time period. Each sounding's position relative to the cyclone center (center of the grid) is then determined in cylindrical coordinates. All of the parameters to be composited, whether directly measured or computed from the directly measured parameters, are determined at the station locations at 19 levels from the surface to $50 \mathrm{mb}$. Certain corrections in the relative positions of the balloon to the storm center are made. These are discussed later.

The cylindrical grid consists of 8 equal octants of $45^{\circ}$ tangential extent and 8 radial bands extending from $0-1^{\circ}, 1-3^{\circ}, 3-5^{\circ}, 5-7^{\circ}, 7-9^{\circ}$, $9-11^{\circ}, 11-13^{\circ}$, and $13-15^{\circ}$. These divide the grid into 64 spaces of various sizes. After all parameters have been measured or computed for each sounding, the value of each parameter is assigned to a point at the geometrical center of the individual grid space in which it falls. All soundings falling in that grid space for the particular group of storms and time periods being analyzed are then averaged or composited.

To obtain the best possible wind values, it is necessary to correct the positions of both the moving storm and the ascending balloon at each 


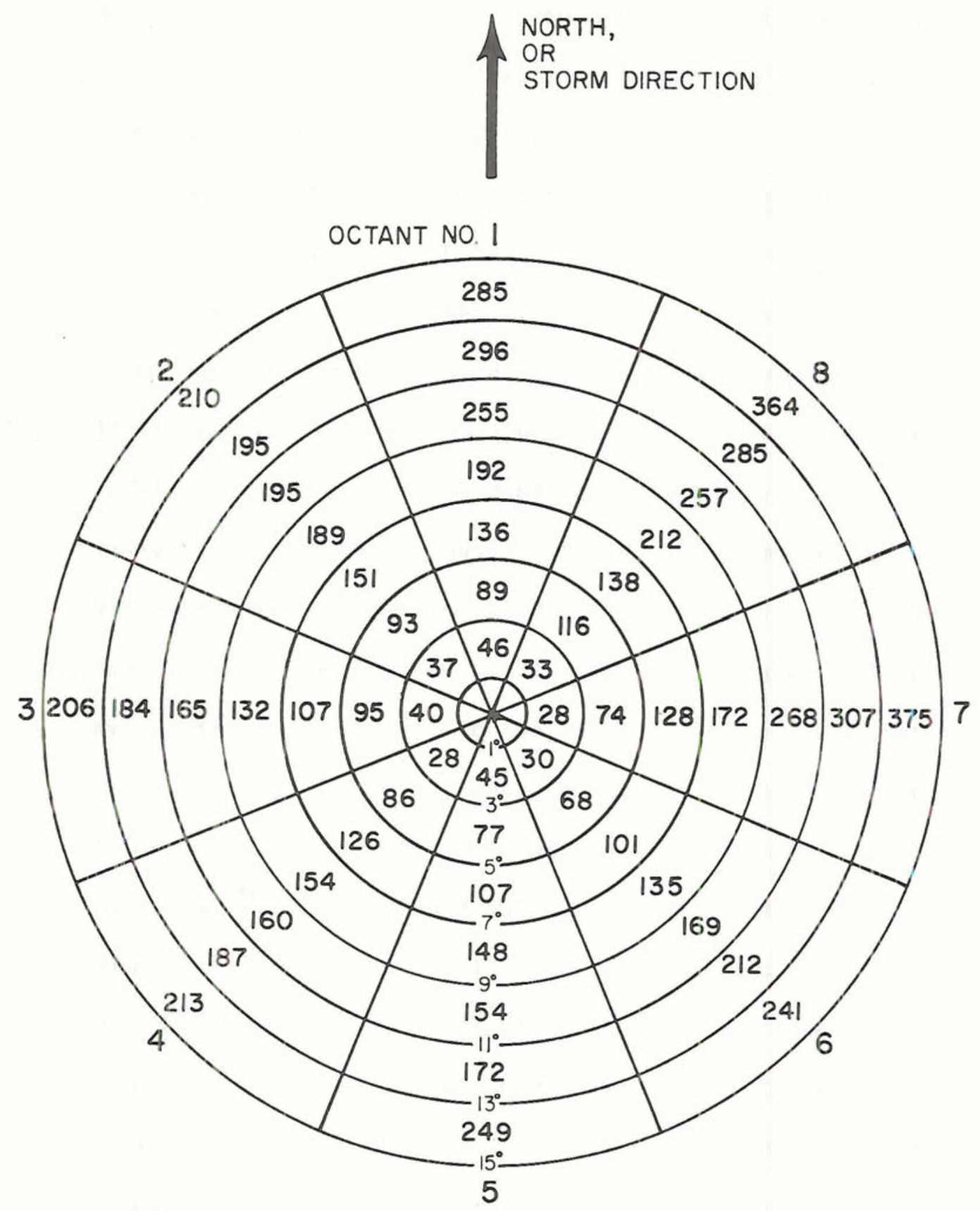

Figure 2. Compositing grid ( $15^{\circ}$ latitude radius) with the number of rawinsonde reports in each octant and each $2^{\circ}$ radial band for the combined data set. 
level of balloon ascent. This is done in the following manner. The initial position of the storm is moved back along its motion vector a distance equal to 30 minutes travel according to its previous 12-hour mean speed and direction of motion. This approximately corrects the storm position to its location at actual balloon release time as estimated from individual sounding reports. A mean balloon ascent rate of $5 \mathrm{~m} / \mathrm{sec}$ is assumed, and a mean ascent time to each of the upper pressure levels is computed. The position of the storm changes along its motion vector at each level according to the assumed balloon ascent time to that level.

Using the same computed ascent times, the position of the balloon is changed at each leve1. For each ascent interval mean $\mathrm{u}$ and $\mathrm{v}$ wind components are computed and the balloon position is corrected by:

$$
\begin{aligned}
& \Delta \mathrm{X}_{i}=\bar{u}_{i} \Delta t_{i} \\
& \Delta \mathrm{Y}_{i}=\bar{v}_{i} \Delta t_{i}
\end{aligned}
$$

Therefore, the balloon position for each sounding changes at each level according to the observed winds.

\subsection{Data Portrayal}

The above rawinsonde information is portrayed in a cylindrical coordinate system relative to the cyclone centers. Four separate reference frames can be used. They are:

a) with respect to the instantaneously fixed cyclone center in a $\mathrm{N}-\mathrm{S}$ or geographical coordinate system,

b) with respect to the cyclone center in a geographical coordinate system with the cyclone motion subtracted out of all the winds - (portrayal of data relative to the moving cyclone center in geographical coordinates), 
c) with respect to the instantaneously fixed cyclone center and the direction to which the storm is moving, and

d) with respect to the cyclone center and the direction to which the storm is moving with the cyclone motion subtracted out of all the winds - (portrayal of data relative to the cyclone center in a reference frame aligned according to the direction toward which the storm is moving).

This study employed the latter two compositing frames.

Information is portrayed at the following pressure levels: the surface, $1000,950,900,850,800,700,600,500,400,300,250,200$, $150,100,80,70,60$, and 50 millibars.

\subsection{Parameters Composited}

The following parameters are measured or computed at each level in each coordinate system for each sounding:

Wind Parameters

$\mathrm{u}$ (zonal wind)

$v$ (meridional wind)

$v_{\theta}$ (tangential wind)

$\mathrm{V}$ (total wind)
Thermodynamic Parameters

H (height)

T (temperature)

The above parameters are composited at each of the 64 grid spaces at each level. As stated previously, the number of soundings in each grid space for the data composites discussed in this paper is shown in the Appendix.

\subsection{Storm Motion Analysis Coordinate System}

From the basic coordinate systems above the following storm motion coordinate system was devised for this study. The grid is rotated to the direction of the cyclone motion, so that in the compositing technique the cyclone motion is always at a zero or a $360^{\circ}$ heading as shown in Figure 3. From the data sample in the two relevant grids (stationary and moving as $c$ and $d$ in Section 4.3), two new environmental wind 


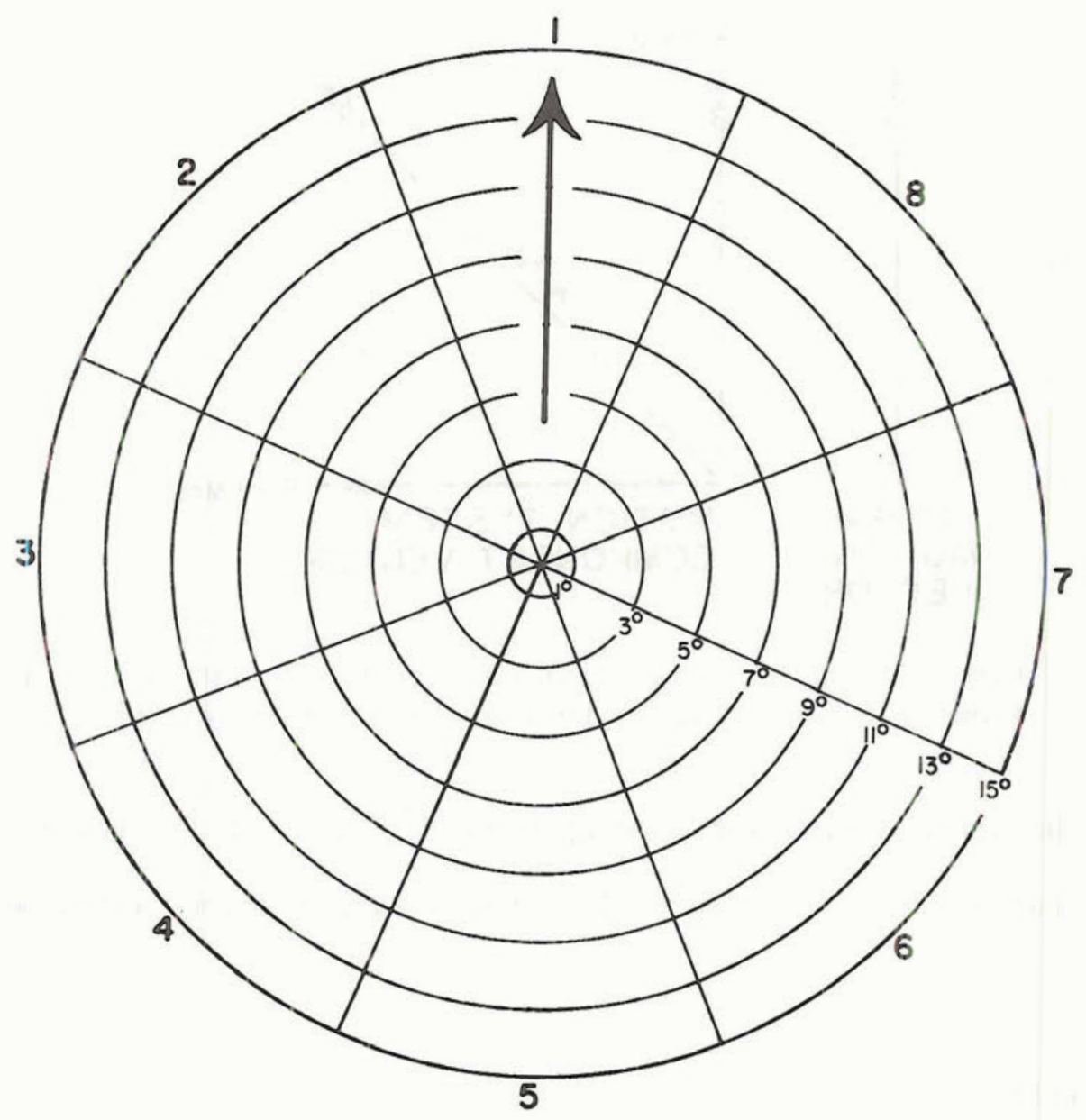

Figure 3. Grid used for compositing the rawinsonde data for the motion studies. The arrow points in the direction of storm motion. Note the 8 octants and 8 radial bands which make up the 64 grid spaces.

vectors at each of the 64 grid points are calculated. These new vectors are defined as the wind components perpendicular $\left(\mathrm{V}_{\mathrm{N}}\right)$ and parallel $\left(\mathrm{V}_{\mathrm{L}}\right)$ to the cyclone motion. The two component vectors of an example wind vector relative to the cyclone are shown in Figure 4. From these data samples, an analysis was performed to determine the relationship between the surrounding wind flow direction and speed and the cyclone's motion. As previously stated, the data were broken down into a group of subsets or stratifications in order to detect differences, if 


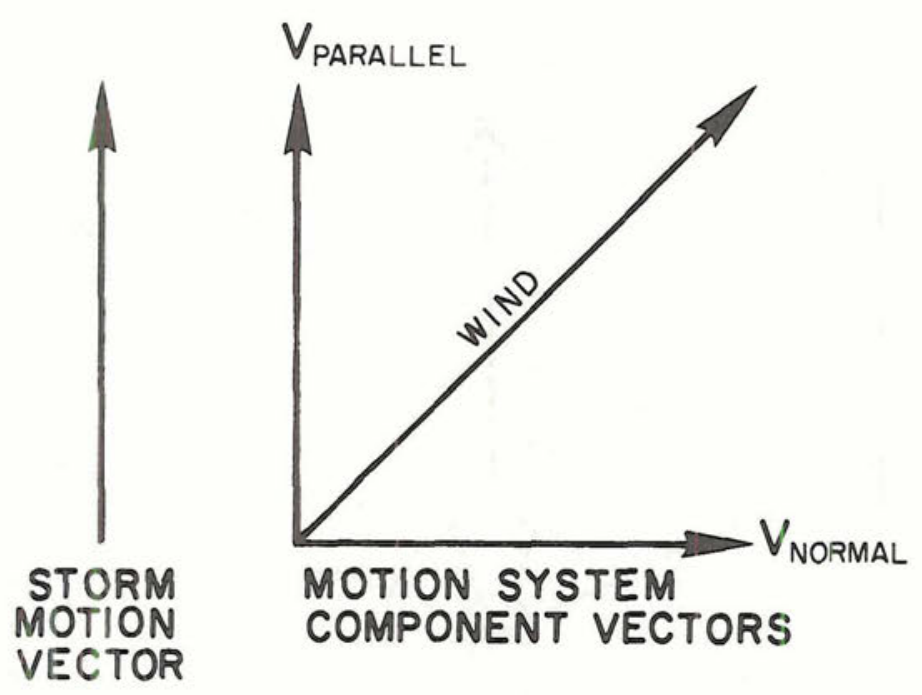

Figure 4. Parallel and perpendicular components of a wind vector showing their relation to the storm motion vector.

any, in the storm motion-surrounding wind relationship for different storm characteristics. Table 2 lists the stratifications which were made.

\subsection{Definitions}

To better clarify how these composites were made, the following definitions are introduced:

a) ROTated coordinate system (ROT) - Stationary grid aligned along the direction of the storm motion (coordinate grid is pointing in the direction of the storm motion). This system depicts the actual winds along and normal to the fixed cyclone center.

b) MOTion and ROTated coordinate system (MOTROT) - Same as the ROT system of a) except the storm motion is vectorially subtracted from all the actual winds. Thus, wind components are portrayed along and normal to the moving storm position.

c) $\mathrm{V}_{\mathrm{N}}$ - The wind component vector normal to the storm motion vector in the ROT system. (Positive to the right, negative to the left looking in the direction to which the storm is moving).

d) $\mathrm{V}_{\mathrm{L}}$ - The wind component vector parallel to the storm motion in the ROT system. (Positive to the direction to which the storm moves (forward), negative opposite to which the storm moves (rear)). 
e) $V_{N R}$ - Same as c) except in the MOTROT system.

f) $V_{L R}-$ Same as d) except in the MOTROT system.

g) Horizontal Radial Band - The horizontal average of the eight octant values of the grid for a single band; $i . e$. the $1-3^{\circ}$ radius band averaged around the storm for a single level.

h) Vertical Radial Band - Horizontal radial bands vertically integrated with respect to pressure levels; i.e. the 1-30 averaged band integrated from $1000 \mathrm{mb}$ to $100 \mathrm{mb}$, etc. for example.

i) Horizontal Multiple Radial Band - An area weighted average for two or more horizontal radial bands; i.e. the $1-7^{\circ}$ radius band.

j) Vertical Multiple Radial Band - Multiple radial bands integrated with respect to pressure levels; i.e. the $1-7^{\circ}$ area weighted radius band integrated from $1000 \mathrm{mb}$ to $100 \mathrm{mb}$.

The relation between the four component vectors, c-f above, is described below. Figure 5 depicts the relation between the storm motion and the two component vectors of a wind in the ROT system. Figure 6 depicts the subtraction of the storm motion vectors which gives the new component $V_{L R}$. The normal component $\left(V_{N}\right)$ is not affected by the subtraction since the grid is always aligned along the storn motion. The magnitude of $\mathrm{V}_{\mathrm{N}}$ and $\mathrm{V}_{\mathrm{NR}}$ are thus the same. For the parallel component in the MOTROT system $\left(V_{L R}\right)$, the following relation holds:

$$
\mathrm{V}_{\mathrm{LR}}+\mathrm{S}_{\mathrm{M}}=\mathrm{V}_{\mathrm{L}}
$$

where $\mathrm{S}_{\mathrm{M}}$ is the magnitude of the storm motion. 
TABLE 2

STRATIFICATIONS

1. LAT $>20^{\circ} \mathrm{N}-\mathrm{A} 11$ storms with a latitude position greater than $20^{\circ} \mathrm{N}$.

2. LAT $<20^{\circ} \mathrm{N}$ - All storms with a latitude position less than $20^{\circ} \mathrm{N}$.

3. SLOW - Speed category for storms moving with a speed between 0 and $3 \mathrm{~ms}^{-1}$.

4. MODERATE - Speed category for storms moving with a speed between 3 and $7 \mathrm{~ms}^{-1}$.

5. FAST - Speed category for storms moving with a speed greater than $7 \mathrm{~ms}^{-1}$.

6. DIRECTION A - Direction category for storms moving between $250^{\circ}$ and $310^{\circ}$.

7. DIRECTION B - Direction category for storms moving between $310^{\circ}$ and $350^{\circ}$.

8. DIRECTION C - Direction category for storms moving between $350^{\circ}$ and $060^{\circ}$.

9. INTENSITY I - Intensity category for storms with central pressures between $1000 \mathrm{mb}$ and $980 \mathrm{mb}$.

10. INTENSITY 2 - Intensity category for storms with central pressures between $980 \mathrm{mb}$ and $950 \mathrm{mb}$.

11. INTENSITY 3 - Intensity category for storms with a central pressure less than $950 \mathrm{mb}$.

12. DEEPENING - Intensity change category for storms whose central pressures were decreasing at the time of observation.

13. FILLING - Intensity change category for storms whose central pressures were increasing at the time of observation. 


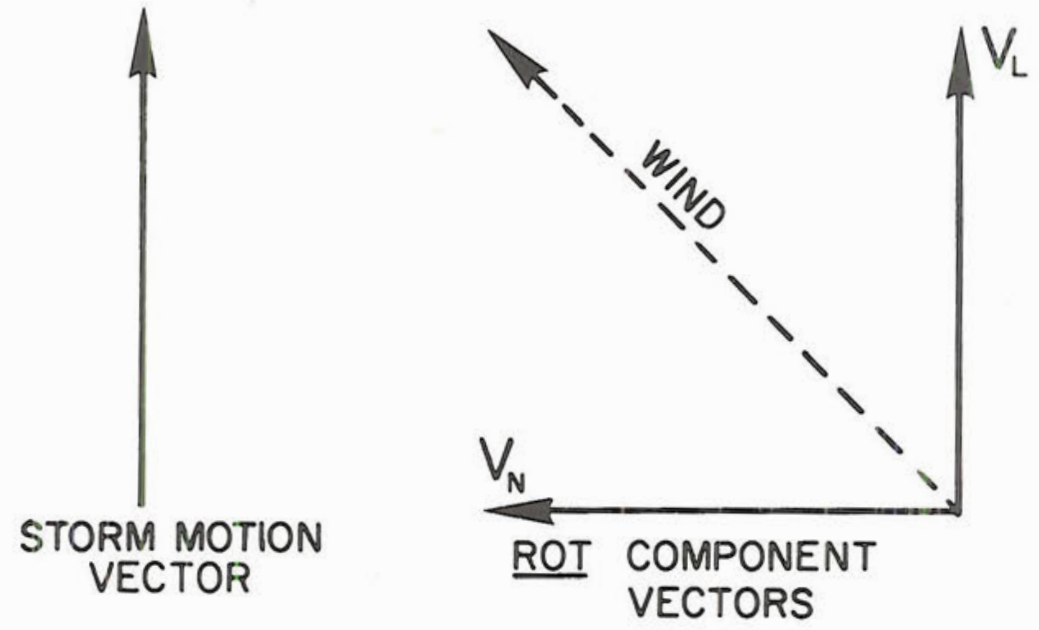
Figure 5. Relation between component vectors $\mathrm{V}_{\mathrm{L}}$ and $\mathrm{V}_{\mathrm{N}}$ to the storm
motion (ROT system).
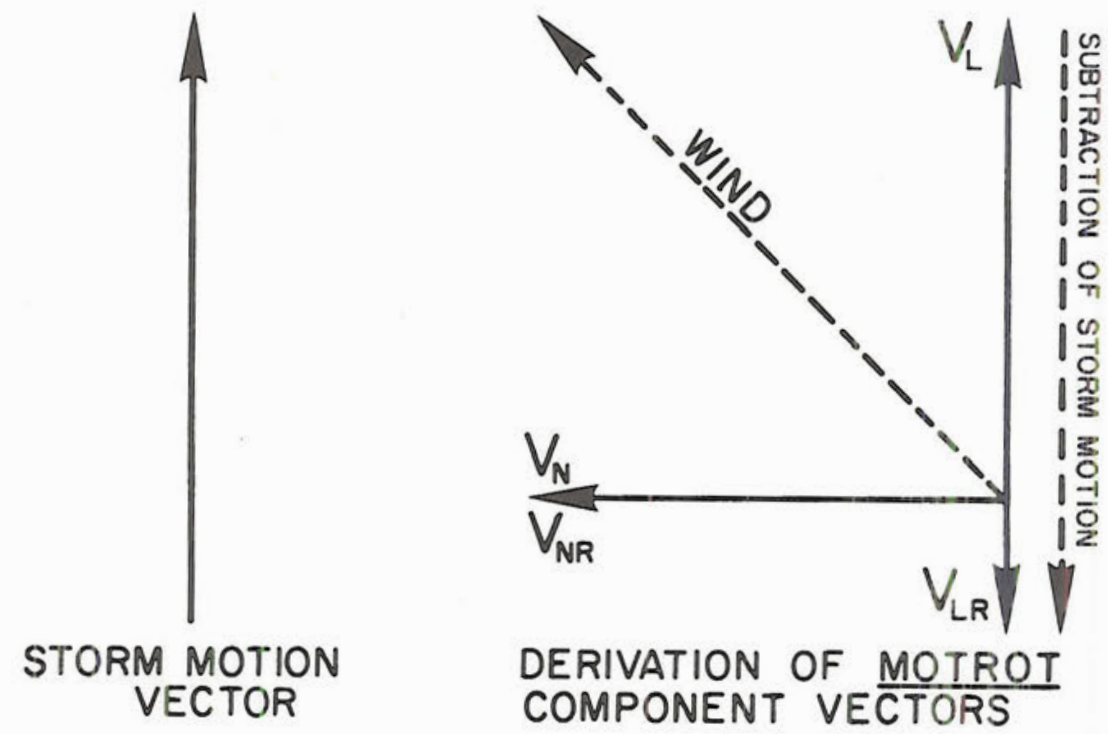

Figure 6. Derivation of relative component vectors $V_{L R}$ and $V_{N R}$ for the MOTROT system. Note that $\mathrm{V}_{\mathrm{N}}$ and $\mathrm{V}_{\mathrm{NR}}$ are identical. 



\section{MOTION COMPOSITE RESULTS}

\subsection{Storm Asymmetry}

It has long been known that the winds around a typhoon are not symmetrical. The right quadrant winds are typically stronger than the left quadrant. In order to examine the asymmetry of the composited data set, the right octant winds were compared with those of the left octant. The results at $700 \mathrm{mb}$ for storms at latitudes greater and less than $20^{\circ} \mathrm{N}$ are portrayed in Figures 7 and 8 , respectively. Inside $1^{\circ}$ radius the multiple hurricane flight data of Shea and Gray (1973) was added to the data sample. This asymmetry is typical for the other stratifications based on storm speed, direction, intensity, and intensity change. Cyclone asymmetry is greatest at the radius of maximum winds which is located $1 / 3^{\circ}$ radius (Shea and Gray, op.cit.) from the storm center. In examining the actual winds, it is seen that the asymetry decreases outward to $10-12^{\circ}$ radius. At $1-6^{\circ}$ radii, most of the right to left side asymmetry is due to the storm motion as can be seen by looking at the relative tangential winds of the right vs. left side with the cyclone motion subtracted out. Very few differences between the right and left side are seen in the $1-6^{\circ}$ radial band. At greater radii, the relative tangential winds are stronger on the left rather than the right octant. As Shea and Gray (op.cit.) discussed, inside $1^{\circ}$ radius a large asymmetry still exists in the relative winds. The important consideration shown here is that between $1-6^{\circ}$ radius, the apparent right to left octant asymmetry is due to the motion of the storm. It is the storm's circulation imposed upon the normal environmental horizontal height gradient which results in the asymmetry. 

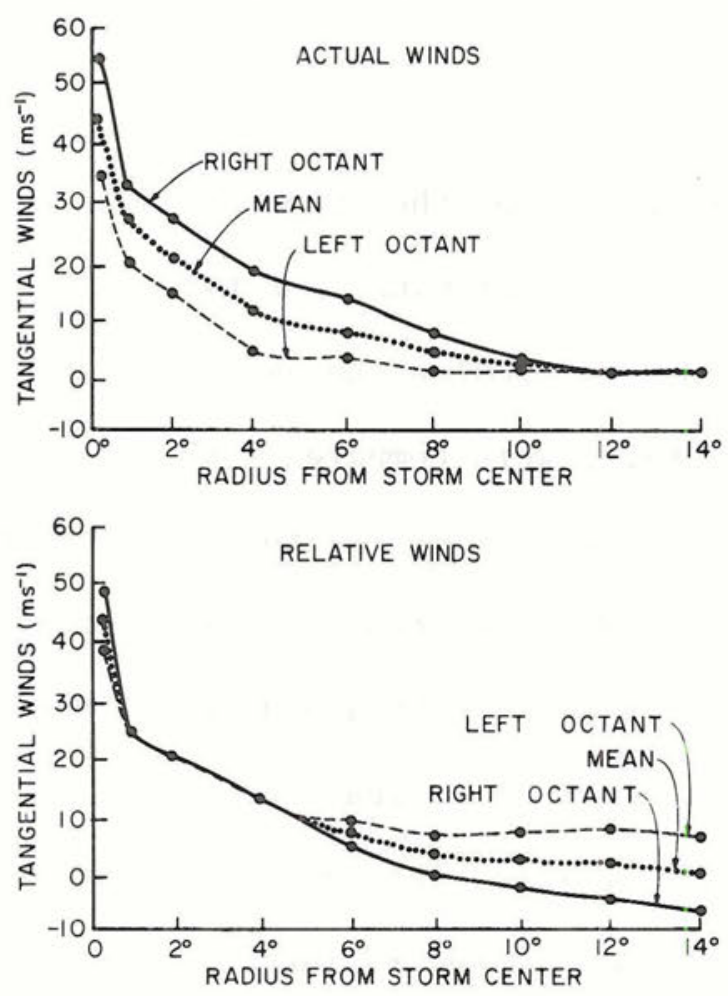

Figure 7. $700 \mathrm{mb}$ tangential wind profiles of actual and relative winds depicting the asymmetry between the right and left octants of tropical cyclones for the LAT $>20^{\circ} \mathrm{N}$ stratification.
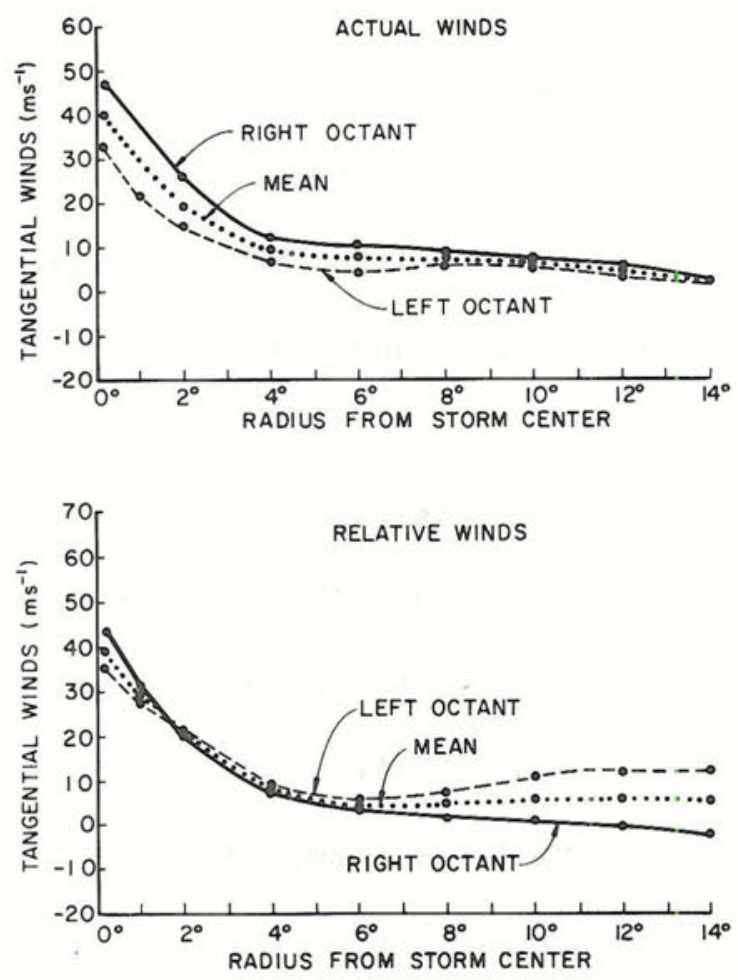

Figure 8. Same as Figure 7 , except LAT $<20^{\circ} \mathrm{N}$ stratification. 


\subsection{Relative Surrounding Flow Normal and Parallel Wind Components}

Figures 9 and 10 depict the mean normal wind component $\left(V_{N R}\right)$ for the single bands through the atmosphere in the relative system (MOTROT) for the two latitude stratifications. For depiction purposes, the radial bands are indicated by a single average radius; i.e. $2^{\circ}$ represents the $1-3^{\circ}$ radial band, etc. The zero line indicates that the surrounding wind is directed only along the storm direction of motion. Positive values indicate that the storm is moving to the left of the mean winds, while negative values indicate a storm movement to the right of the mean winds. At the majority of the levels it is apparent that the composite storm is moving to the left of the surrounding mean winds. Similar results are obtained for the other 9 stratifications.

Figures 11 and 12 depict the parallel wind component $\left(\mathrm{V}_{\mathrm{LR}}\right)$ for the single levels in the MOTROT system. Positive values indicate that the surrouncling winds are moving faster than the storm, while negative values indicate that the component of the surrounding wind along the direction of the storm motion is less than the storm motion. Except at close in radii, the majority of the points show that the mean storm motion is greater than the mean surrounding flow. Again, similar results are obtained for the 9 other stratifications. Thus, at a majority of radii and levels, tropical cyclones are propagating faster than and to the left of the mean surrounding flow field. A consistency of storm movement in relation to the surrounding wind is evident. 


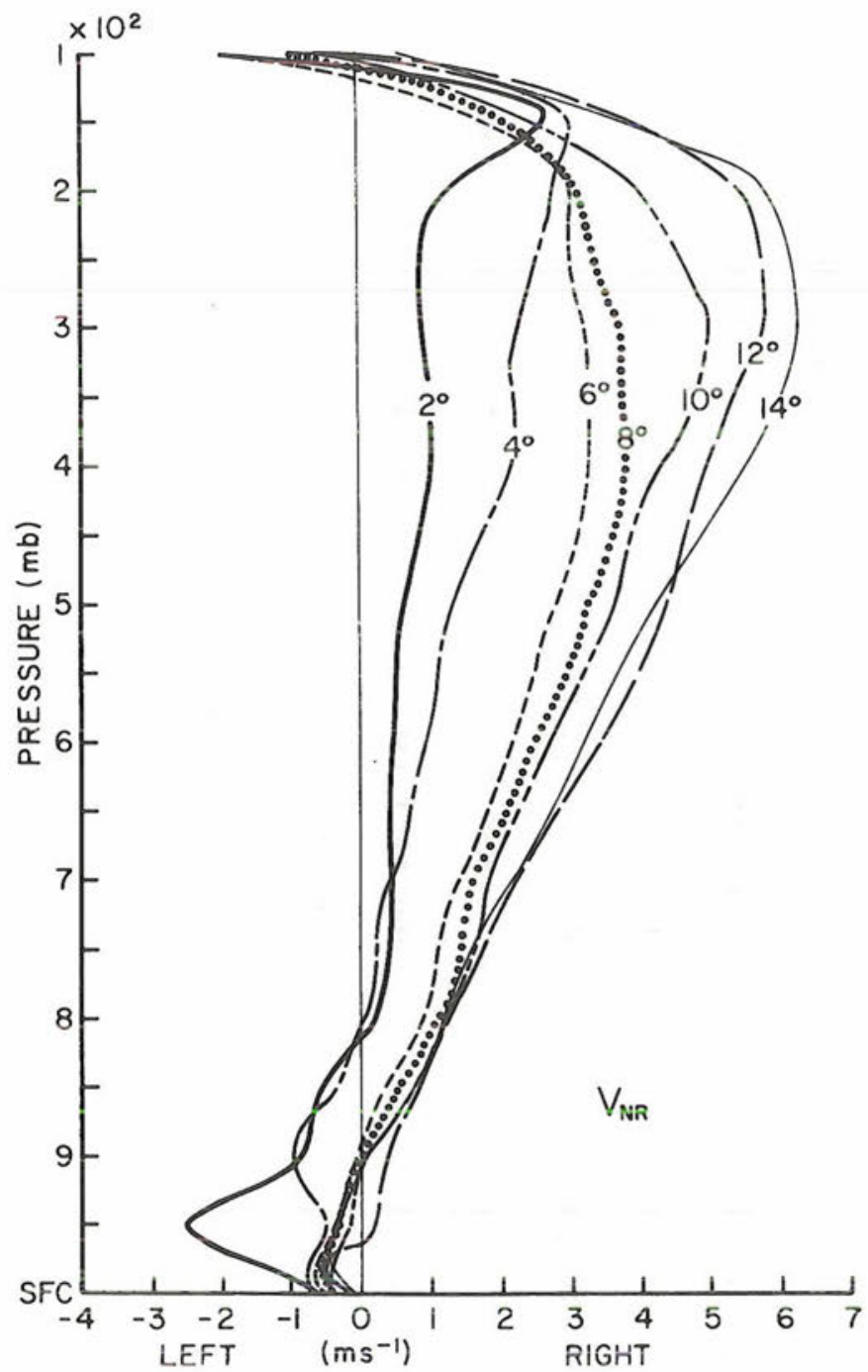

Figure 9. Relative wind component vector normal $\left(V_{N R}\right)$ to the storm motion vector for the various radial band averages and levels for the LAT $>20^{\circ} \mathrm{N}$ stratification.

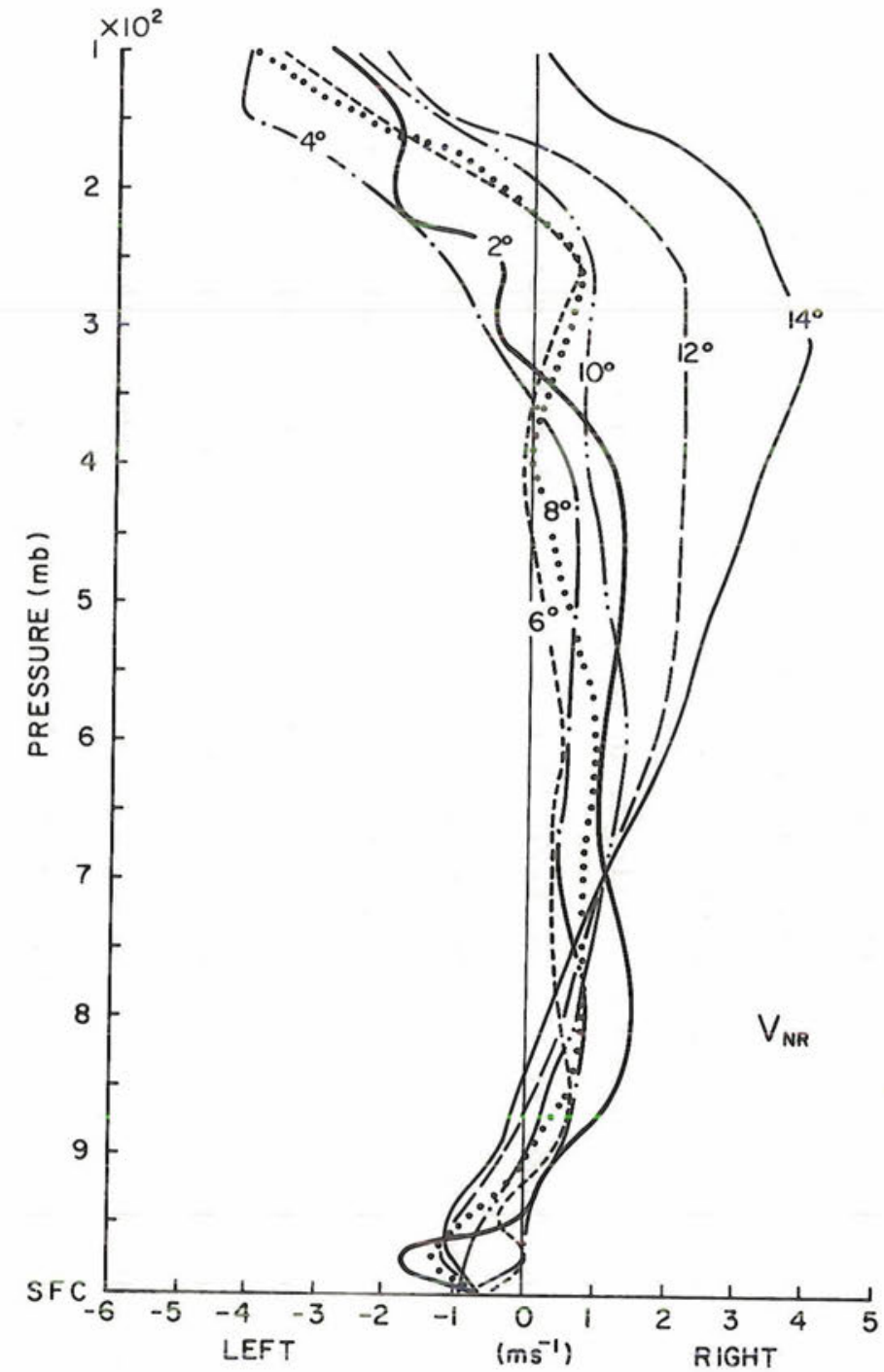

Figure 10. Same as Figure 9, except for the LAT $<20^{\circ} \mathrm{N}$ stratification. 

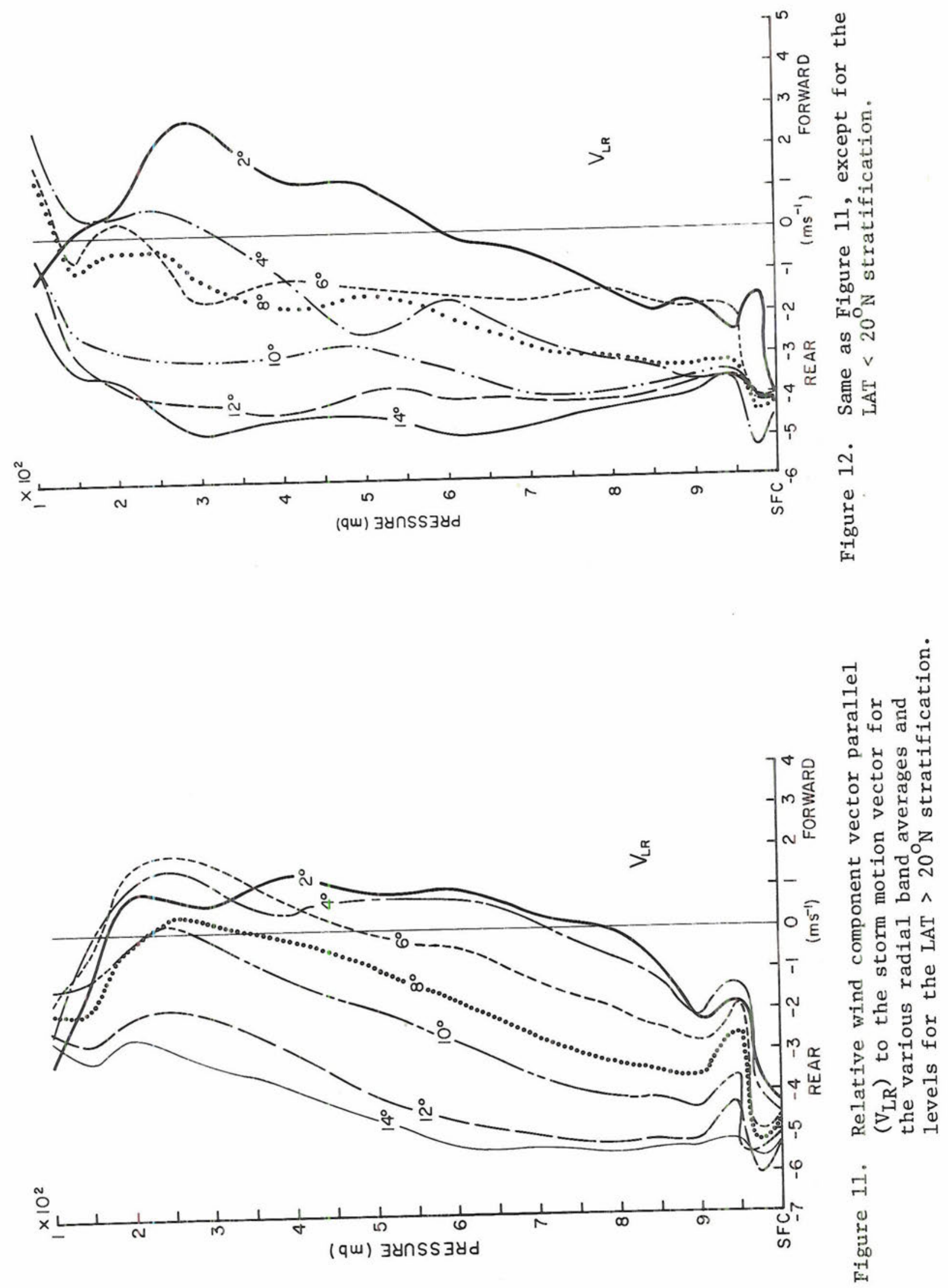



\subsection{Horizontal Radial Band Vectors}

Figures 13 and 14 portray the vector sum of the $V_{N R}$ and $V_{L R}$ relative component vectors for the individual bands at $700 \mathrm{mb}$. As above the radial bands are indicated by a single average radius. In essence, these figures depict the individual bands' average wind relative to the storm. It is seen that the individual band averages of the mean surrounding wind move from the front left to the right rear quadrant of the composite storm. Thus, the total vector for the band indicates that the storms are propagating faster and moving to the left of the mean wind for each radial band at $700 \mathrm{mb}$.

\subsection{Vertical Radial Band Vectors}

In a similar manner as above, the horizontal band vectors were integrated over various portions of the atmosphere (1000-100 mb, 1000-500 $\mathrm{mb}, 500-100 \mathrm{mb}, 850-250 \mathrm{mb}, 850-700 \mathrm{mb}$ ). The $1000-500 \mathrm{mb}$ integrations show the best consistency. These are portrayed in Figures 15 and 16 for the individual bands. Again, the vectors move from the right front to the left rear quadrant, denoting the same relationship as found for the individual horizontal radial band vectors.

\subsection{Storn Motion vs. Actual Surrounding Mean Wind Direction and Speed (Horizontal Multiple Radial Bands)}

Using actual winds (ROT), the composite data were investigated for a relationship between the storm motion (direction and speed) and the surrounding wind flow. Data for twenty-one $\left(1-5^{\circ}, 1-7^{\circ}, 1-9^{\circ}, \ldots 13-15^{\circ}\right)$ multiple bands were examined at the various pressure levels. The composited data were examined separately for a cyclone surrounding wind direction relationship, and a cyclone surrounding wind speed relationship. 

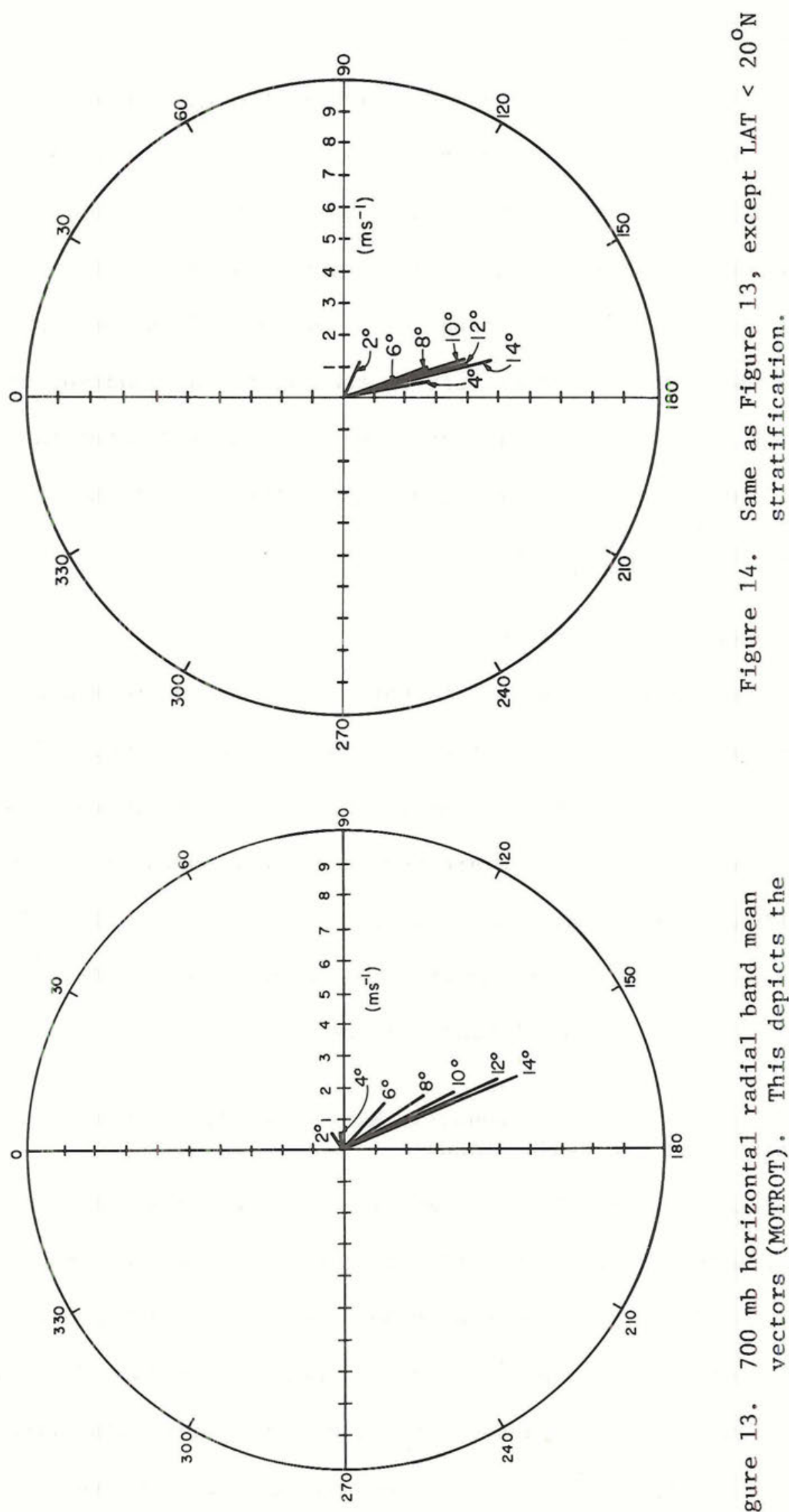

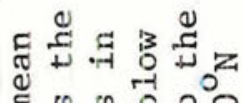

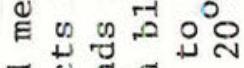

돈.

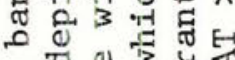

ซ

चै

䀡

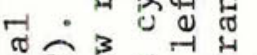

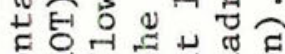

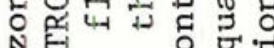

ती

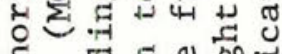

م

官 000 स

○

m 

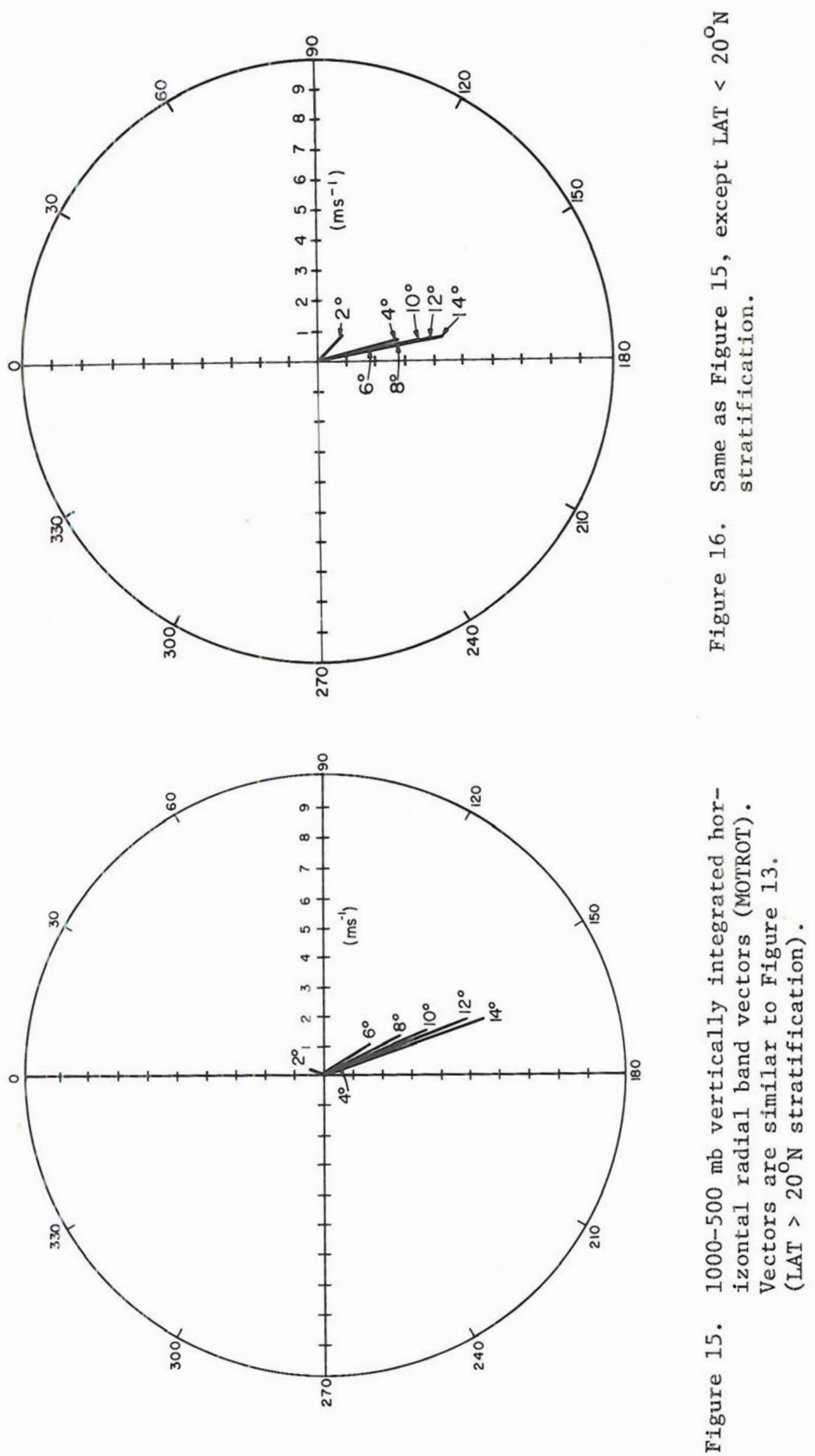

For: the directional relationship, each of the 13 stratifications was examined comparing the mean wind direction at the various levels with the mean direction of storm movement for each stratification. The most consistent finding for a directional relationship was found to be the $1-7^{\circ}$ radial band at $500 \mathrm{mb}$ as shown in Figure 17 . Shown are the three mean storm directions (solid line) for the three direction stratifications (A, B, C). The dashed line is the mean surrounding wind direction for each of the cases at $500 \mathrm{mb}\left(1-7^{\circ}\right.$ radius). It is seen that the mean storm deviates an average of $16^{\circ}$ to the left of the mean winds at this level for the 3 stratifications. As stated above, this level represents the best consistency for all the stratifications. Consistency refers to the smallest range of the angle between the storm direction and the mean surrounding flow that was found for al1 13 stratifications. The standard deviation of these differences for the $1-7^{\circ}$ band direction is $3.4^{\circ}$. Comparisons with other bands are shown later. The $1-7^{\circ} 500 \mathrm{mb}$ storm direction-surrounding wind direction angle difference ranged from 12 to $23^{\circ}$ for all 13 stratifications.

Figure 18 depicts the same relationship for the speed and intensity stratifications. Table 3 summarizes the results for all 13 stratifications. As previously stated, the storms are moving to the left of the mean flow. However, an empirical relationship is now seen as the storms are deviating about $\sim 15-18^{\circ}$ to the left of the mean flow $\left(1-7^{\circ}\right.$ radius at $500 \mathrm{mb}$ ) regardless of the storms' latitude, direction of motion, speed, intensity, or intensity change.

For the storm speed/surrounding flow relationship, the 13 stratifications were again examined at all levels for a relation between the mean storm speed (S) of each stratification and the surrounding wind 


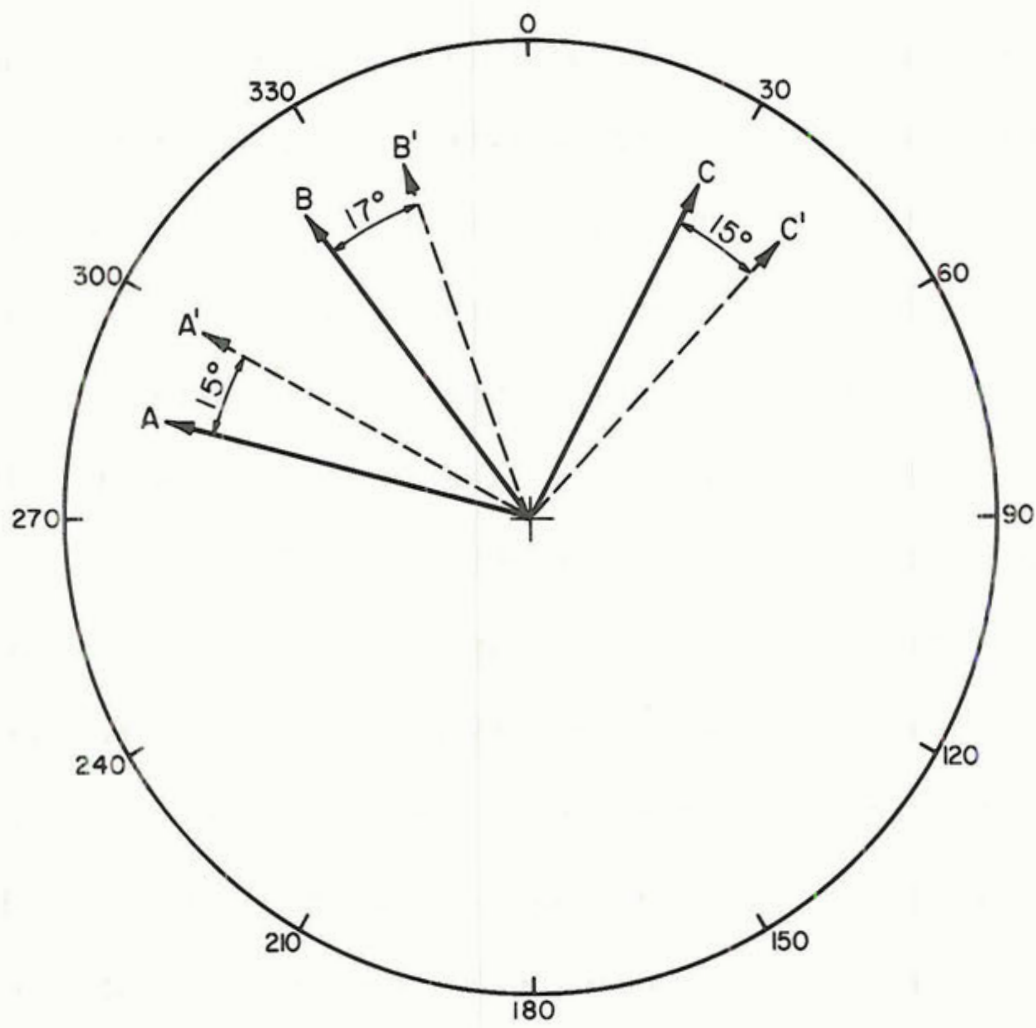

A: Mean Storm Direction for Direction Stratification A (250-310 $)$

B: Mean Storm Direction for Direction Stratification B (310 $\left.350^{\circ}\right)$

C: Mean Storm Direction for Direction Stratification C (350-060 $)$

$\mathrm{A}^{\prime}: 500 \mathrm{mb}\left(1-7^{\circ}\right.$ radius band) Wind Direction for Stratification $\mathrm{A}$

$B^{\prime}$ : $500 \mathrm{mb}\left(1-7^{\circ}\right.$ radius band) Wind Direction for Stratification $B$

$C^{\prime}$ : $500 \mathrm{mb}\left(1-7^{\circ}\right.$ radius band) Wind Direction for Stratification $C$

Figure 17. Relationship between the mean storm direction and the surrounding wind flow for three direction stratifications (horizontal multiple radial band). 

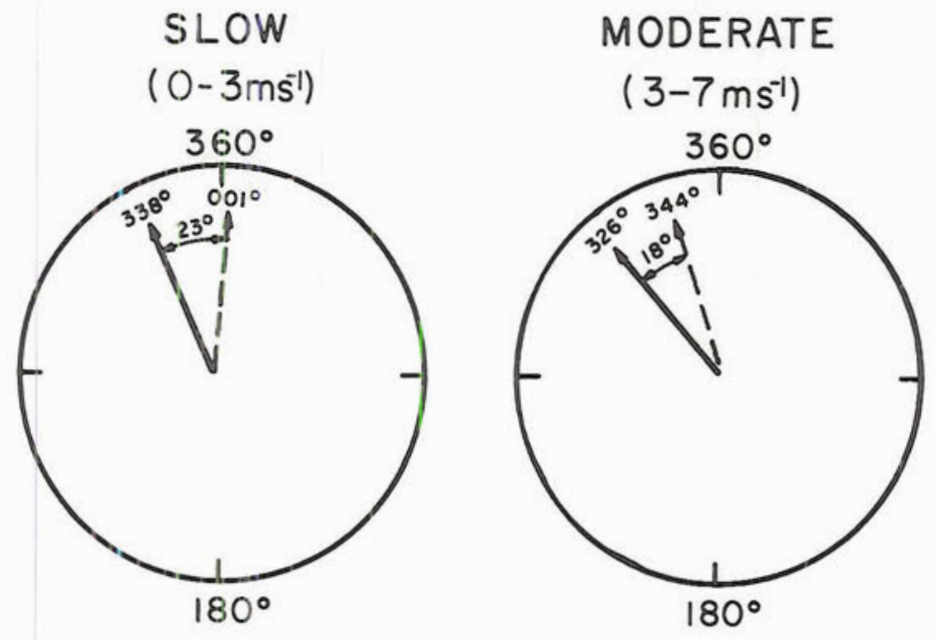

FAST
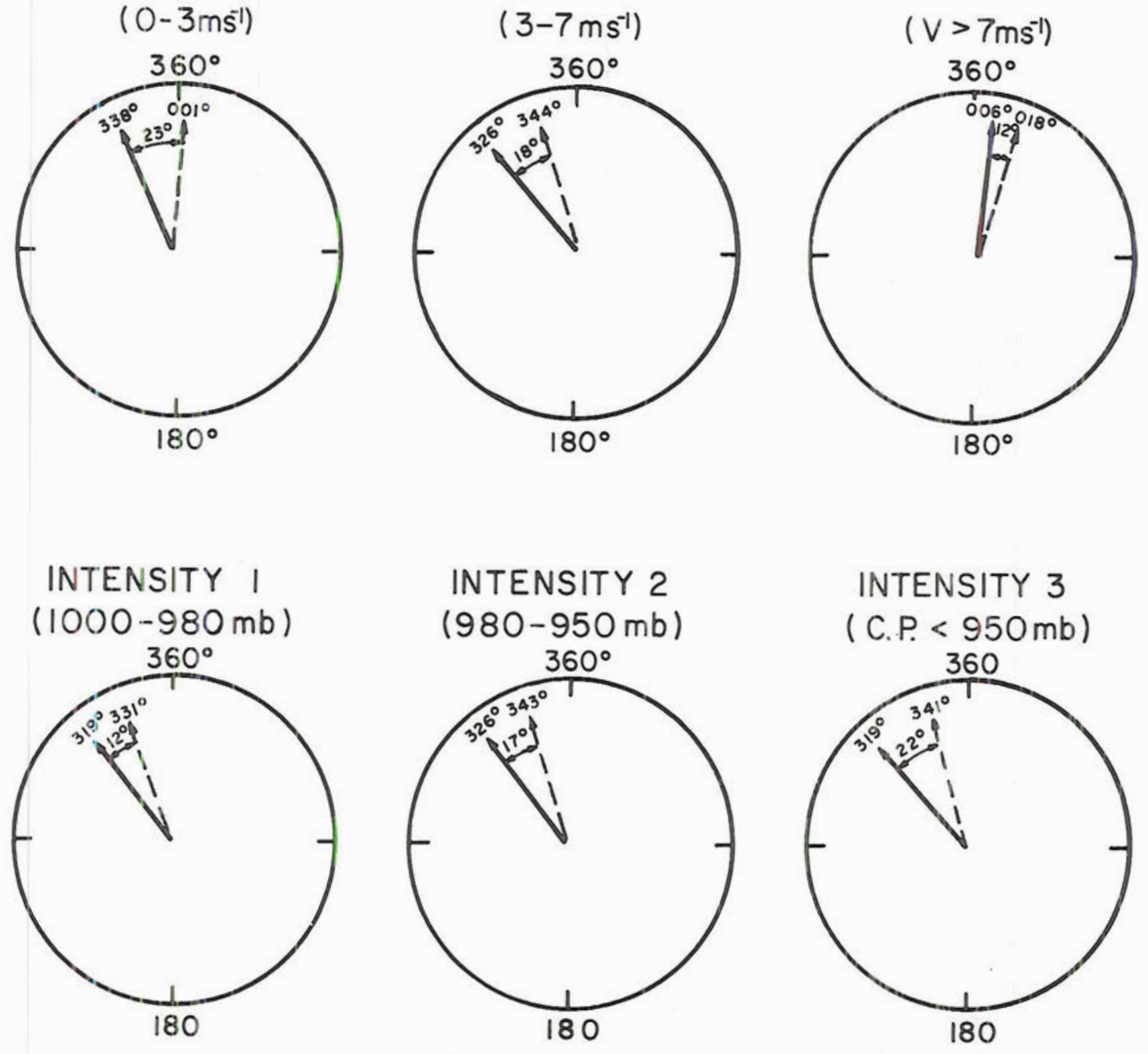

INTENSITY 3
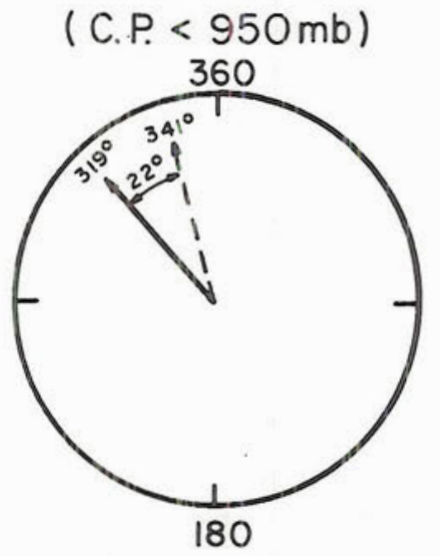

MEAN STORM

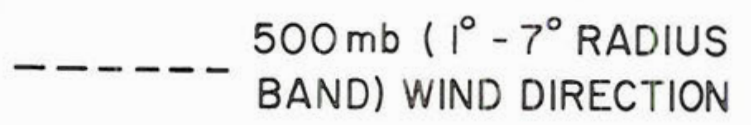

Figure 18. Relationship between the mean storm direction and the surrounding wind flow for speed and intensity stratifications (horizontal multiple radial band). 
TABLE 3

HORIZONTAL MULTIPLE RADIAL BAND SUMMARY FOR $1-7^{\circ}$ BAND

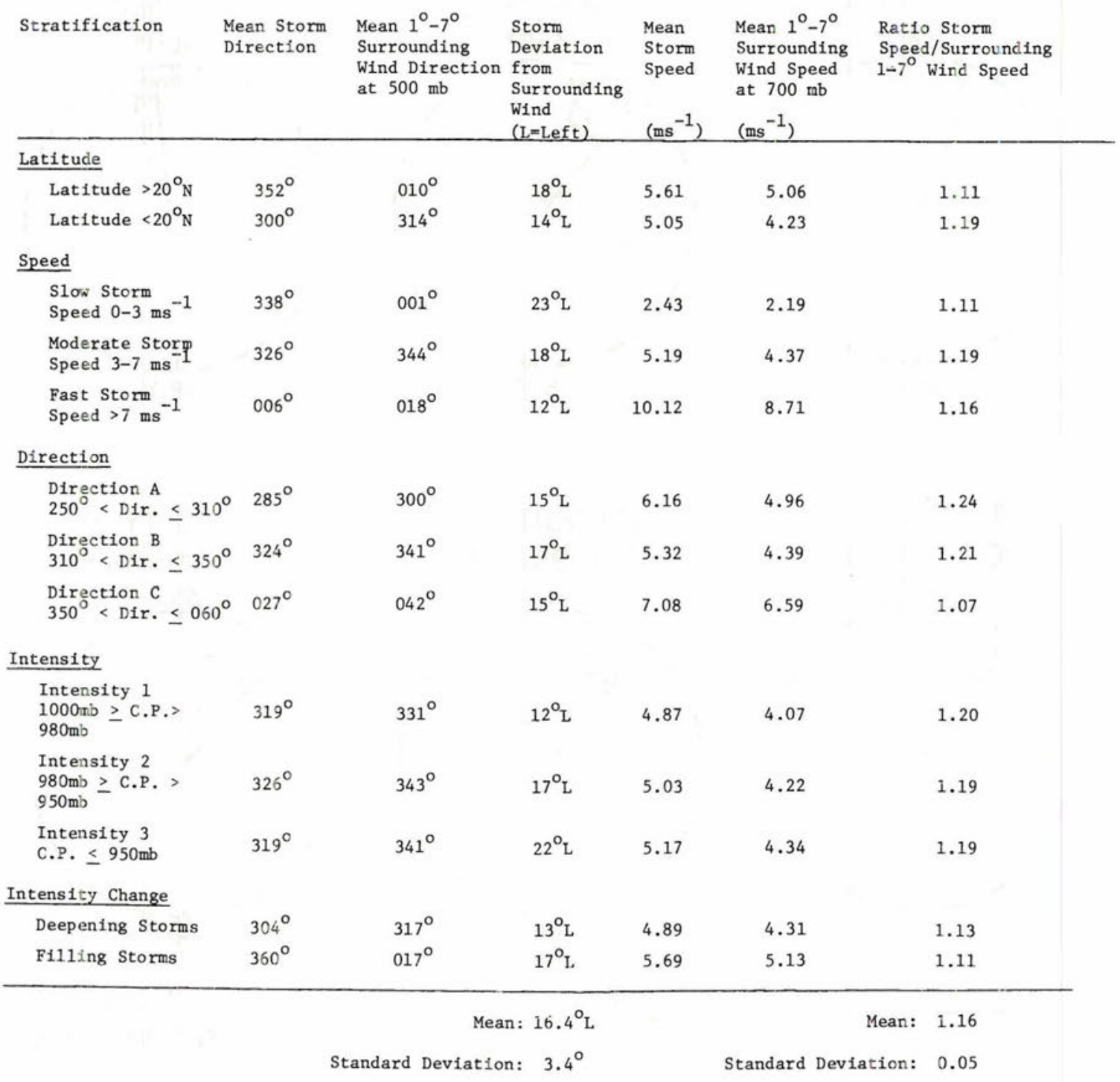


speed (W) in the direction of the storm motion. The ratio of the mean storm speed and the mean wind speed $(\mathrm{S} / \mathrm{W})$ was calculated for the various levels in the atmosphere. The most consistent results were found at the $700 \mathrm{mb}$ level for the $1-7^{\circ}$ radial band. For this band, the average ratio of the storm speed to the mean surrounding flow in the direction of motion is 1.16. The storm speed surrounding wind speed ratio ranged from 1.07 to 1.24 with a standard deviation of 0.05 . These relationships are depicted in Figures 19 and 20, and are summarized in Table 3. The above two findings regarding the relationship of the storm motion to the environmental wind direction/speed verify, for the western North Pacific area, the "steering" concept for tropical storms. Indeed, storm movement is directly related to the storm's surrounding flow. That is, as this flow changes, there is also a corresponding change in the storm movement. The composited data indicates that the mean storm moves about $16^{\circ}$ to the left of the mean surrounding flow for the $1-7^{\circ}$ radius band at $500 \mathrm{mb}$, while the ratio of the storm speed to the mean surrounding flow in the direction of the storm motion $\left(1-7^{\circ}\right.$ radius at $700 \mathrm{mb}$ ) is 1.16 . As stated previous $1 \mathrm{y}$, the above two findings represent the most consistent findings. Other multiple bands show similar relationships but with larger deviations.

Table 4 depicts storm direction deviation from the surrounding winds for various multiple radial bands and stratifications. Table 5 shows the ratio of the storm speeds to the surrounding wind speeds for the sane multiple bands. Notice that for the larger bands and for the outside bands the deviations are larger. As the cyclones are often 1ocated at the southwestern edge of a sub-tropical anticyclone, the flow at large radii to the north and west will show more southerly components. 


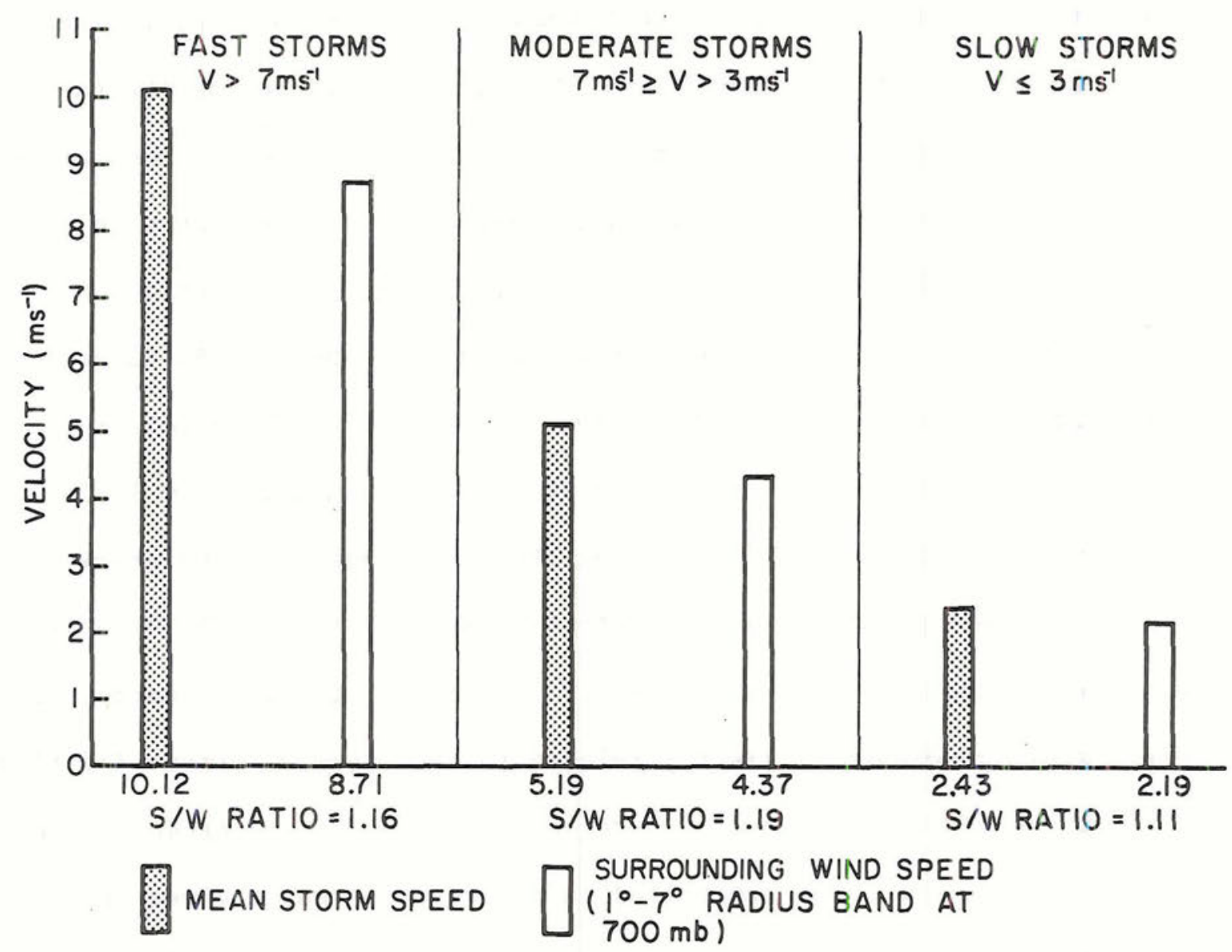

Figure 19. Relationship between the mean storm speed and the surrounding wind component along the direction of motion for the three speed stratifications (horizontal multiple radial band) at $700 \mathrm{mb}$.

This will cause the surrounding flow to be more to the right of the cyclone motion.

5.6 Storm Motion vs. Actual Surrounding Mean Wind Direction and Speed (Vertical Multiple Radial Bands)

In a similar manner as above, vertically integrated multiple bands were investigated for cyclone motion/surrounding wind relationships. Seventeen vertical multiple radial band integrations were examined (i.e. 1000-500 mb, $1000-100 \mathrm{mb}, 500-100 \mathrm{mb}$, etc.). The most consistent relationship between the storm direction and surrounding wind was found to be the $1-7^{\circ}$ radial band integrated between 700 and $500 \mathrm{mb}$. The average 

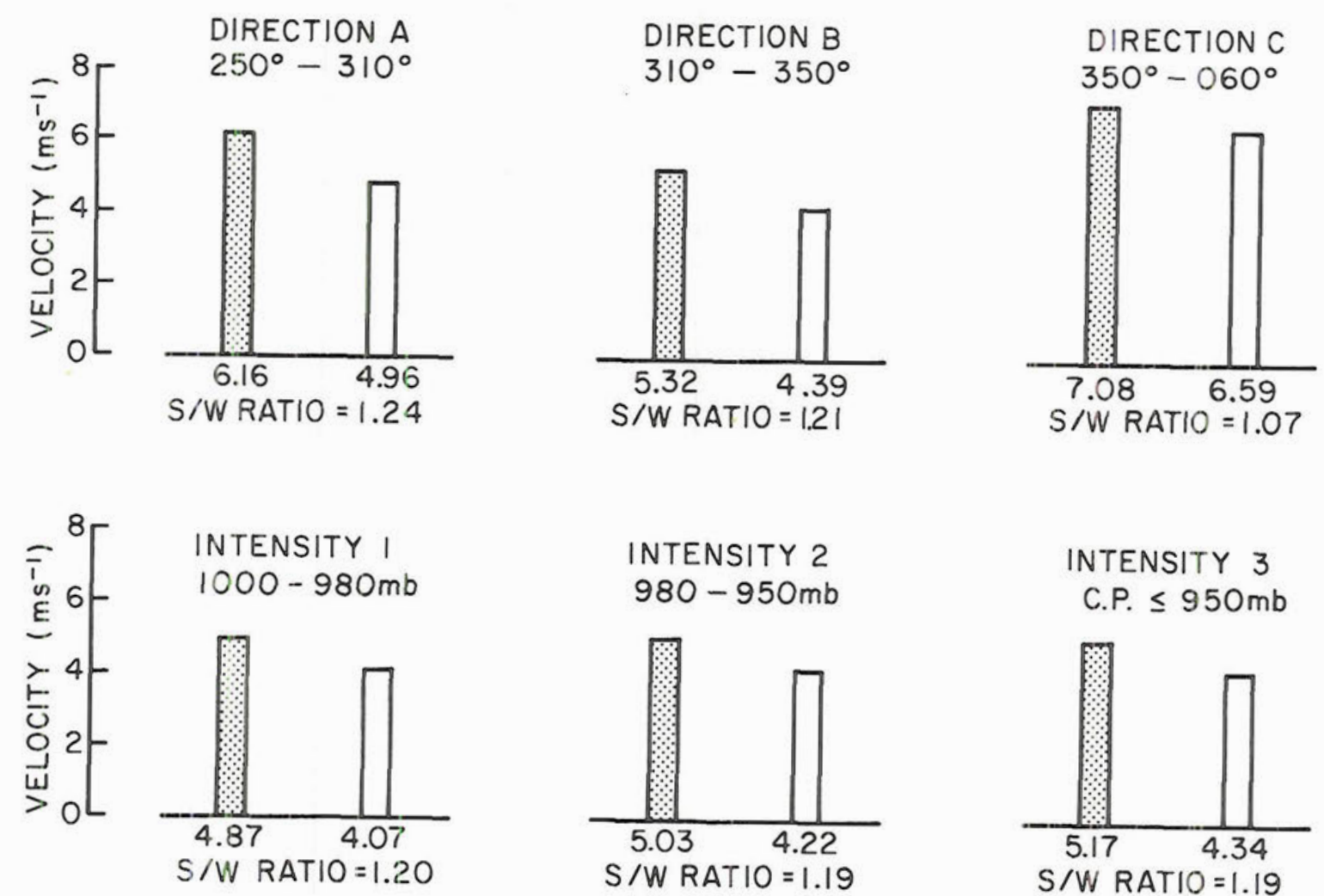

IMEAN STORM SPEED

$S / W$ RATIO $=1.19$

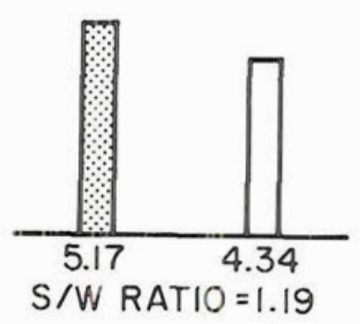

Figure 20. Relationship between the mean storm speed and the surrounding wind component along the direction of motion for the direction and intensity stratifications (horizontal multiple radial band) at $700 \mathrm{mb}$.

angle deviation between the mean storm direction and the surrounding flow was again found to be about $16^{\circ}$ with a standard deviation of $3.3^{\circ}$. Figures 21 and 22 depict this relationship.

The speed relationship for the integrated multiple bands was found to be best for the $1-7^{\circ}$ band integrated from $1000 \mathrm{mb}$ to $500 \mathrm{mb}$ as shown in Figures 23 and 24. The average storm speed/surrounding flow ratio is 1.27 with a standard deviation of 0.03 . As in the single level multiple bands, the integrated multiple bands show a consistent relationship between the storm motion and the surrounding wind flow. Table 6 

TABLE 4

DIRECTION COMPARISONS FOR VARIOUS MULTIPLE BANDS

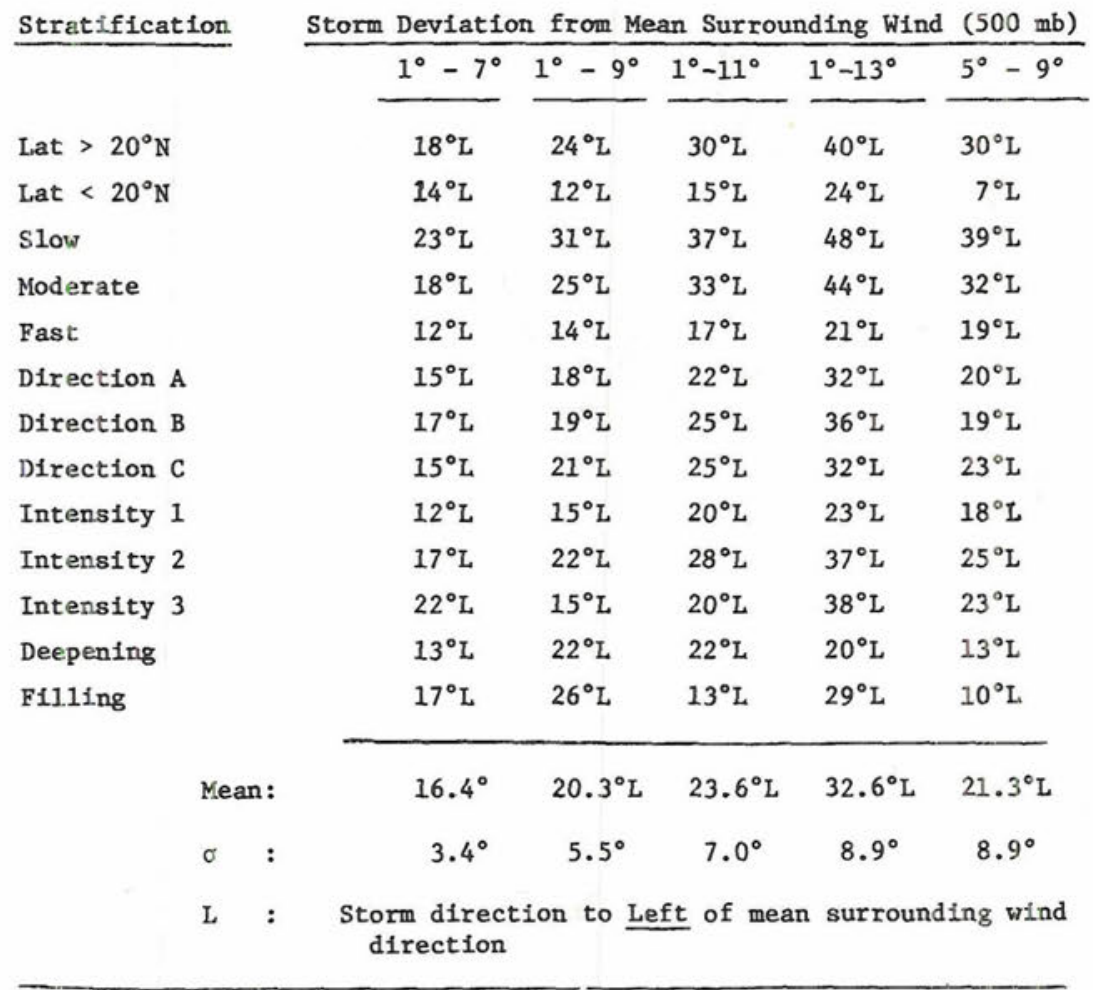

TABLE 5

SPEED COMPARISONS FOR VARIOUS MULTIPLE BANDS

Stratification Storm Speed/Surrounding Wind Speed Ratio (S/W) at $700 \mathrm{mb}$

Lat $>20^{\circ} \mathrm{N}$
Lat $<20^{\circ} \mathrm{N}$
Slow
Moderate
Fast
Direction A
Direction B
Direction C
Intensity 1
Intensity 2
Intensity 3
Deepening
Filling

\begin{tabular}{|c|c|c|c|c|}
\hline $1^{\circ}-7^{\circ}$ & $1^{\circ}-9^{\circ}$ & $1^{\circ}-11^{\circ}$ & $1^{\circ}-13^{\circ}$ & $5^{\circ}-9^{\circ}$ \\
\hline 1.11 & 1.32 & 1.61 & 2.12 & 1.54 \\
\hline 1.19 & 1.74 & 2.22 & 2.76 & 1.86 \\
\hline 1.11 & 1.42 & 1.69 & 2.78 & 1.56 \\
\hline 1.19 & 1.40 & 1.75 & 2.32 & 1.47 \\
\hline 1.16 & 1.39 & 1.67 & 2.08 & 2.47 \\
\hline 1.24 & 1.25 & 1.50 & 1.86 & 1.48 \\
\hline 1.21 & 1.13 & 1.37 & 1.69 & 1.33 \\
\hline 1.07 & 1.96 & 2.36 & 3.45 & 2.43 \\
\hline 1.20 & 1.38 & 1.62 & 1.96 & 1.56 \\
\hline 1.19 & 1.42 & 1.79 & 2.38 & 1.69 \\
\hline 1.19 & 1.57 & 2.03 & 2.66 & 2.76 \\
\hline 1.19 & 1.38 & 2.06 & 2.50 & 1.84 \\
\hline 1.11 & 1.24 & 1.33 & 2.04 & 1.25 \\
\hline
\end{tabular}

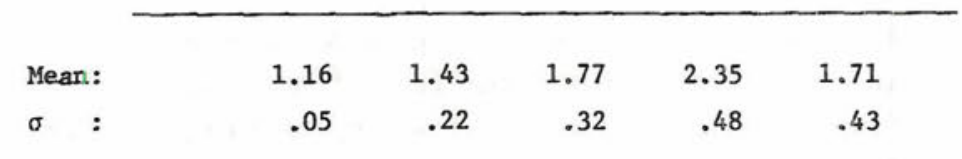




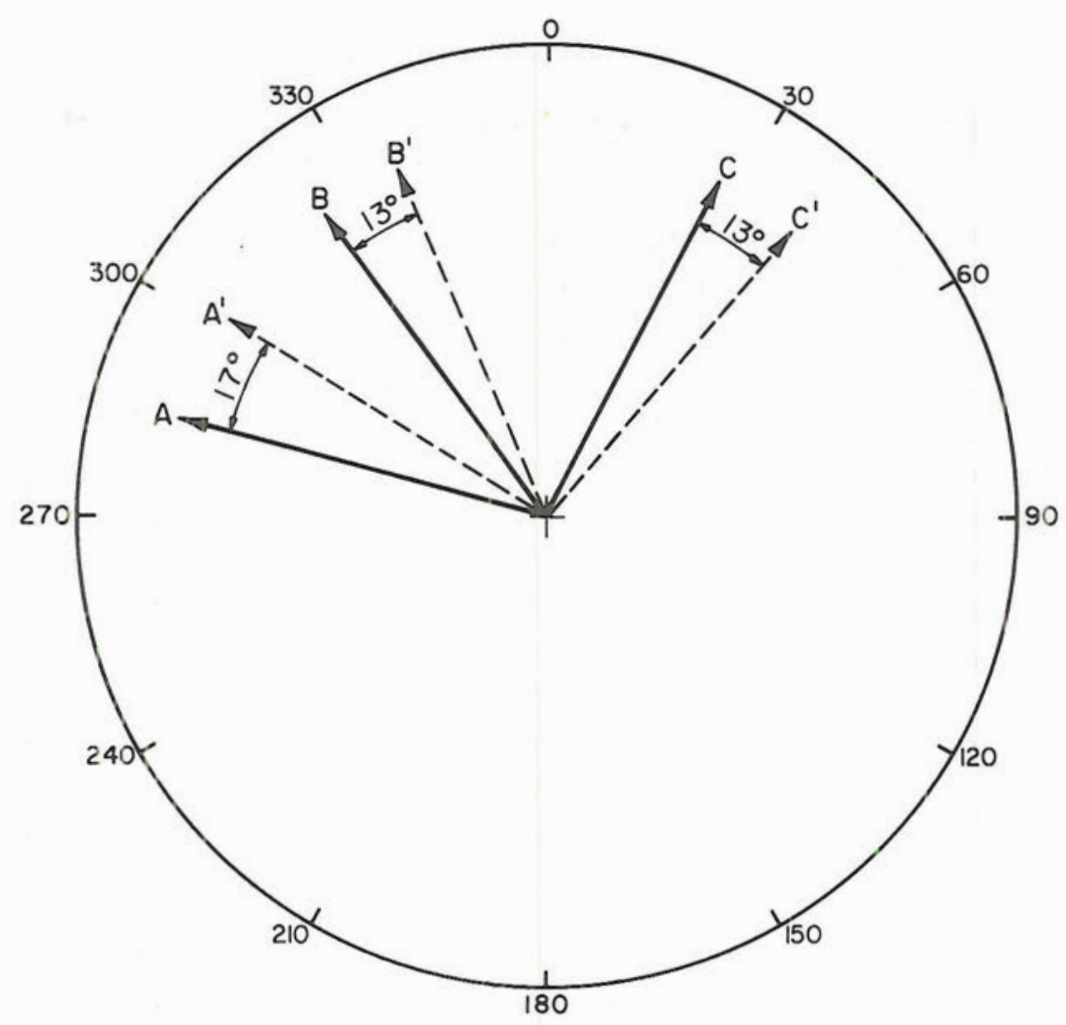

A: Mean Storm Direction for Direction Stratification A (250-310 $)$

B: Mean Storm Direction for Direction Stratification B (310-350 )

C: Mean Storm Direction for Direction Stratification C (350-060)

$\mathrm{A}^{\prime}$ : Integrated $700 \mathrm{mb}-500 \mathrm{mb}\left(1-7^{\circ}\right.$ radius band) Wind Direction for A $B^{\prime}$ : Integrated $700 \mathrm{mb}-500 \mathrm{mb}\left(1-7^{\circ}\right.$ radius band) Wind Direction for $B$ $\mathrm{C}^{\prime}$ : Integrated $700 \mathrm{mb}-500 \mathrm{mb}\left(1-7^{\circ}\right.$ radius band) Wind Direction for $\mathrm{C}$

Figure 21. Relationship between the mean storm direction and the surrounding wind flow for three direction stratifications (vertical multiple radial band) between $700-500 \mathrm{mb}$ and $1-7^{\circ}$ radius. 

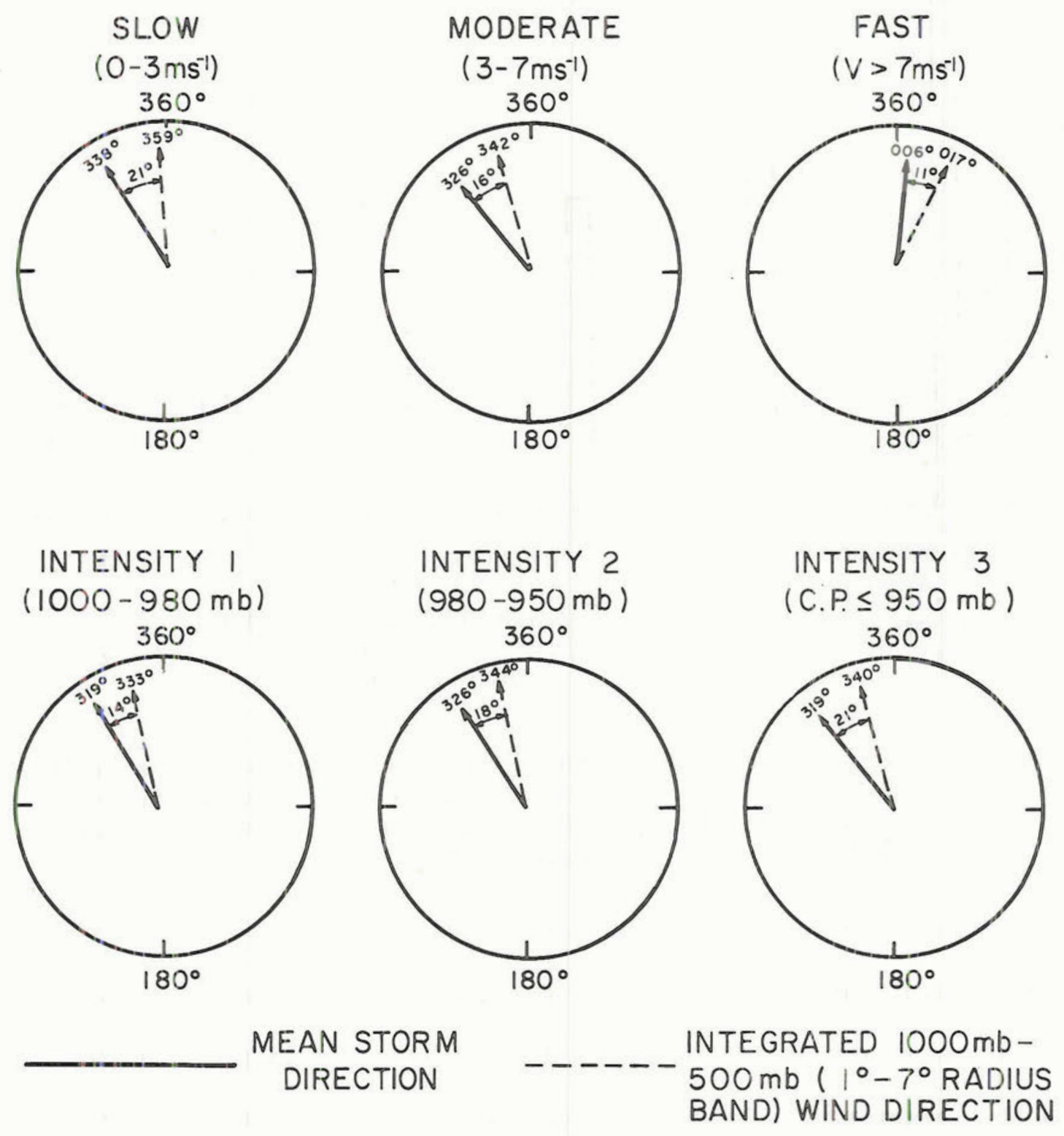

Figure 22. Relationship between the mean storm direction and the surrounding wind flow for speed and intensity stratifications (vertical multiple radial band) between 1000-500 mb and $1-7^{\circ}$ radius. 


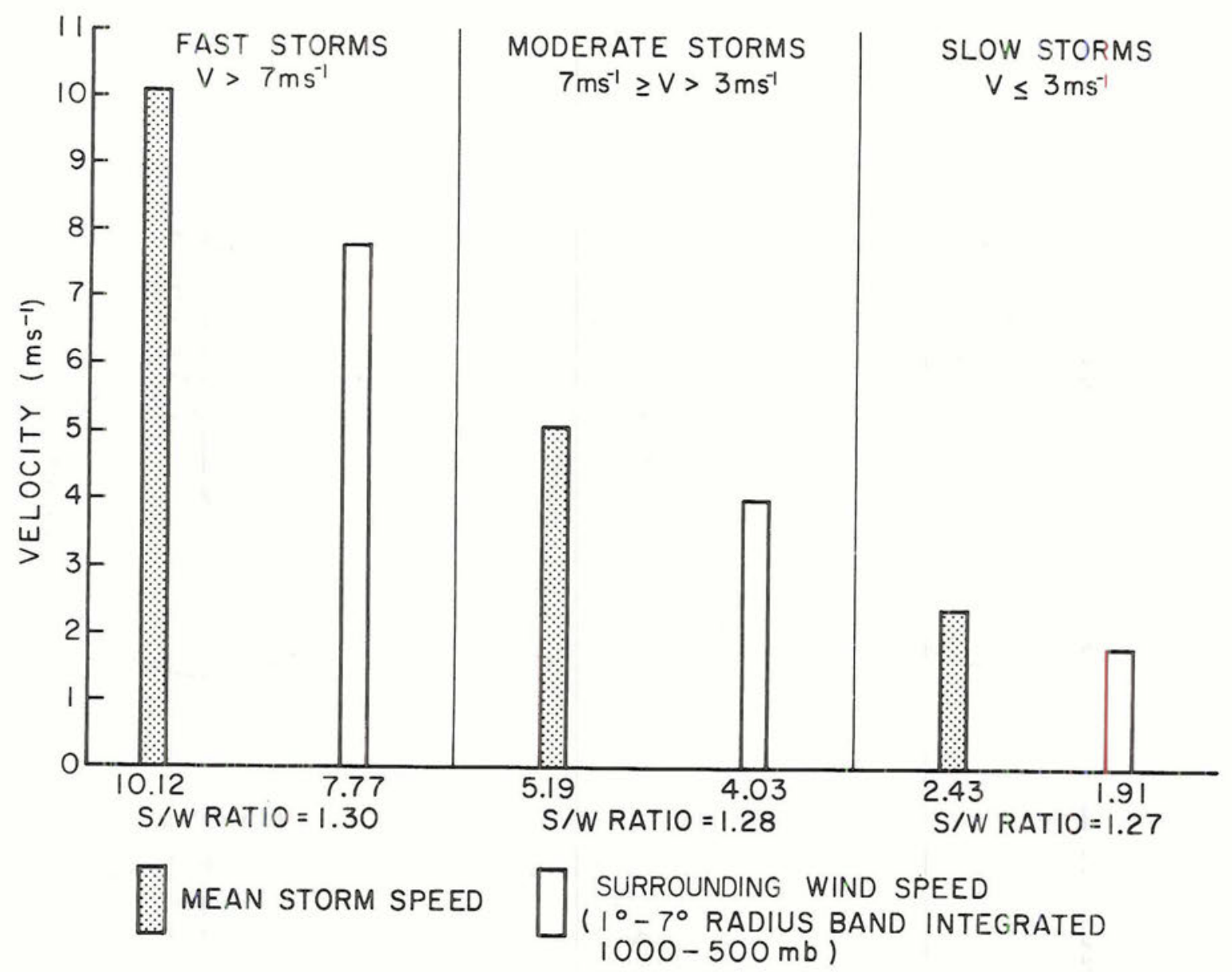

Figure 23. Relationship between the mean storm speed and the surrounding wind component along the direction of motion for the three speed stratifications (vertical multiple radial band) between $1000-500 \mathrm{mb}$ and $1-7^{\circ}$ radius.

summarizes the results for these best integrated multiple bands, while Tables 7 and 8 show comparisons with other integrated bands for all stratifications. As in the single level bands, the larger integrated bands and the larger radius bands show the greatest deviations from the cyclone motion.

5.7 Comparison of Composite Wind Components vs. Ca.1culated Geostrophic Components

From the composite height data, the geostrophic components of the wind were calculated inside $7^{\circ}$ radius. Tables 9-11 depict the comparison of the composited wind components with the geostrophic wind 

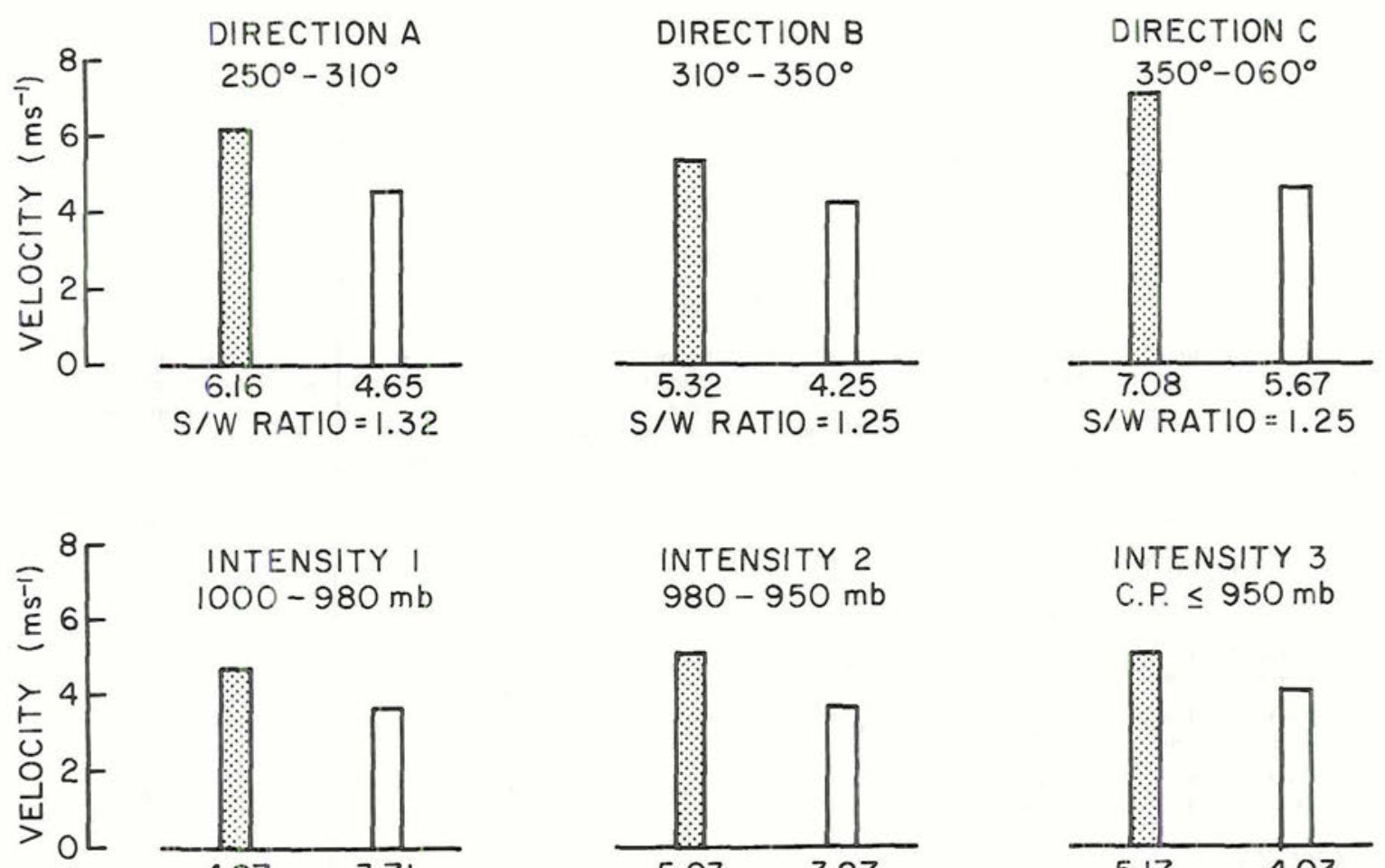

INTENSITY 2

$980-950 \mathrm{mb}$

INTENSITY 3

C.P. $\leq 950 \mathrm{mb}$
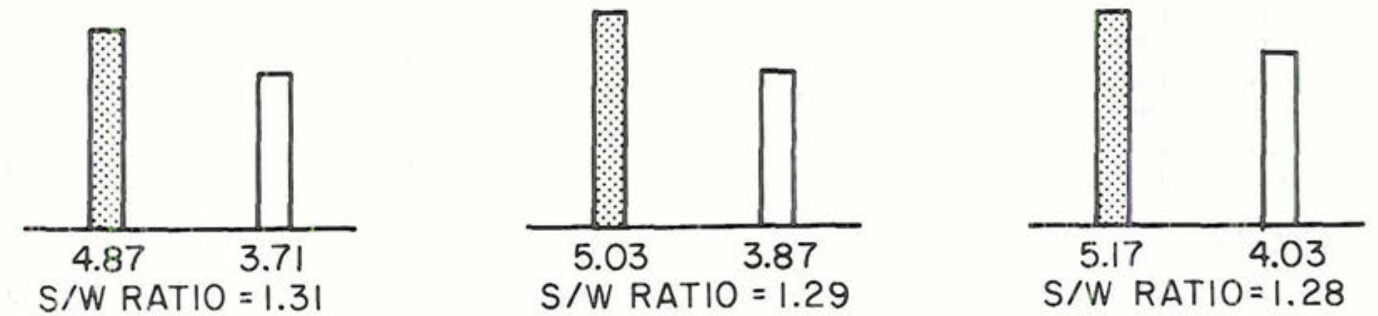

S/W RATIO $=1.29$

S/W RATIO $=1.28$

3 MEAN STORM SPEED

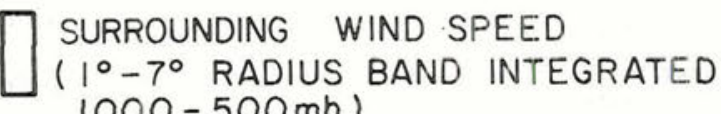
$(000-500 \mathrm{mb})$

Figure 24. Relationship between the mean storm speed and the surrounding wind component along the direction of motion for the direction and intensity stratifications (vertical multiple radial band) between $1000-500 \mathrm{mb}$ and $1-7^{\circ}$ radius.

components at 850,700 , and $500 \mathrm{mb}$ for all thirteen stratifications. At $850 \mathrm{mb}$ the mean normal geostrophic minus actual wind component differences are $\sim 0.4 \mathrm{~m} / \mathrm{sec}$, while the parallel component mean differences are only $\sim 0.1 \mathrm{~m} / \mathrm{sec}$. The ratio of actual to geostrophic parallel component for al1 13 stratifications is nearly one, indicating excellent agreement. At $700 \mathrm{mb}$, the mean normal component difference is $\sim 0.1 \mathrm{~m} / \mathrm{sec}$, the mean parallel component difference is $\sim 0.6 \mathrm{~m} / \mathrm{sec}$, and the actual/ geostrophic parallel component ratio is $\sim 0.9$. Again, this shows a close relation between the actual and geostrophic winds. At $500 \mathrm{mb}$, 
TABLE 6

VERTICAL MULTIPLE RADIAL BAND SUMMARY FOR $1-7^{\circ}$ BAND

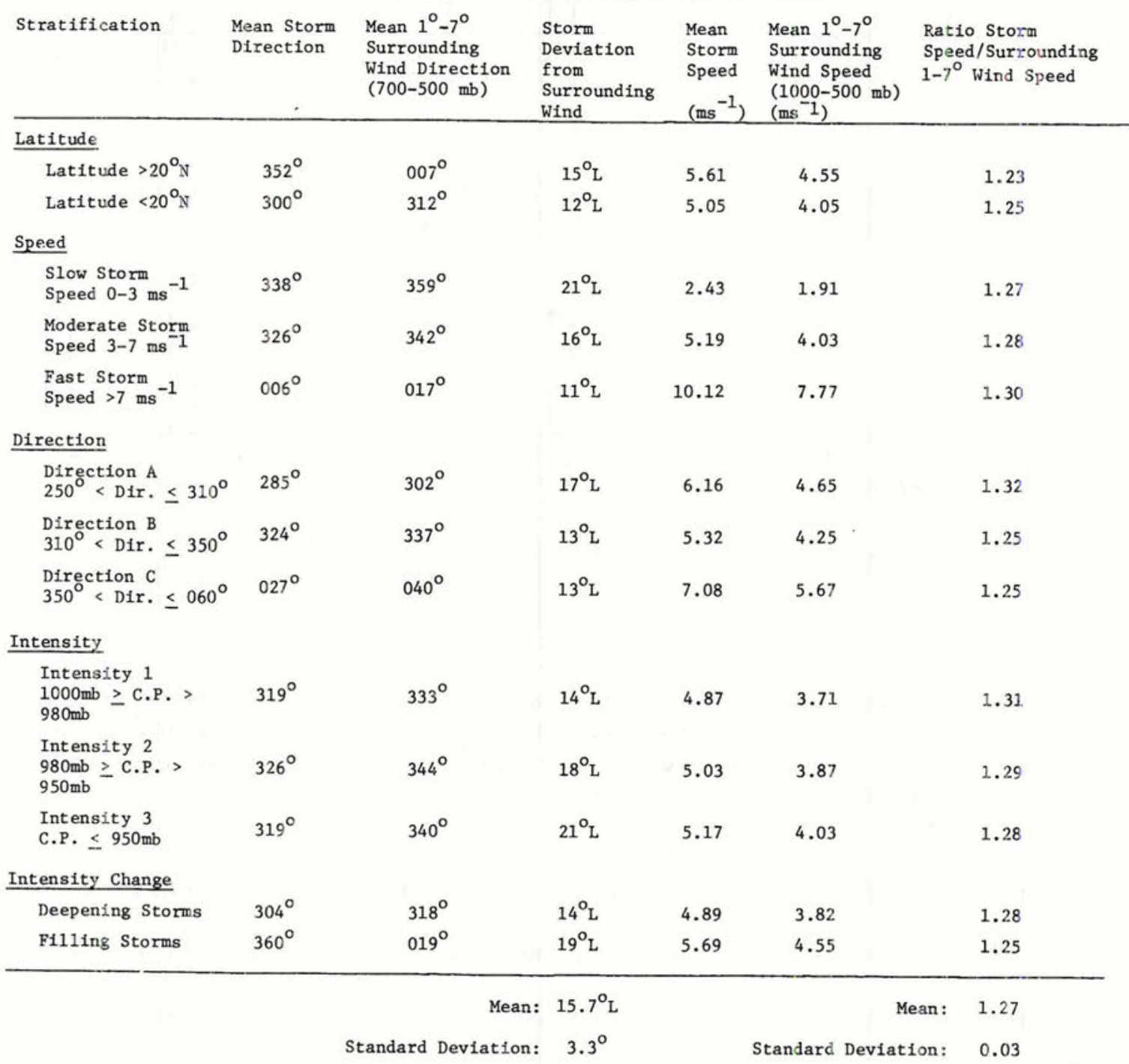


TABLE 7

DIRECTION COMPARISONS FOR VARIOUS INTEGRATED MULTIPLE BANDS

Stratification Storm Deviation from Mean Surrounding Wind (700-500 mb)

\begin{tabular}{|c|c|c|c|c|c|c|}
\hline Lat $>20^{\circ} \mathrm{N}$ & & $15^{\circ} \mathrm{L}$ & $20^{\circ} \mathrm{L}$ & $26^{\circ} \mathrm{L}$ & $37^{\circ} \mathrm{L}$ & $27^{\circ} \mathrm{L}$ \\
\hline Lat $<20^{\circ} \mathrm{N}$ & & $12^{\circ} \mathrm{L}$ & $14^{\circ} \mathrm{L}$ & $18^{\circ} \mathrm{L}$ & $27^{\circ} \mathrm{L}$ & $13^{\circ} \mathrm{L}$ \\
\hline Slow & & $21^{\circ} \mathrm{L}$ & $27^{\circ} \mathrm{L}$ & $30^{\circ} \mathrm{L}$ & $44^{\circ} \mathrm{L}$ & $50^{\circ} \mathrm{L}$ \\
\hline Moderate & & $16^{\circ} \mathrm{L}$ & $22^{\circ} \mathrm{L}$ & $29^{\circ} \mathrm{L}$ & $40^{\circ} \mathrm{L}$ & $28^{\circ} \mathrm{L}$ \\
\hline Fast & & $11^{\circ} \mathrm{L}$ & $14^{\circ} \mathrm{L}$ & $17^{\circ} \mathrm{L}$ & $21^{\circ} \mathrm{L}$ & $19^{\circ} \mathrm{L}$ \\
\hline Direction A & & $17^{\circ} \mathrm{L}$ & $22^{\circ} \mathrm{L}$ & $27^{\circ} \mathrm{L}$ & $37^{\circ} \mathrm{L}$ & $27^{\circ} \mathrm{L}$ \\
\hline Direction B & & $13^{\circ} \mathrm{L}$ & $16^{\circ} \mathrm{L}$ & $22^{\circ} \mathrm{L}$ & $32^{\circ} \mathrm{L}$ & $22^{\circ} \mathrm{L}$ \\
\hline Direction C & & $13^{\circ} \mathrm{L}$ & $17^{\circ} \mathrm{L}$ & $22^{\circ} \mathrm{L}$ & $29^{\circ} \mathrm{L}$ & $22^{\circ} \mathrm{L}$ \\
\hline Intensity 1 & & $14^{\circ} \mathrm{L}$ & $19^{\circ} \mathrm{L}$ & $23^{\circ} \mathrm{L}$ & $26^{\circ} \mathrm{L}$ & $23^{\circ} \mathrm{L}_{\mathrm{L}}$ \\
\hline Intensity 2 & & $18^{\circ} \mathrm{L}$ & $22^{\circ} \mathrm{L}$ & $27^{\circ} \mathrm{L}$ & $37^{\circ} \mathrm{L}$ & $26^{\circ} \mathrm{I}$ \\
\hline Intensity 3 & & $21^{\circ} \mathrm{L}$ & $29^{\circ} \mathrm{L}$ & $38^{\circ} \mathrm{L}$ & $48^{\circ} \mathrm{L}$ & $39^{\circ} \mathrm{L}$ \\
\hline Deepening & & $14^{\circ} \mathrm{L}$ & $15^{\circ} \mathrm{L}$ & $17^{\circ} \mathrm{L}$ & $19^{\circ} \mathrm{L}$ & $21^{\circ} \mathrm{L}$ \\
\hline Filling & & $19^{\circ} \mathrm{L}$ & $24^{\circ} \mathrm{L}$ & $32^{\circ} \mathrm{L}$ & $41^{\circ} \mathrm{L}$ & $29^{\circ} \mathrm{L}$ \\
\hline & Mean: & $15.7^{\circ}$ & $20.1^{\circ}$ & $25.2^{\circ}$ & $33.7^{\circ}$ & $26.6^{\circ}$ \\
\hline & & $3.3^{\circ}$ & $4.8^{\circ}$ & $6.2^{\circ}$ & $8.9^{\circ}$ & $9.3^{\circ}$ \\
\hline
\end{tabular}

TABLE 8

SPEED COMPARISONS FOR VARIOUS INTEGRATED MULTIPLE BANDS

Stratification Storm Speed/Surrounding Wind Speed Ratio (S/W) for (1000-

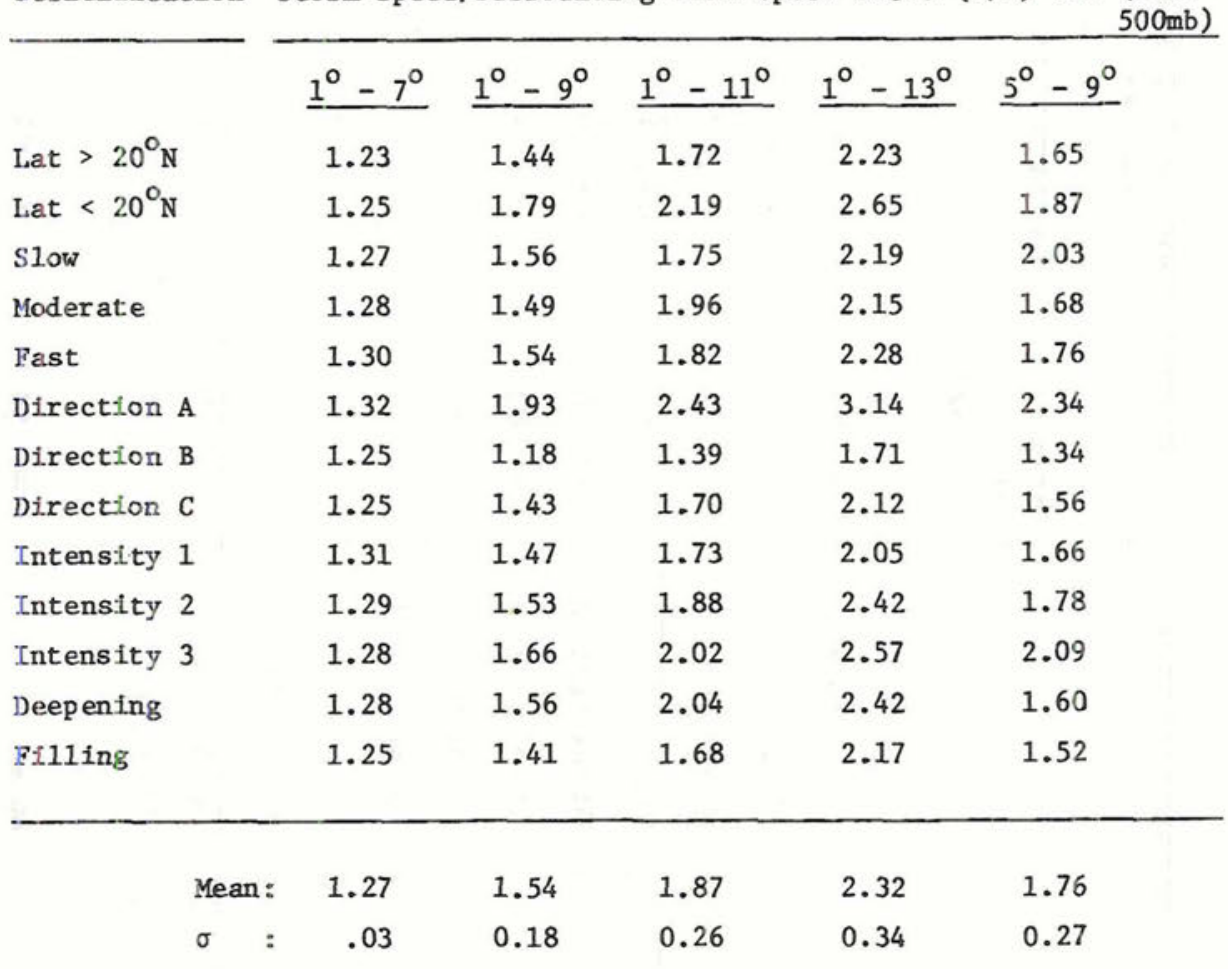


TABLE 9

$850 \mathrm{mb}$ COMPARISON OF COMPOSITE WIND COMPONENTS VS. CALCULATED GEOSTROPHIC COMPONENTS

\begin{tabular}{|c|c|c|c|c|c|c|c|}
\hline \multirow[t]{2}{*}{ Stratification } & \multicolumn{3}{|c|}{$\begin{array}{c}\text { Normal Component Inside } 7^{\circ} \text { Radius } \\
\left(\mathrm{ms}^{-1}\right)\end{array}$} & \multicolumn{4}{|c|}{$\begin{array}{c}\text { Parallel Component Inside } 7^{\circ} \text { Radius } \\
\left(\mathrm{ms}^{-1}\right)\end{array}$} \\
\hline & $\begin{array}{l}\text { Actual } \\
\text { Wind } \\
\text { Composite }\end{array}$ & $\begin{array}{l}\text { Geostrophic } \\
\text { Wind } \\
\text { Composite }\end{array}$ & Difference & $\begin{array}{l}\text { Actual } \\
\text { Wind } \\
\text { Composite }\end{array}$ & $\begin{array}{l}\text { Geostrophic } \\
\text { Wind } \\
\text { Composite }\end{array}$ & Difference & $\begin{array}{l}\text { Ratio } \\
\text { Actual/ } \\
\text { Geostrophic }\end{array}$ \\
\hline 1. Lat $>20^{\circ} \mathrm{N}$ & -.01 & -.10 & +.09 & +3.81 & +3.90 & -.09 & .98 \\
\hline 2. Lat $<20^{\circ} \mathrm{N}$ & +.96 & +.93 & +.03 & +2.84 & +3.73 & -.89 & .76 \\
\hline 3. Slow & -.11 & +.81 & -.92 & +2.13 & +3.24 & -1.11 & .66 \\
\hline 4. Moderate & +.22 & +1.22 & -1.00 & +3.86 & +4.05 & -.19 & .95 \\
\hline 5. Fast & +.44 & +1.44 & -1.00 & +5.56 & +5.49 & +.07 & 1.01 \\
\hline 6. Direction A & +1.40 & +1.28 & +.12 & +4.32 & +2.75 & +1.57 & 1.57 \\
\hline 7. Direction B & +.03 & +.14 & -.11 & +5.24 & +5.81 & -.57 & .91 \\
\hline 8. Direction C & -.33 & +.12 & -.45 & +4.23 & +4.59 & -.36 & .92 \\
\hline 9. Intensity 1 & +1.00 & +1.12 & -.12 & +3.34 & +2.82 & +.52 & 1.18 \\
\hline 10. Intensity 2 & +.81 & +1.97 & -1.16 & +3.35 & +3.67 & -.32 & .91 \\
\hline 11. Intensity 3 & +.69 & +.99 & -.30 & +3.97 & +2.96 & +1.01 & 1.34 \\
\hline 12. Deepening & +1.36 & +.82 & +.54 & +3.25 & +2.50 & +.75 & 1.30 \\
\hline 13. Filling & +.60 & +1.15 & -.55 & +3.41 & +5.13 & -1.72 & .66 \\
\hline Mean & +.54 & +.91 & -.37 & +3.79 & +3.89 & -.10 & 1.01 \\
\hline
\end{tabular}




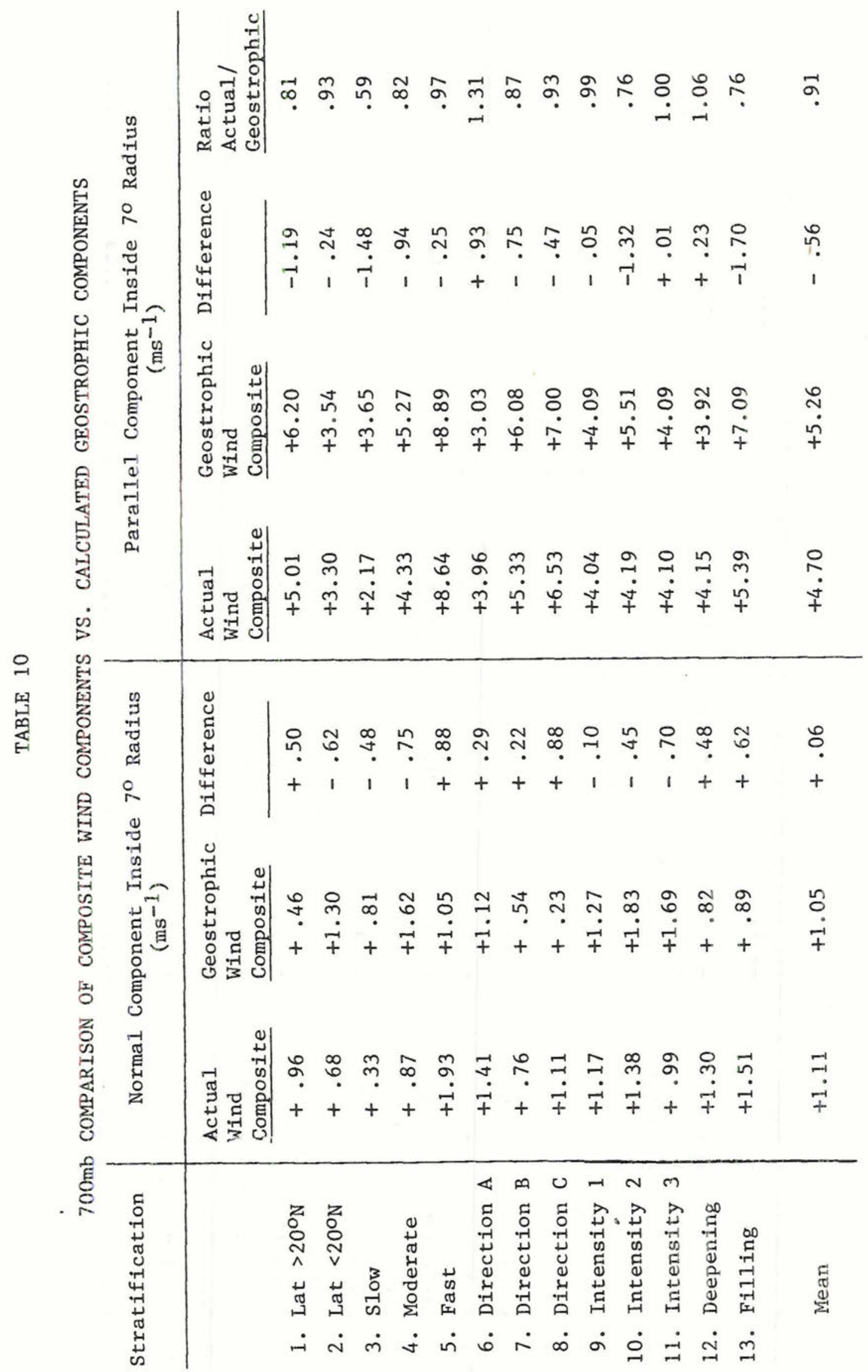


TABLE 11

$500 \mathrm{mb}$ COMPARISON OF COMPOSITE WIND COMPONENTS VS. CALCULATED GEOSTROPHIC COMPONENTS

\begin{tabular}{|c|c|c|c|c|c|c|c|}
\hline Stratification & \multicolumn{3}{|c|}{ Normal Component Inside $7^{\circ}$ Radius } & \multicolumn{4}{|c|}{$\begin{array}{c}\text { Parallel Component Inside } 7^{\circ} \text { Radius } \\
\left(\mathrm{ms}^{-1}\right)\end{array}$} \\
\hline & $\begin{array}{l}\text { Actual } \\
\text { Wind } \\
\text { Composite } \\
\end{array}$ & $\begin{array}{l}\text { Geostrophic } \\
\text { Wind } \\
\text { Composite }\end{array}$ & Difference & $\begin{array}{l}\text { Actual } \\
\text { Wind } \\
\text { Composite } \\
\end{array}$ & $\begin{array}{l}\text { Geostrophic } \\
\text { Wind } \\
\text { Composite }\end{array}$ & Difference & $\begin{array}{l}\text { Ratio } \\
\text { Actual/ } \\
\text { Geostrophic }\end{array}$ \\
\hline 1. Lat $>20^{\circ} \mathrm{N}$ & +1.92 & +1.03 & +.89 & +5.91 & +7.11 & -1.20 & .83 \\
\hline 2. Lat $<20^{\circ} \mathrm{N}$ & +.95 & +1.30 & -.35 & +3.82 & +2.98 & +.84 & 1.28 \\
\hline 3. Slow & +1.08 & +.54 & +.54 & +1.92 & +3.24 & $-1 \cdot 32$ & .59 \\
\hline 4. Moderate & +2.80 & +1.89 & -.09 & +4.53 & +7.16 & -2.63 & .63 \\
\hline 5. Fast & +2.15 & +.52 & +1.63 & +11.95 & +13.61 & -1.66 & .88 \\
\hline 6. Direction A & +1.18 & +.16 & +1.02 & +4.36 & +4.78 & -.42 & .91 \\
\hline 7. Direction B & +1.39 & +.00 & +1.39 & +4.43 & +6.22 & -1.79 & .71 \\
\hline 8. Direction C & +2.45 & +1.95 & +.50 & +8.56 & +10.67 & -2.11 & .80 \\
\hline 9. Intensity 1 & +1.03 & +.85 & +.18 & +4.73 & +5.50 & -.77 & .86 \\
\hline 10. Intensity 2 & +1.96 & +4.09 & -2.13 & +5.01 & +5.36 & -.35 & .93 \\
\hline 11. Intensity 3 & +1.99 & +1.69 & +.30 & +3.61 & +5.36 & -1.75 & .67 \\
\hline 12. Deepening & +1.15 & +.15 & +1.00 & +4.58 & +5.00 & -.42 & .92 \\
\hline 13. Filling & +2.49 & +1.64 & +.85 & +6.72 & +7.26 & -.54 & .93 \\
\hline Mean & +1.66 & +1.22 & +.44 & +5.39 & +6.48 & -1.09 & .91 \\
\hline
\end{tabular}


the normal and parallel differences are 0.4 and $1.10 \mathrm{~m} / \mathrm{sec}$, respectively, while the actual/geostrophic parallel ratio is $\sim 0.9$. Considering the possible influence of the storm's changing acceleration and cumulus convection in upsetting the wind-height relationship, these results are better than expected. In essence, these relationships show that the geostrophic height fields fit almost as well as the actual winds.

Because of the good correlation between winds and height, it might be possible in operational analysis to substitute winds for heights or heights for winds depending on which measurement is available. As seen from the tables, the low level wind-height correlations are especially good. It would thus seem feasible that low level satellite derived winds might be used to fill in missing surrounding data points needed for a surrounding flow field. These satellite derived winds might also be converted to heights. Overall, it appears encouraging that the height data can be used to derive the wind fields or vice versa.

\subsection{Cyclone Motion Relation to Right Octant Winds}

The relationship between the storm motion and the right octant winds was also investigated following the research of Chin (1970) and others who indicated that the right quadrant wind is we11 related to the cyclone center motion. Total wind vector values for the right octant were evaluated at different levels. Figure 25 shows the result for the LAT $>20^{\circ} \mathrm{N}$ stratification in the ROT system which is also typical for the other stratifications. In this figure the individual radial bands are represented by an average radius, i.e. $2^{\circ}$ represents the $1-3^{\circ}$ radius, etc. With the mean storm moving at $5.6 \mathrm{~m} / \mathrm{sec}$ to $360^{\circ}$ (indicated by the heavy arrow), it is seen that no single radial band well 


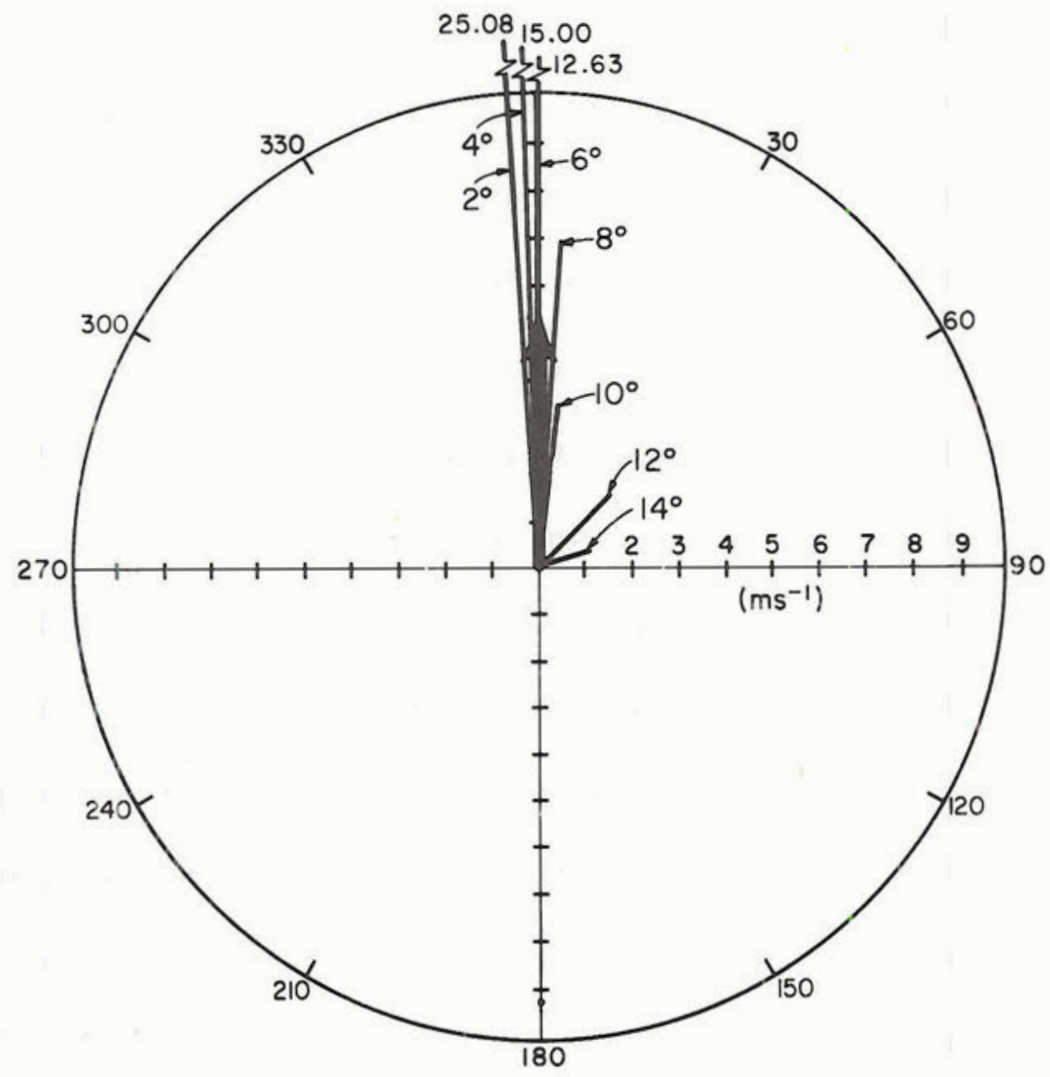

Figure 25. Right octant vectors (ROT) at $850 \mathrm{mb}$. Mean storm moving to $360^{\circ}$ at $5.6 \mathrm{~m} / \mathrm{sec}$ as shown by the heavy arrow. (LAT $>20^{\circ} \mathrm{N}$ stratification).

represents the storm speed. However, from $2^{\circ}$ to $8^{\circ}$ radius the direction of the winds was found to be within $5^{\circ}$ of the storm direction. The $850 \mathrm{mb}$ level shows the closest relationship between storm direction and the right octant vector. It can be concluded that the right octant winds parallel the storm motion and give good directional information but not necessarily precise storm speed information. 


\section{DISCUSSION}

These results appear to verify the compositing philosophy. Thus, the inherent errors and unrepresentative sampling by the individual rawinsonde reports must be largely random and mostly average themselves out in the statistical average. This is very encouraging for future studies of synoptic and meso-weather systems and is a major result of this paper. The rawinsonde networks cannot be expanded, but the massive statistical averaging of past data sets can be accomplished with the new computer tape techniques. Thus, it appears that one can substitute time resolution for space resolution on specific types of weather systems.

It has been shown statistically that tropical cyclone motion is directly related to the surrounding wind and height fields. Thus, the general concept of a steering flow seems valid. This steering concept has been basically accepted and applied when possible by forecasters for a number of years, but up to now, little quantitative verification of this steering hypothesis has been provided. Tropical cyclone direction seems to be very well related to the mean $1-7^{\circ}$ radius $500 \mathrm{mb}$ surrounding wind direction while cyclone speed is best related to the $1-7^{\circ}$ radius $700 \mathrm{mb}$ surrounding wind speed. Close relationships exist between the wind and height fields. This shows that these two fields can be used interchangeably.

As seen from the results, the surrounding flow dictates the storm motion very well, regardless of storm latitude, speed, direction, intensity, and intensity change. Thus, it appears that the structure of tropical cyclones such as the inner convective activity is not a primary factor in influencing storm movement. In the statistical 
average, it appears that variations in the eye wall and inner region cumulus convection do not make a significant contribution to the surrounding steering flow and cyclone motion.

If the surrounding flow could be better monitored, the information in this paper might be used to improve cyclone forecasting. Furthermore, for critical forecasts, such as when a major storn is threatening a large population area, aircraft could fly around the cyclone at 5 to 70 radius and monitor the surrounding steering flow and determine how this changes. If there is a lag in response of the cyclone center motion to the winds or heights at outer radii, then some forecasting skills may be derived by monitoring the outer fields on a continuous basis. The next logical step in this research appears to be an investigation of the likely lag in response of the cyclone center motion to the outer wind and height changes. This requires the comparing of the cyclone center motion changes with the prior $12,24,36$, etc. hour surrounding field changes. Future tropical cyclone motion research will be directed along these lines. 
PART II

SURROUNDING ENVIRONMENTAL DIFFERENCES BETWEEN RECURVING AND NON-RECURVING TROPICAL CYCLONES 



\section{INTRODUCTION}

A basic problem of tropical cyclone forecasting is the one of determining whether recurvature will occur. Westward moving cyclones will sometimes turn to the north and then to the northeast and undergo recurvature. Other cyclones will not recurve. Long ago Riehl and Shafer (1944) stated that if the base of the polar westerlies lowers greatly west of a storm in connection with an eastward moving middle-latitude trough and remains low, northward recurvature results. General synoptic conditions favorable for recurvature have been documented by Dunn and Miller (1964). Typical flow patterns associated with recurvature are:

1) large-amplitude troughs, extending southward from the westerlies and located within a few hundred miles to the west of the storm center,

2) we11-marked low-latitude troughs building northward into the westerlies, and

3) weak troughs between two separate high cells.

Flow patterns associated with non-recurvature include:

1) a strong subtropical high to the north of the storm, with the major trough in the westerlies located far to the west of the longitude of the storm and

2) westerlies flat, i.e., waves having a very small amplitude at their normal latitudes or further north.

Burroughs and Brand (1972) also have shown how recurvature is related to the strength of the $300 \mathrm{mb}$ winds to the north. Dunn and Miller (op. cit.) further comment that the period when the storm oscillates between the influences of the easterlies and the westerlies is the most critical. When these types of situations exist the forecaster faces a very serious problem of whether to forecast recurvature or not. An incorrect recurvature/non-recurvature forecast will greatly affect the population 
areas in the actual storm track, and lead to very large forecast errors. Forecasting recurvature 1-3 days before it takes place is usually very difficult. Thus, basic research on the recurvature problem would seem warranted. 


\section{METHODOLOGY}

This study uses the same composited data set described in Part I to examine the recurvature problem in the western North Pacific. Twenty-one pairs of tropical cyclone tracks were selected from the data set. Each pair includes one storm that recurved and one that did not. The pairs were selected in a manner such that the earlier portion of each storm track was within $5^{\circ}$ latitude of the other. The twenty-one tracks of recurving storms are shown in Figure 26, while the non-recurving storm tracks are depicted in Figure 27. Four examples of the paired storms are shown in Figures 28-31. Also an example of each type of storm in its surrounding environment at $700 \mathrm{mb}$ is depicted on Japanese daily weather maps (1963) as shown in Figures 32 and 33.

For the composite fields, a separation point (S) was selected. The $\mathrm{S}$ point is arbitrarily defined at the longitude where the recurving storm track begins to deviate significantly from the non-recurving track and acquires a northwesterly to northerly component (see Figures 28-31 for examples). This is a significant location. It is hypothesized that the surrounding tropospheric flow field 1-3 days before separation time should show a difference between the storms that recurve and those that do not. Rawinsoncle data has been composited separately for the recurving storms and non-recurving storms at the time of the $S$ point, and also prior to and after the $\mathrm{S}$ point time.

To assure that the data samples were sufficiently large, it was decided to composite three consecutive 12-hour time periods together. For example, data at the time of the separation point (S), data 12 hours before this time, and data 24 hours before were all composited 

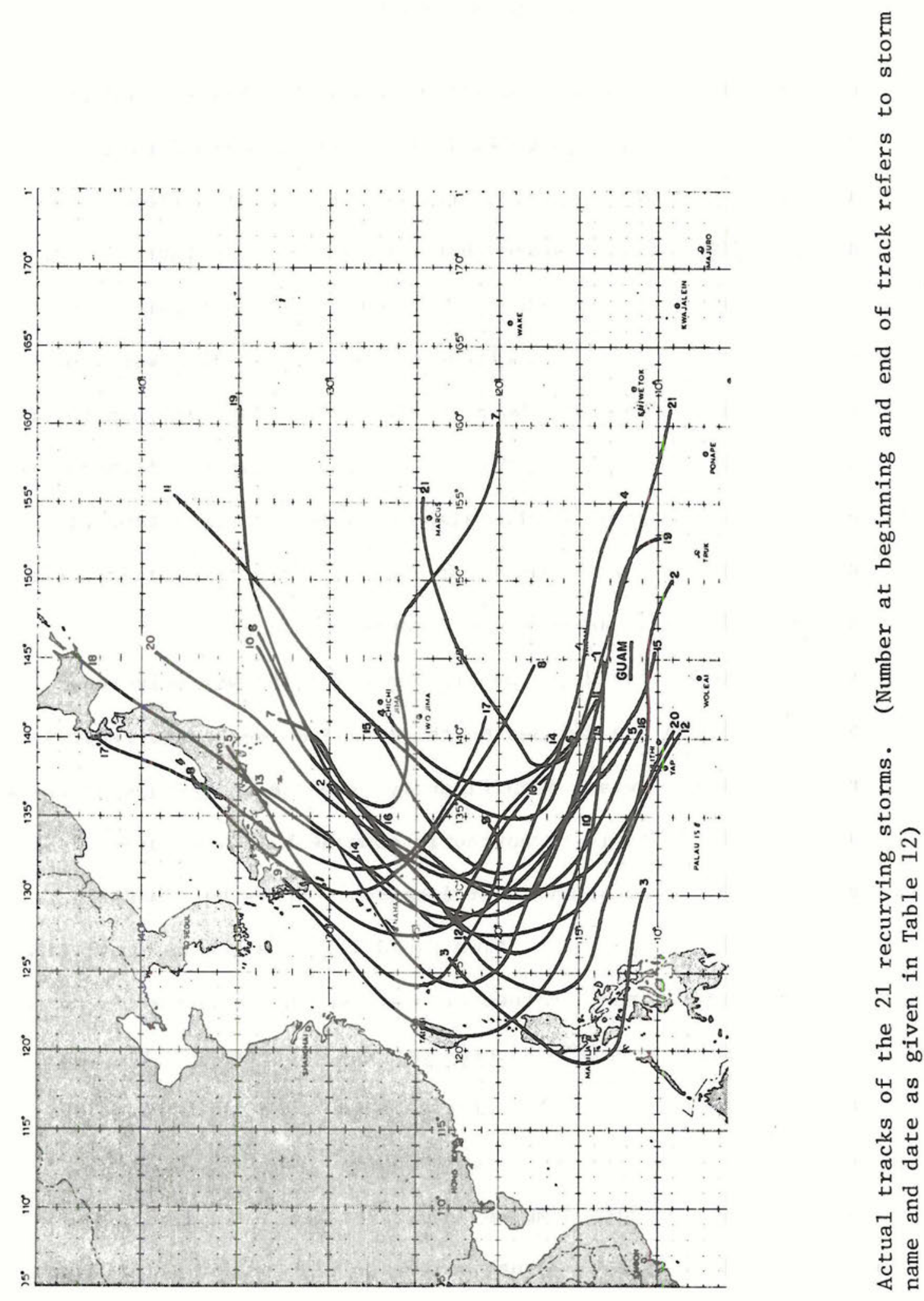

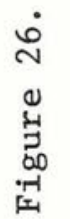



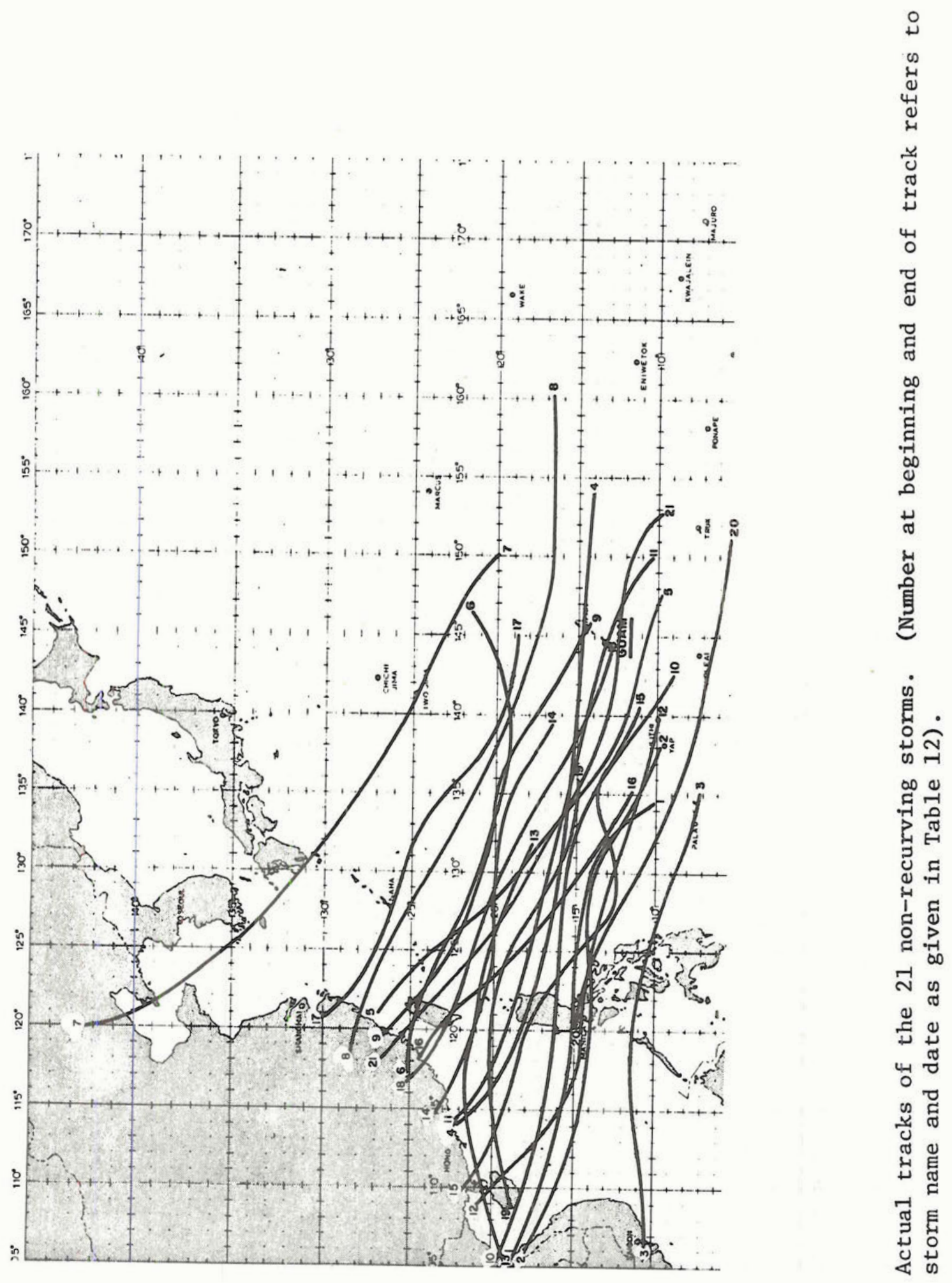

㐫 


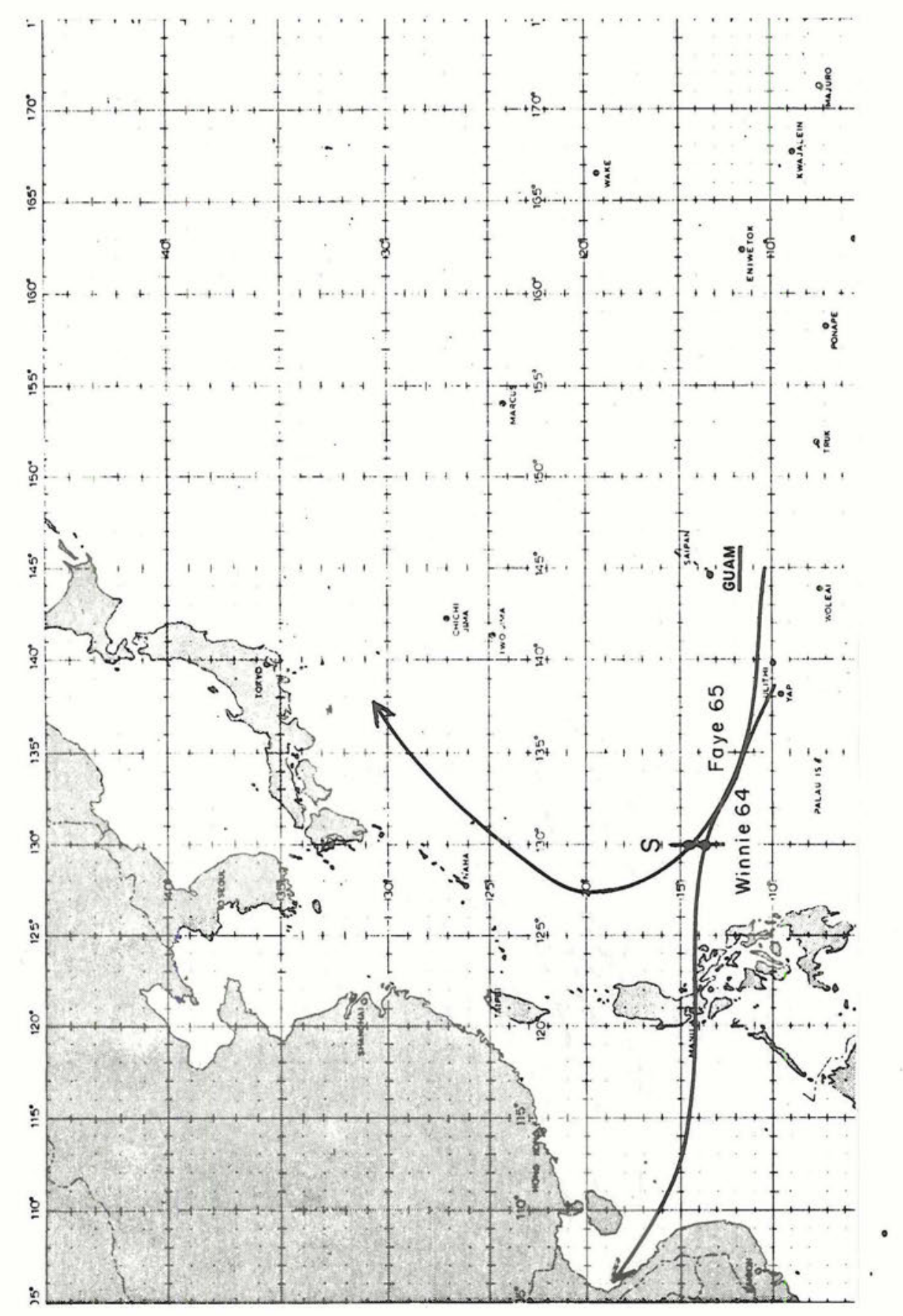

0
0
0
0
0
0
0
0

ช

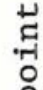

a

站

0
+
0
$z$

$\underset{0}{0}$

탱

00
.
0
0
0
0
0
0
1
1
0
0
0

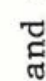

o

ᄅ્ટુ

ن

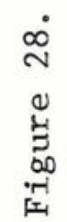




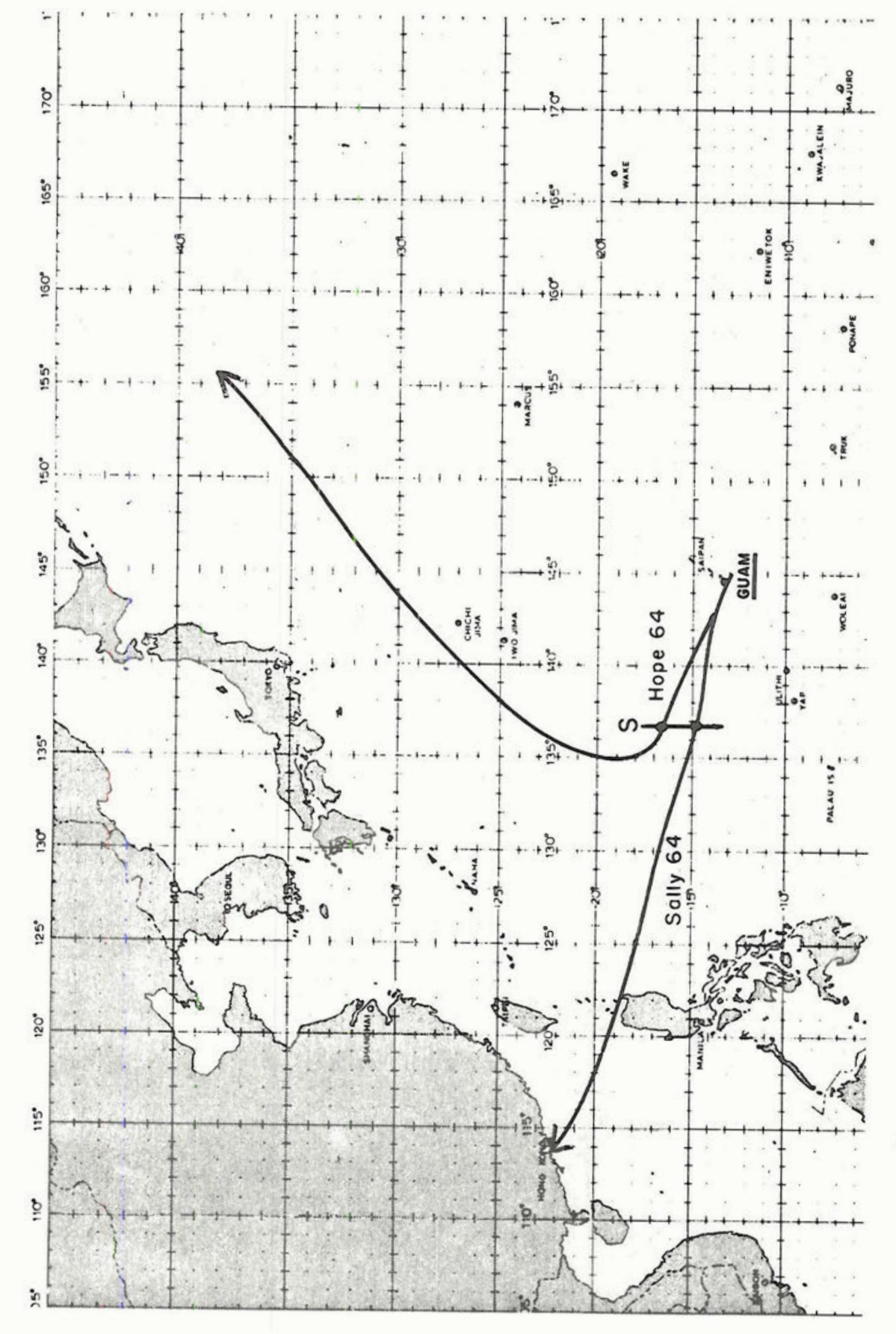

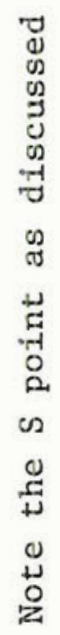

悤

具

苟

뮤

点

प्त

㟧

芦

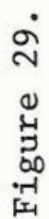




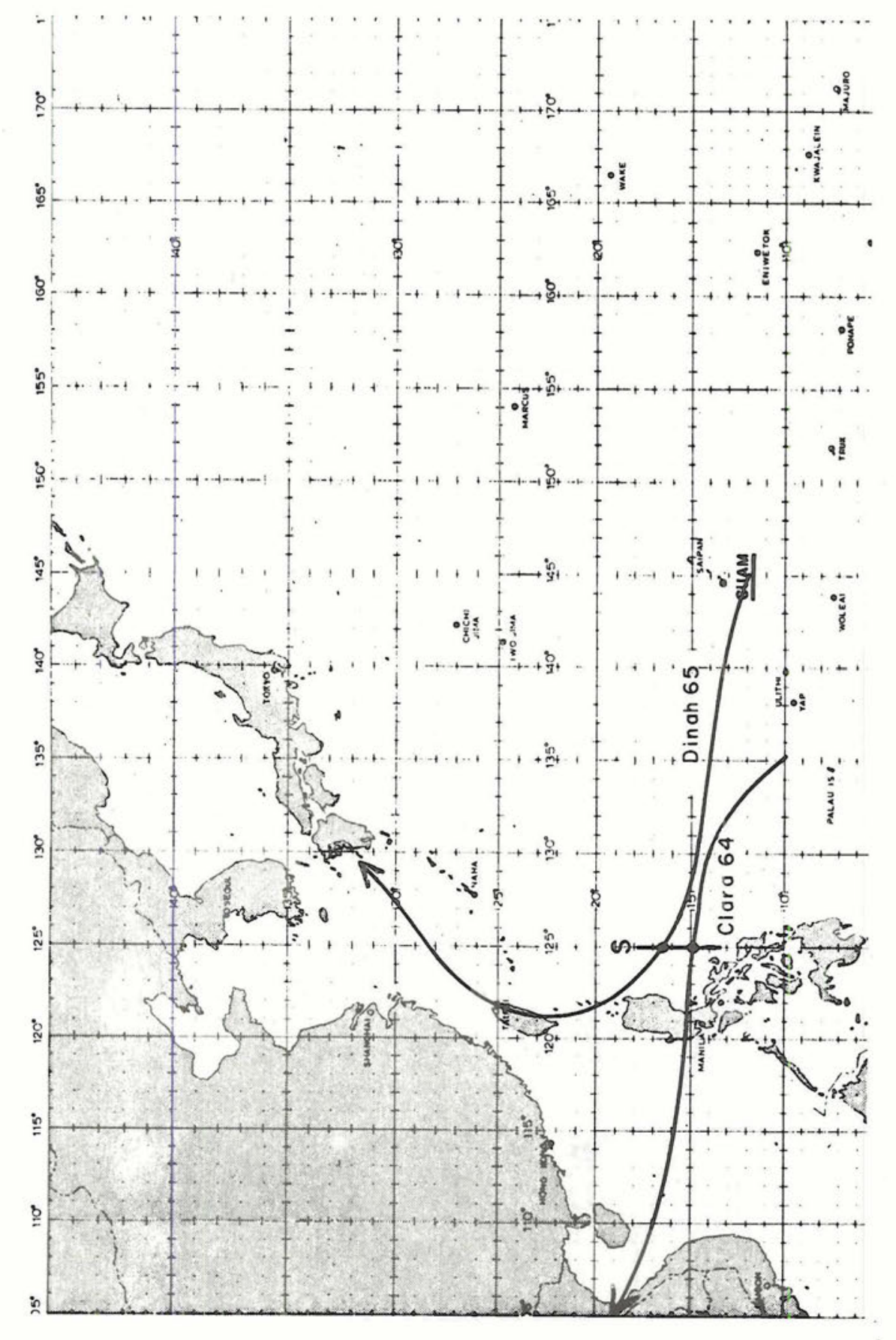

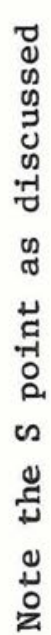

苟

है

苂

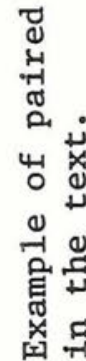

ஓं

峁 


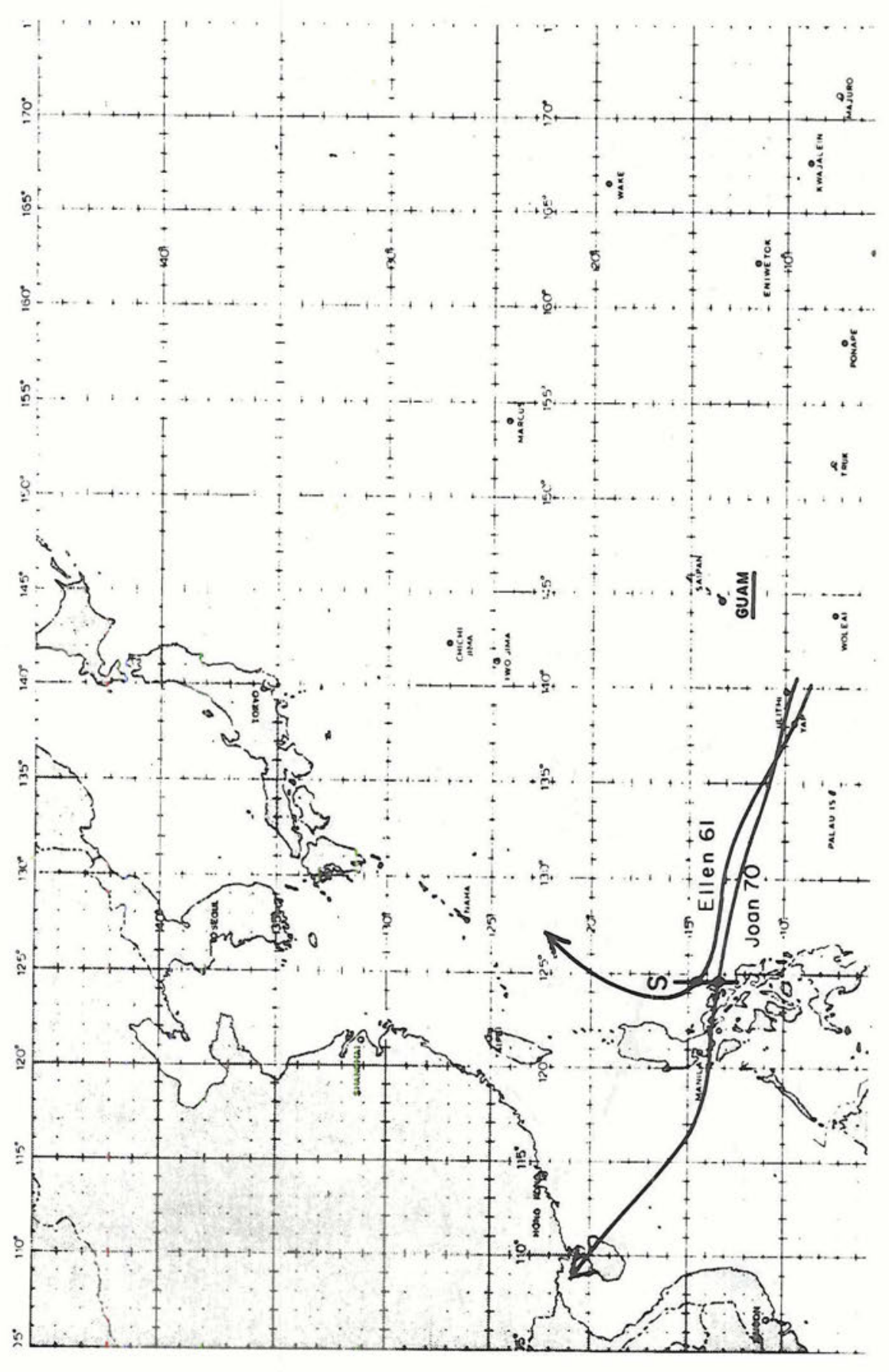

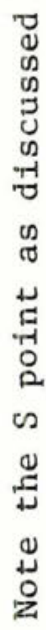

瓷

bิ

"ত্

岱

نَّ

ल- 


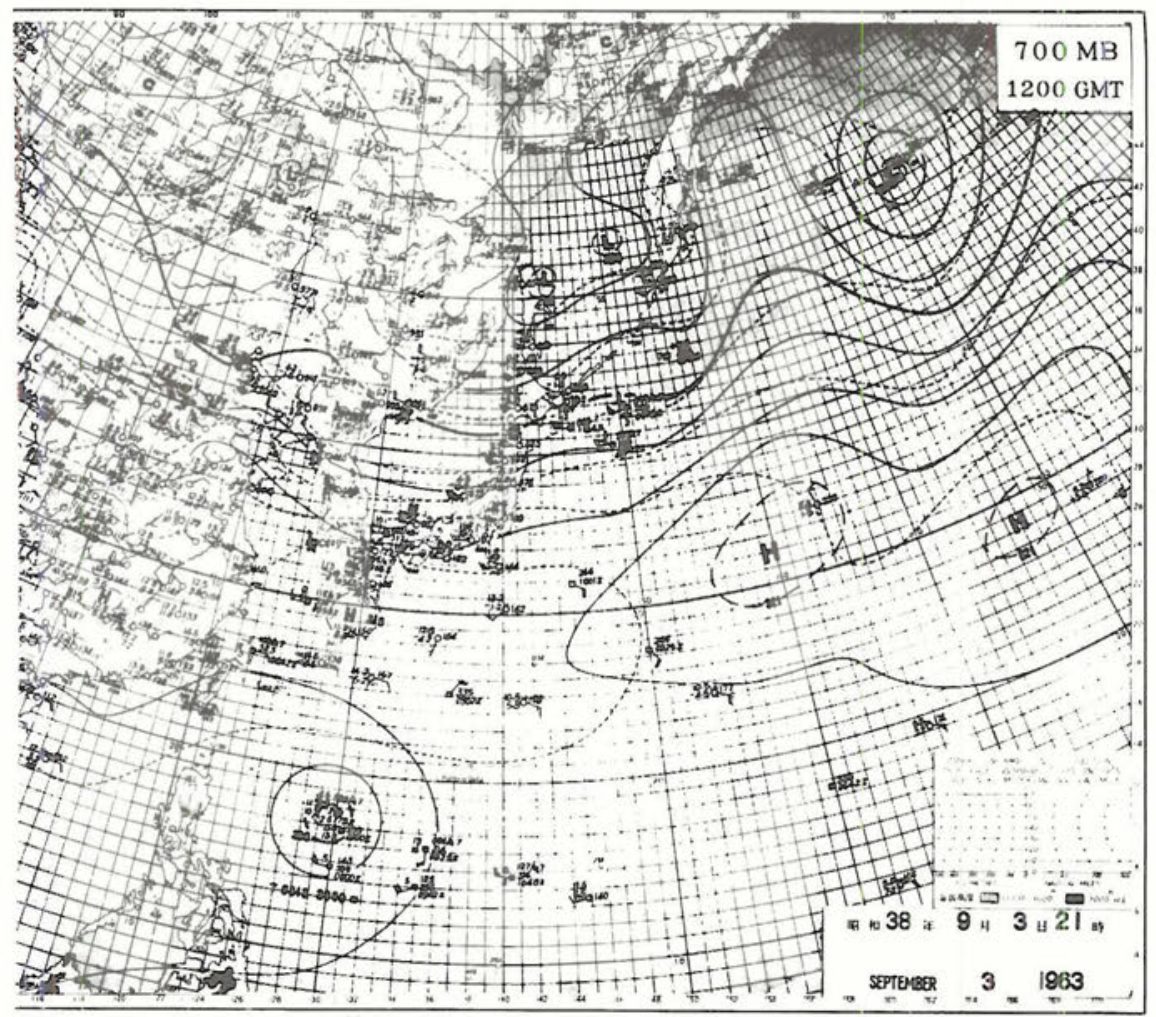

Figure 32. $700 \mathrm{mb}$ level daily weather at the time of $\mathrm{S}$ point for tropical storm Kit (1963) which eventually recurved.

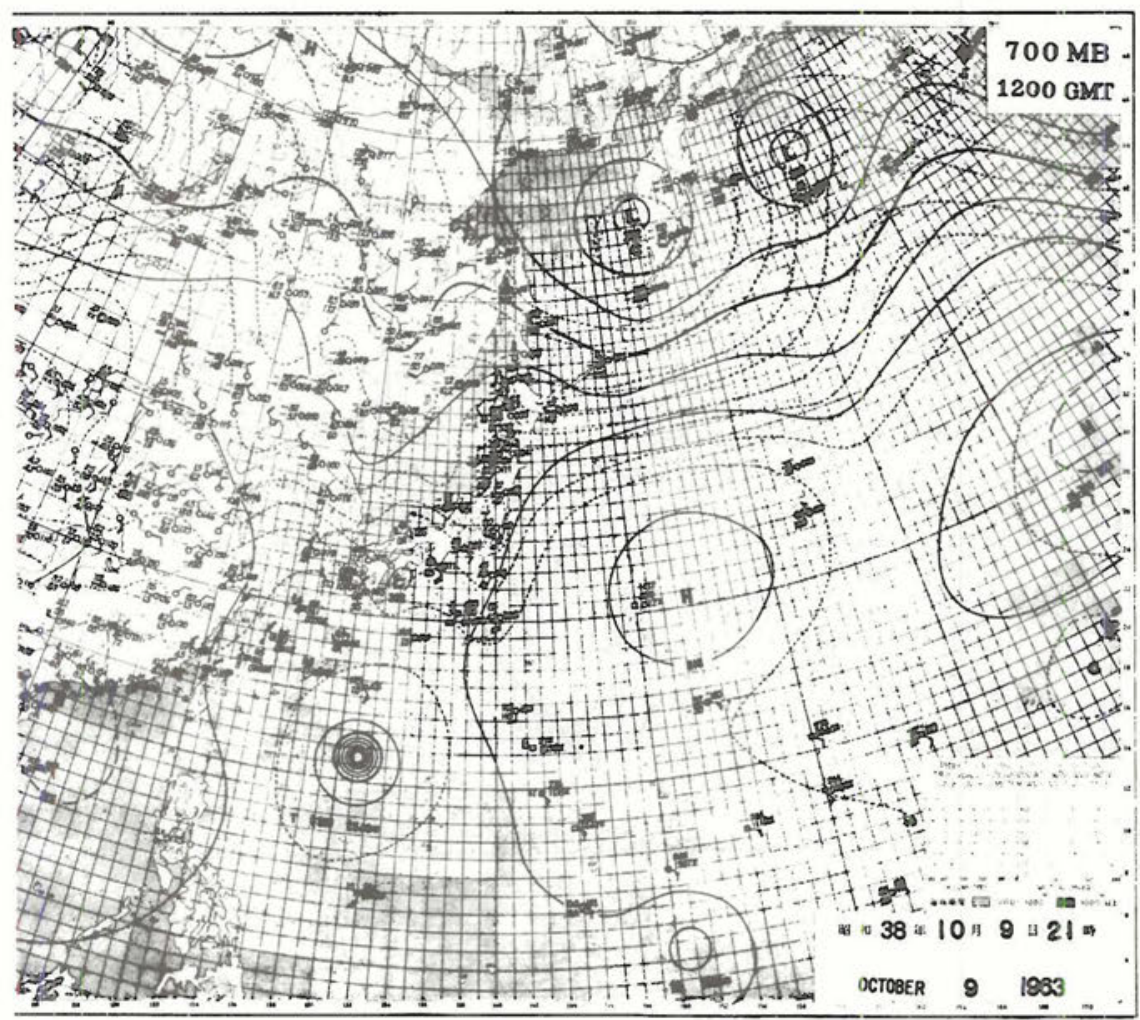

Figure 33. $700 \mathrm{mb}$ level daily weather map at time of $\mathrm{S}$ point for tropical storm Faye (1963) which did not recurve. 
together relative to the cyclone centers at each time period to give a mean composite time of $(\mathrm{S}-12)$. The $(\mathrm{S}-36)$ composite data time consists of the three time periods 24,36 and 48 hours before the $\mathrm{S}$ point and the (S-60) time data of 48 to 72 hours prior to recurvature. Some of the tropical storms of the $(\mathrm{S}-36)$ and $(\mathrm{S}-60)$ periods were in their early stages of development. Thus, the composite depictions presented in this paper are not for a single time period, but rather for a 24-hour combination of time periods. This technique results in typical rawinsonde case counts of 30-50 for grid points to the north of the storm location. Less data is available to the south. The Appendix lists the actual case count for each of the grid points for this study.

The basic compositing grid (see Part I) was expanded out to $21^{\circ}$ radius in order to note large scale parameter differences which are correlated with recurvature. Thus, from the composite fields of height, winds, temperature, etc. basic differences in the overall fields between storms that recurve and those that do not should, if they exist, be discerned. Table 1.2 lists the storm pairs with the dates and times of the $\mathrm{S}$ points on their respective tracks. 
TABLE 12

SELECTED STORM PAIRS FOR RECURVATURE COMPOSITE STUDY

Recurving Storms

\begin{tabular}{|c|c|c|c|c|c|c|c|c|}
\hline \multirow{2}{*}{1.} & \multirow{2}{*}{ Name } & \multirow{2}{*}{$\frac{\text { Year }}{1965}$} & \multicolumn{2}{|c|}{$\begin{array}{l}\text { Date and Time } \\
\text { of S Point }\end{array}$} & \multirow{2}{*}{$\frac{\text { Name }}{\text { Clara }}$} & \multirow{2}{*}{$\frac{\text { Year }}{1964}$} & \multicolumn{2}{|c|}{$\begin{array}{l}\text { Date and Time } \\
\text { of } S \text { Point }\end{array}$} \\
\hline & & & $6 / 17$ & $00 \mathrm{Z}$ & & & $10 / 04$ & $12 \mathrm{Z}$ \\
\hline 2. & Faye & 1965 & $11 / 23$ & $00 \mathrm{Z}$ & Winnie & 1964 & $6 / 28$ & $00 \mathrm{Z}$ \\
\hline 3. & Irma & 1966 & $5 / 18$ & $00 \mathrm{Z}$ & Lucy & 1962 & $11 / 28$ & $00 \mathrm{Z}$ \\
\hline 4. & Harriet & 1967 & $11 / 20$ & $00 \mathrm{Z}$ & Patsy & 1970 & $11 / 16$ & $00 Z$ \\
\hline 5. & Cora & 1969 & $8 / 18$ & $00 \mathrm{Z}$ & Doris & 1964 & $7 / 13$ & $12 \mathrm{Z}$ \\
\hline 6. & Kit & 1963 & $10 / 09$ & $00 \mathrm{Z}$ & Clara & 1967 & $7 / 08$ & $12 \mathrm{Z}$ \\
\hline 7. & Opal & 1967 & $9 / 11$ & $00 z$ & Helen & 1964 & $7 / 31$ & $00 Z$ \\
\hline 8. & Wilda & 1964 & $9 / 23$ & $00 \mathrm{Z}$ & Elsie & 1969 & $9 / 25$ & $00 \mathrm{Z}$ \\
\hline 9. & Della & 1968 & $9 / 22$ & $00 \mathrm{Z}$ & Viola & 1969 & $7 / 26$ & $00 Z$ \\
\hline 10. & Gilda & 1962 & $10 / 25$ & $12 \mathrm{Z}$ & Emma & 1967 & $11 / 03$ & $00 \mathrm{Z}$ \\
\hline 11. & Hope & 1964 & $10 / 25$ & $12 \mathrm{Z}$ & Sally & 1964 & $9 / 06$ & $12 \mathrm{Z}$ \\
\hline 12. & Ellen & 1961 & $12 / 09$ & $00 \mathrm{Z}$ & Joan & 1970 & $10 / 13$ & $00 \mathrm{Z}$ \\
\hline 13. & 0lga & 1970 & $7 / 01$ & $12 \mathrm{Z}$ & Tilda & 1964 & $9 / 14$ & $00 Z$ \\
\hline 14. & Lucy & 1968 & $6 / 30$ & $12 \mathrm{Z}$ & Dinah & 1962 & $10 / 01$ & $12 \mathrm{Z}$ \\
\hline 15. & Kim & 1968 & $6 / 01$ & $12 \mathrm{Z}$ & Freda & 1965 & $7 / 09$ & $12 \mathrm{Z}$ \\
\hline 16. & Kathy & 1969 & $11 / 07$ & $00 \mathrm{Z}$ & June & 1961 & $8 / 02$ & $12 \mathrm{Z}$ \\
\hline 17. & Shirley & 1965 & $9 / 08$ & $12 Z$ & Tilda & 1961 & $10 / 01$ & $12 \mathrm{Z}$ \\
\hline 18. & Trix & 1965 & $9 / 14$ & $12 \mathrm{Z}$ & Harriet & 1965 & $7 / 24$ & $12 \mathrm{Z}$ \\
\hline 19. & Karen & 1962 & $11 / 14$ & $00 \mathrm{Z}$ & Faye & 1963 & $9 / 03$ & $12 Z$ \\
\hline 20. & Kit / & 1966 & $6 / 24$ & $12 Z$ & Opal & 1964 & $12 / 12$ & $12 \mathrm{Z}$ \\
\hline 21. & Susan & 1963 & $12 / 26$ & $12 \mathrm{Z}$ & Ope1 & 1962 & $8 / 02$ & $12 \mathrm{Z}$ \\
\hline
\end{tabular}

Non-Recurving Storms 


\section{RECURVATURE COMPOSITE RESULTS}

\subsection{Depiction}

It is important to understand the depiction presented in the following figures. The grid has been extended out to $21^{\circ}$ radius from the center of the storm. The first data point shown from the storm center is not near the center but at $7-9^{\circ}$ radius from the center. Thus, the depiction in this section shows the outer $7-21^{\circ}$ radius from the storm. No data within $7^{\circ}$ radius of the storm center is portrayed. The inner $7^{\circ}$ radius motion has been previously described in Part I. The wind barb depictions are in $\mathrm{m} / \mathrm{sec}$ with the single barb representing $5 \mathrm{~m} / \mathrm{sec}$ and the large triangular barb representing $25 \mathrm{~m} / \mathrm{sec}$. These values can be approximately doubled in order to convert the wind speed into knots.

\subsection{Wind Direction and Speed}

Figures 34 to 39 portray the $700 \mathrm{mb}$ and $200 \mathrm{mb}$ wind fields 60 to 12 hours prior to recurvature. Figure 34 depicts the composite $700 \mathrm{mb}$ wind field at the $(\mathrm{S}-60)$ mean composite time period for nonrecurving and recurving storms, along with the non-recurving minus recurving difference. Westerlies are located approximately 16-20 to the north of non-recurving storms. For the recurving storms the westerlies are found at only $10^{\circ}$ to the north of the cyclone center and are slightly stronger. As seen, the differential speed difference between the non-recurving and recurving storms to the north is $5-10 \mathrm{~m} / \mathrm{sec}$. Thus, at 48 to 72 hours, or 60 hours average time before the separation point, the $700 \mathrm{mb}$ wind field out to $14-16^{\circ}$ radius shows slight westerly wind differences for the storms that recurve vs. those that do not. The same depictions for the $24-48$ hours prior 

time period, or $(\mathrm{S}-36)$ at $700 \mathrm{mb}$ are shown in Figure 36. At this time period, the westerlies are located approximately $14-16^{\circ}$ to the north of the non-recurving storms, while only $10^{\circ}$ to the north for recurving storms. For the recurving storms the westerlies are slightly stronger than for the non-recurving storms. The difference between the nonrecurving and recurving storms to the north of the center is again 5-10 $\mathrm{m} / \mathrm{sec}$. Figure 38 shows a similar depiction for the (S-12) time period. Though 24 hours closer to actual recurvature, there are few differences between the $(S-36)$ and $(S-12)$ time periods. Again at $(S-12)$ the westerlies are deeper and slightly stronger to the north of recurving storms.

Major differences in the wind fields can be seen at the $200 \mathrm{mb}$ level. Figure 35 depicts the composite $200 \mathrm{mb}$ wind field at the (S-60) mean composite time period for non-recurving and recurving storms, along with the non-recurving minus recurving difference. Figure 37 and 39 show the same for the $(\mathrm{S}-36)$ and $(\mathrm{S}-12)$ time periods, respectively. It is readily apparent that a significant $200 \mathrm{mb}$ difference between storms that recurve and those that do not is the width and strength of the westerlies to the north of the storm at a distance of $10-20^{\circ}$ radius to the north. At $(\mathrm{S}-60)$, non-recurving storms do not have westerlies within $16^{\circ}$ of their center, while the recurving storms have the westerlies at $10^{\circ}$ radius to the north. At $(\mathrm{S}-36)$ the westerlies are closer to the storm center and stronger for both categories of storms. This trend continues as shown by the (S-12) time period. The three time period differences between the non-recurving and recurving storms range up to $30-36 \mathrm{~m} / \mathrm{sec}$ to the north of the storm. Thus, it appears that even at an average time period of 60 hours before the point at which the recurving storms begin to shift their courses, their $200 \mathrm{mb}$ wind fields are 


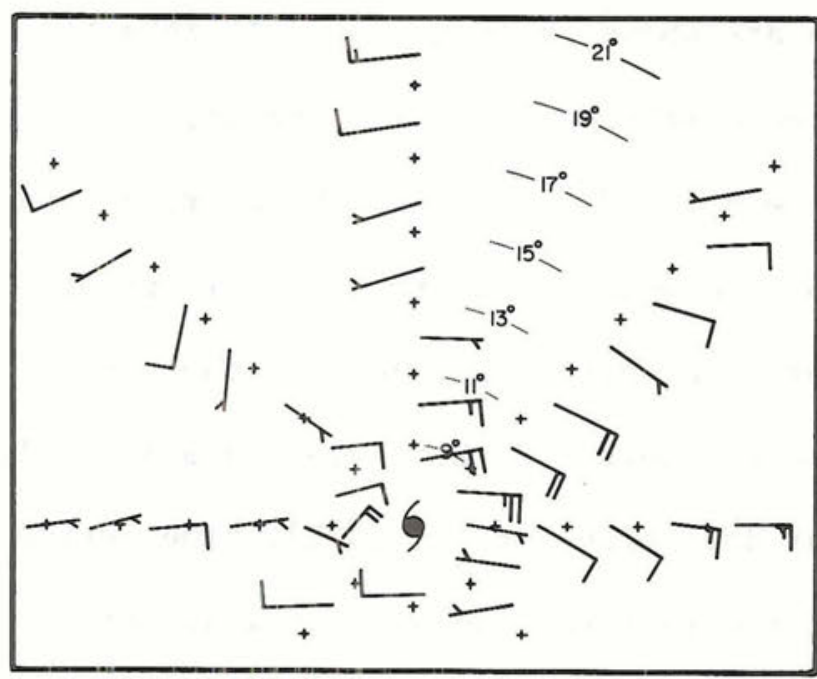

$700 \mathrm{mb}$ Dir. \& Speed NON-RECURVING at time S-60 hrs.

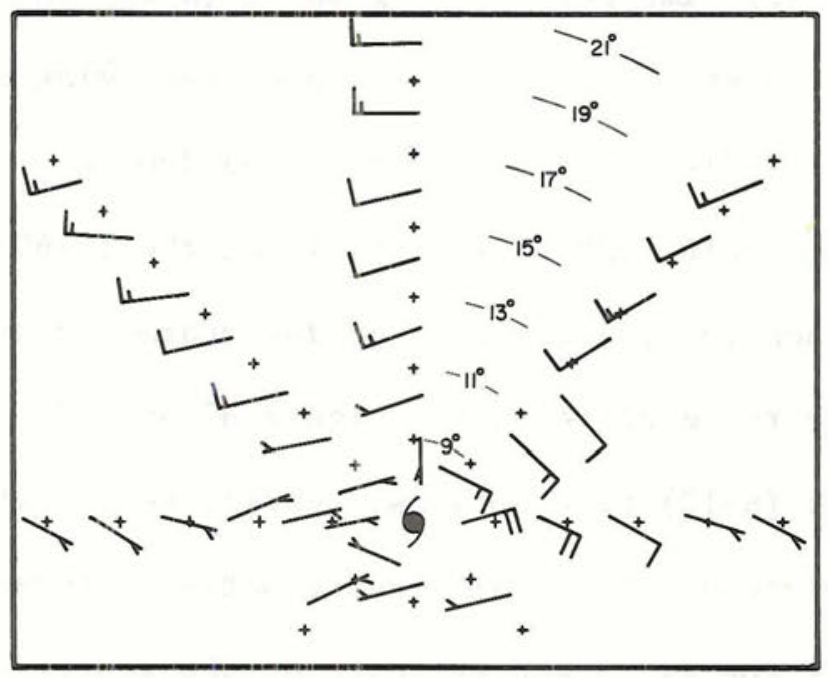

$700 \mathrm{mb}$ Dir. \& Speed RECURVING at time S-60 hrs.

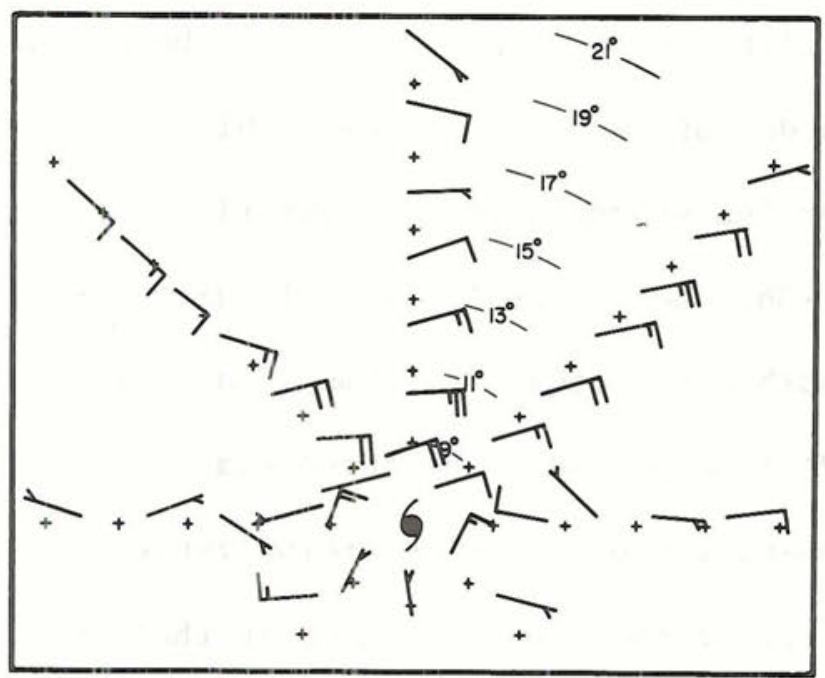

$700 \mathrm{mb}$ Dir. \& Speed NON-RECURVING-RECURVING DIFFERENCE at time S-60 hrs.

Figure 34. $700 \mathrm{mb}$ direction and speed composite depictions for nonrecurving and recurving storms with the non-recurving minus recurving difference at (S-60). 


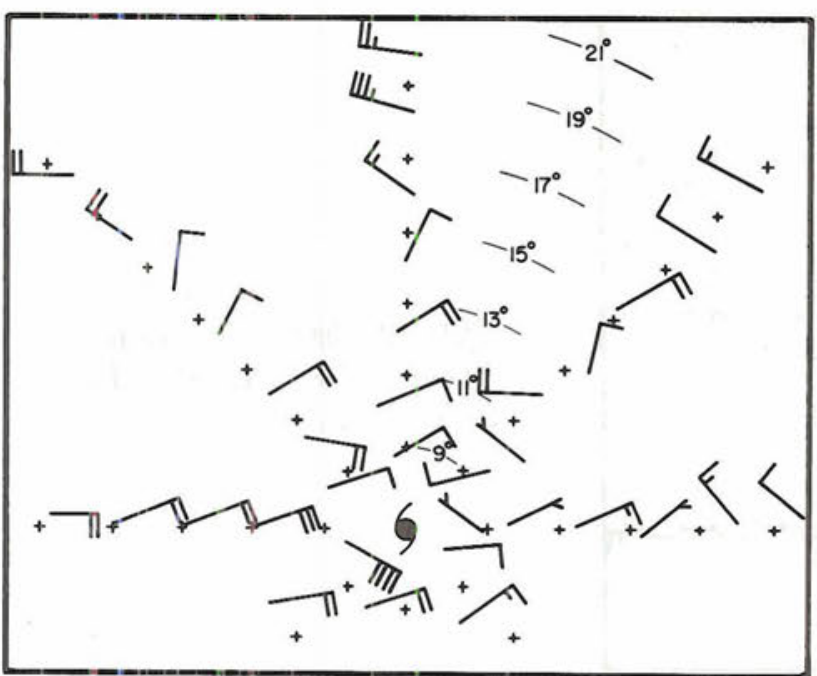

$200 \mathrm{mb}$ Dir. \& Speed NON-RECURVING at time S-60 hrs.

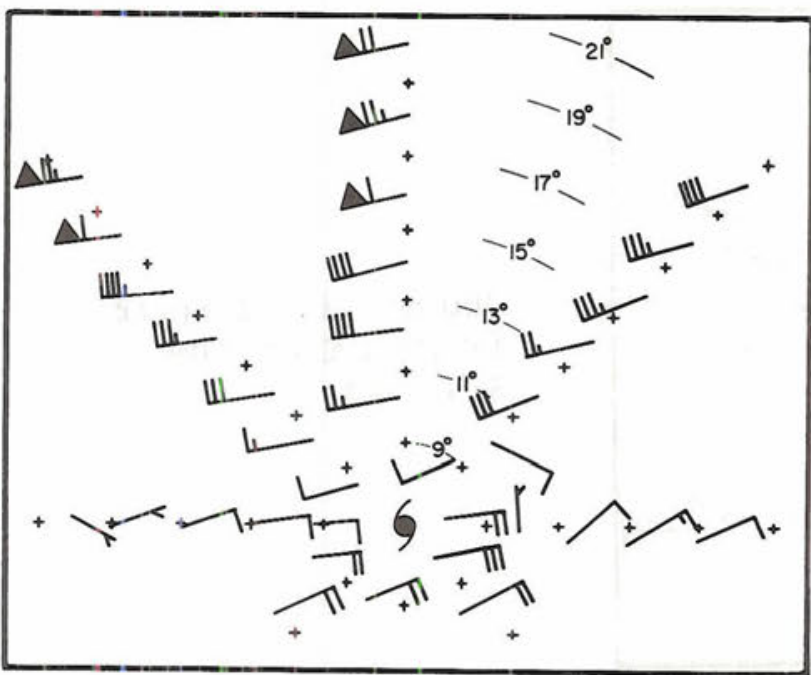

$200 \mathrm{mb}$ Dir. \& Speed RECURVING at time S-60 hrs.

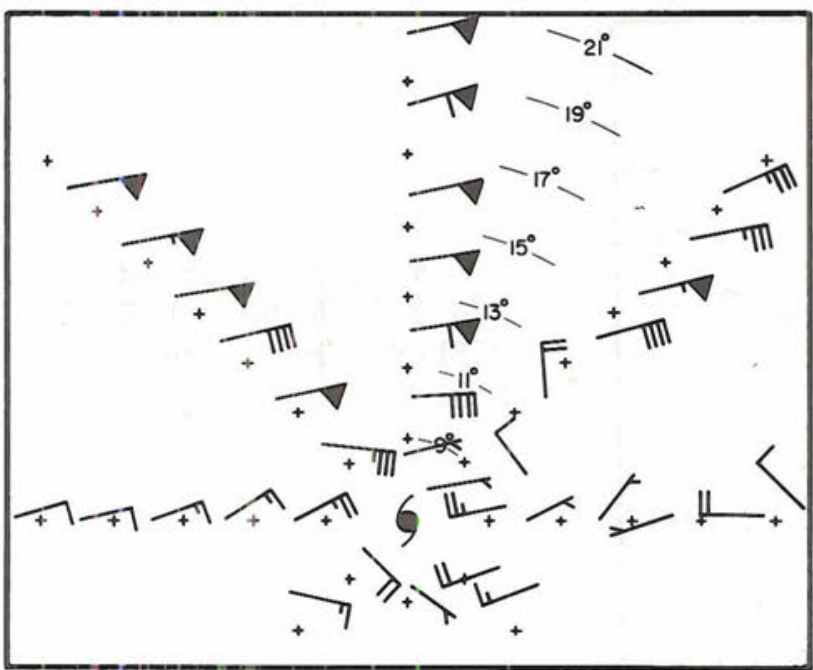

$200 \mathrm{mb}$ Dir. \& Speed NON-RECURVING-RECURVING DIFFERENCE at time S -60 hrs.

Figure 35. Same as Fig. 34, except for the $200 \mathrm{mb}$ level. 

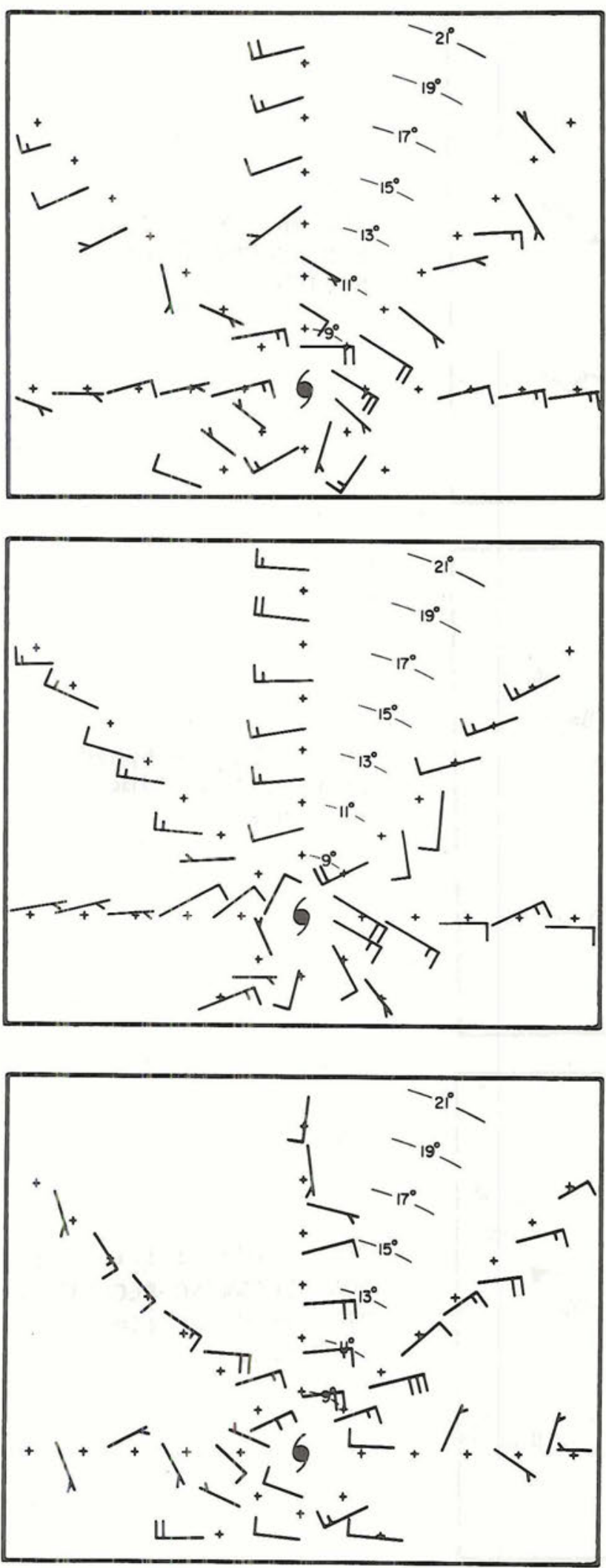

700 mb Dir. \& Speed

NON-RECURVING at time S-36 hrs.
700 mb Dir. \& Speed RECURVING at time S-36 hrs.
$700 \mathrm{mb}$ Dir. \& Speed NON-RECURVING -RECURVING DIFFERENCE at time S-36 hrs.

Figure 36. Same as Figure 34, except for the (S-36) mean composite time period. 

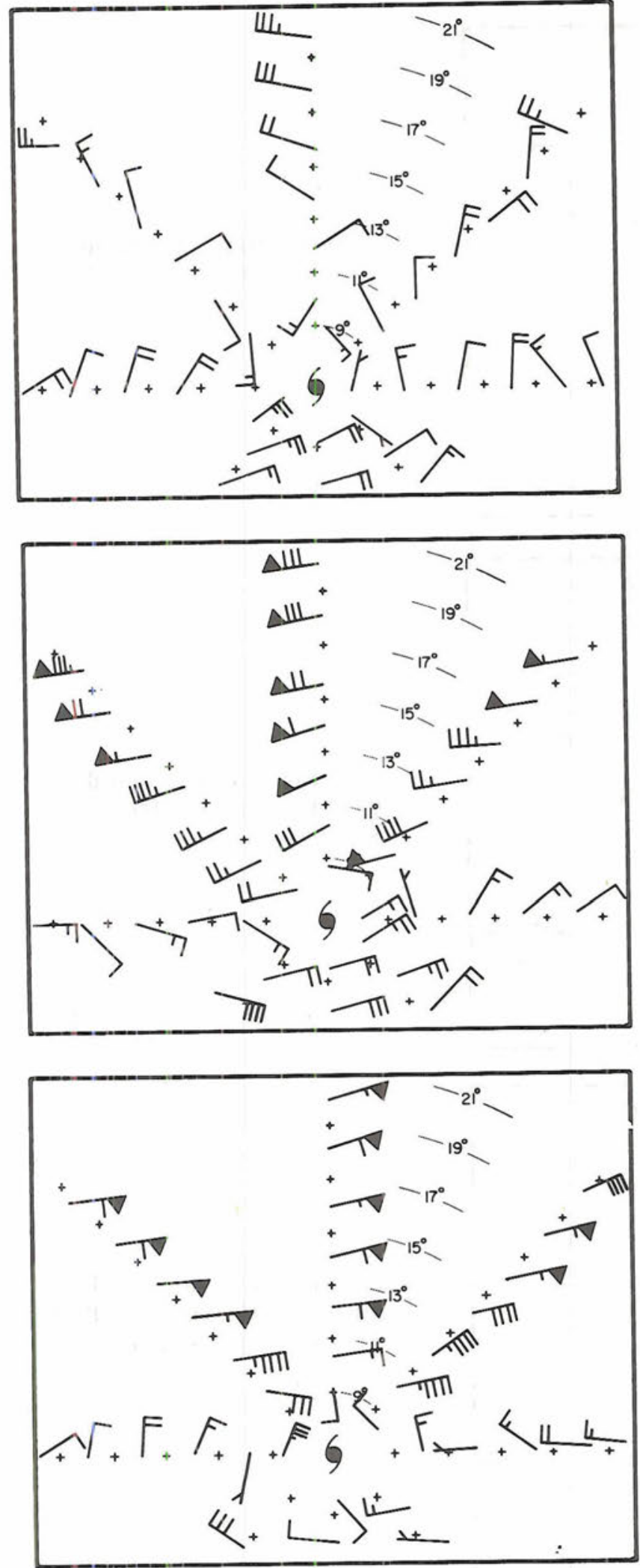

$200 \mathrm{mb}$ Dir. \& Speed NON-RECURVING at time S-36 hrs.
200 mb Dir. \& Speed RECURVING at time S-36 hrs.
200 mb Dir. \& Speed NON-RECURVING-RECURVING DIFFERENCE at time S-36 hrs.

Figure 37. Same as Figure 35, except for the (S-36) mean composite time period. 


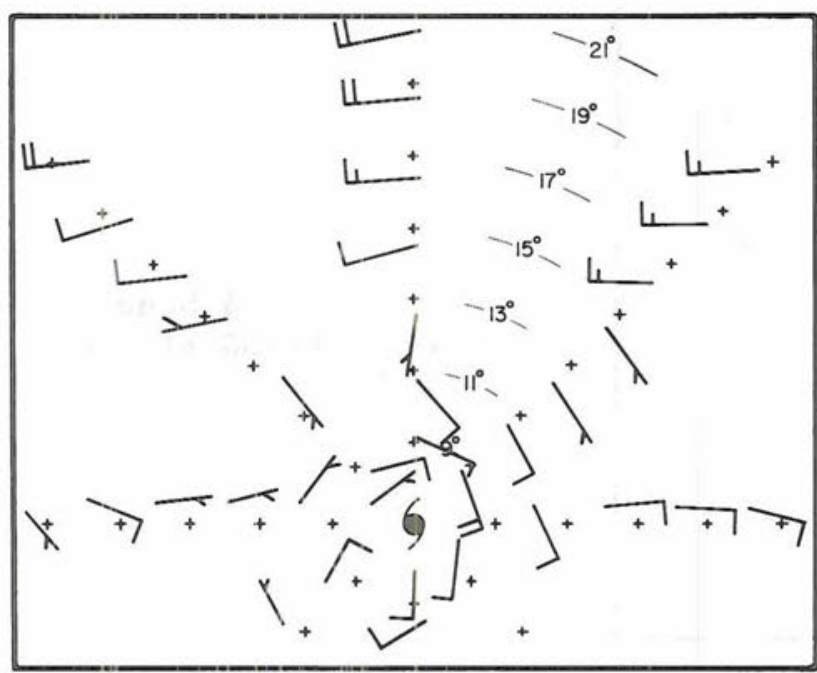

$700 \mathrm{mb}$ Dir. \& Speed NON-RECURVING at time S-12 hrs.

$700 \mathrm{mb}$ Dir. \& Speed RECURVING at time $\mathrm{S}-12$ hrs.

$700 \mathrm{mb}$ Dir. \& Speed NON-RECURVING-RECURVING DIFFERENCE at time S-12 hrs.

Figure 38. Same as Figure 34, except for the (S-12) mean composite time period. 


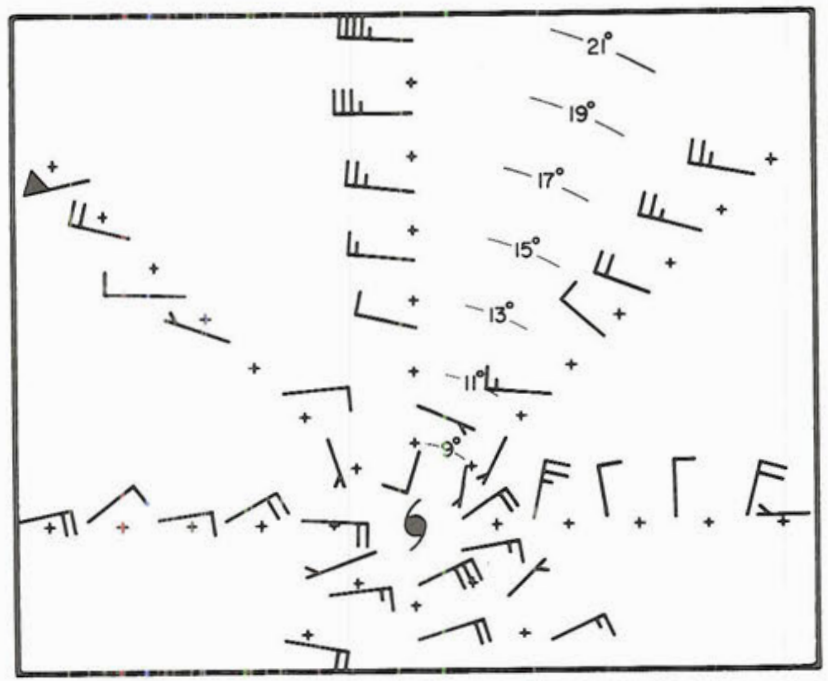

$200 \mathrm{mb}$ Dir. \& Speed NON-RECURVING at time S-12 hrs.

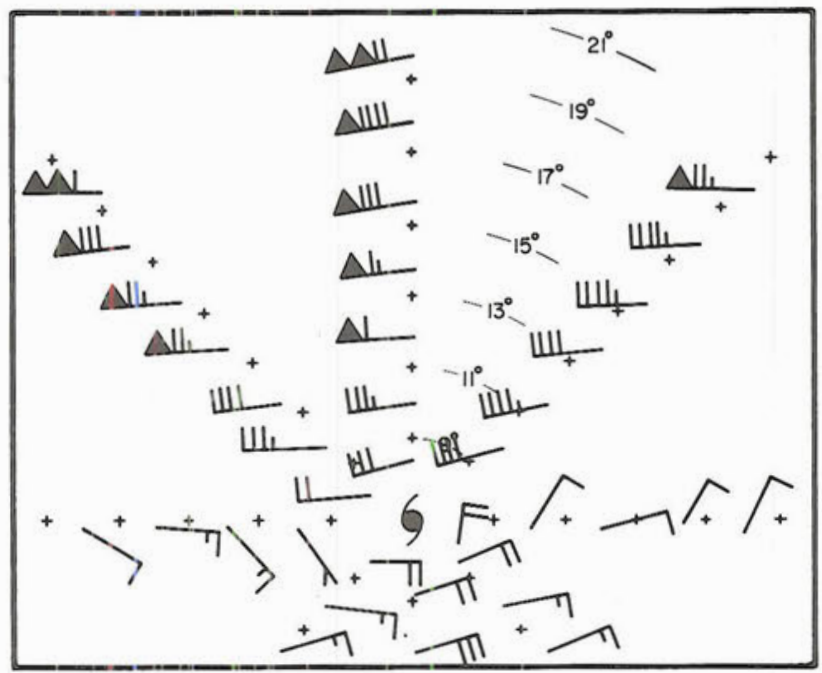

$200 \mathrm{mb}$ Dir. \& Speed RECURVING at time S-12 hrs.

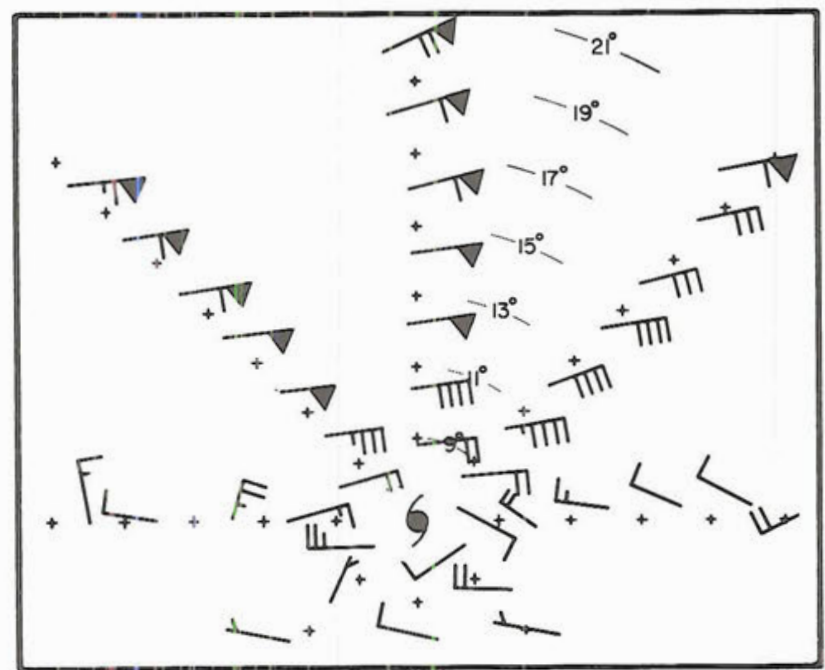

$200 \mathrm{mb}$ Dir. \& Speed NON-RECURV ING-RECURV ING DIFFERENCE at time S-12 hrs.

Figure 39. Same as Figure 35, except for the (S-12) mean composite time period. 
significantly different from those storms which do not recurve. Thus, a considerable gain in recurvature forecasting skill may be possible at a long time range. These upper level westerly wind differences are not greatly surprising. Forecasters have always qualitatively known that the westerlies are stronger and closer to the recurving storm. To the author's knowledge, however, there has not been any explicit documentation of these differences. Also, it is doubtful that it was generally known that the flow field differences were so large 48 to 72 hours before recurvature.

At least 60 hours before the first northward change in a recurving storm's westerly movement, the $200 \mathrm{mb}$ wind field is a strong indicator as to whether a storm is likely to recurve or not. Recurving vs. nonrecurving storn differences are somewhat accentuated at the (S-36) and S-12) time periods. Thus, it appears that storm recurvature in the tropics is indeed tied to the strength of the westerlies in the midlatitudes to the north of the storm's position and that these differences occur at long time periods prior to recurvature. An increase of forecasting skill may be possible if more research effort is devoted to the study of the $200 \mathrm{mb}$ flow patterns.

\subsection{Zonal Wind}

Figure 40 shows the analysis of the u component vector differences (non-recurving storm ninus recurving storm) for the $700 \mathrm{mb}$ level at the three mean composite time periods. Figure 41 shows the same for the 200 $\mathrm{mb}$ level. Negative numbers indicate stronger westerly components for the recurving storms. As seen, the $700 \mathrm{mb}$ level differences are small 

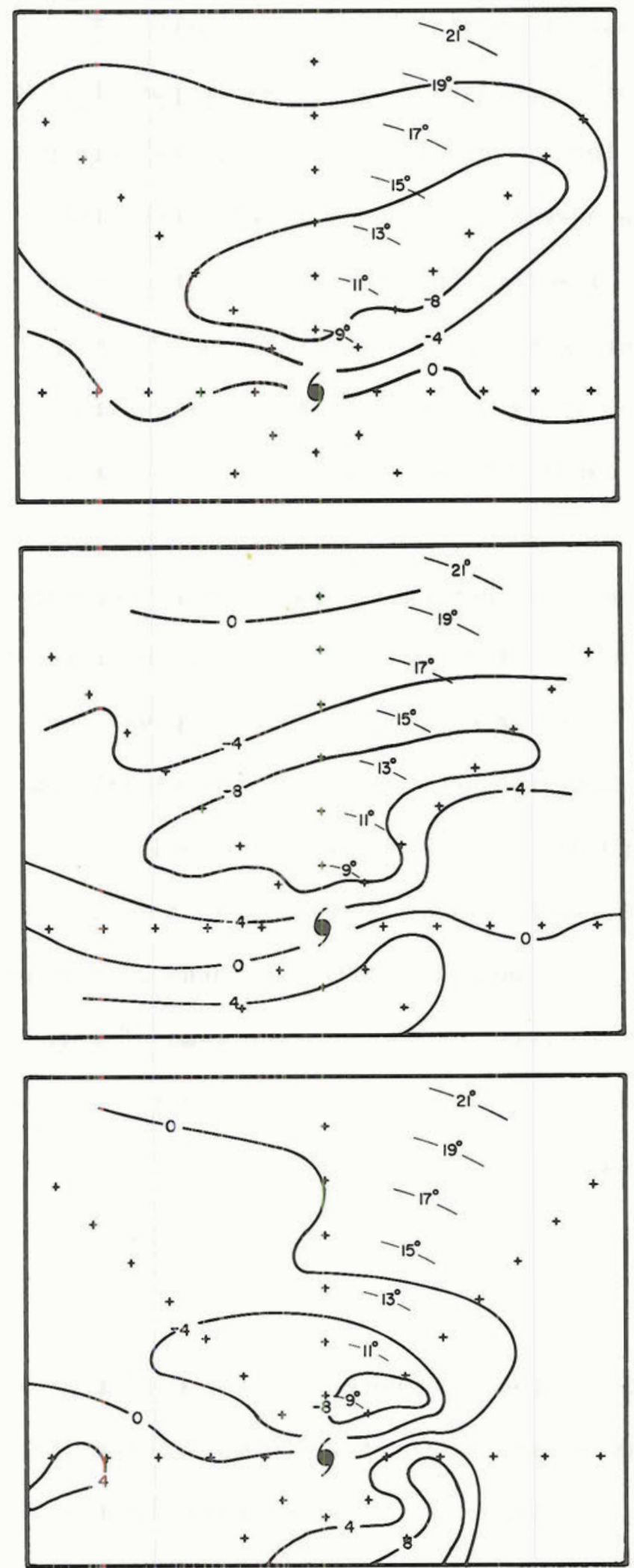

$700 \mathrm{mb}$ Zonal

DIFFERENCE at time

$\mathrm{s}-60 \mathrm{hrs}$. (m/ sec)
$700 \mathrm{mb}$ Zonal

DIFFERENCE at time

$\mathrm{S}-36 \mathrm{hrs}$. (m/sec)
$700 \mathrm{mb}$ Zonal

DIFFERENCE at time

$\mathrm{S}-12 \mathrm{hrs}$. (m/sec)

Figure 40. $700 \mathrm{mb}$ non-recurving minus recurving storm zonal component difference in meters per second $(\mathrm{m} / \mathrm{sec})$ for the three mean composite time periods. 


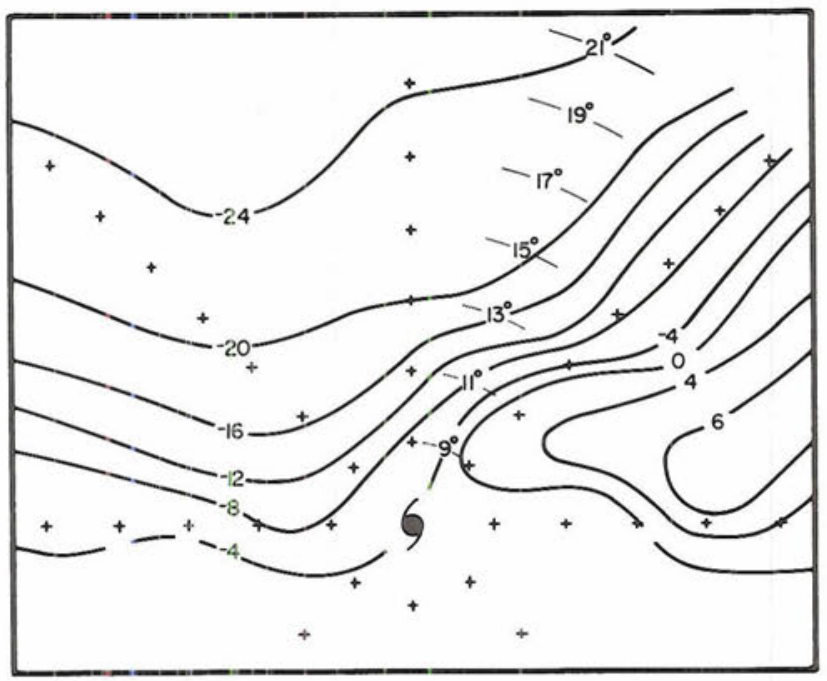

$200 \mathrm{mb}$ Zonal

DIFFERENCE at time

$\mathrm{s}-60 \mathrm{hrs}$. (m/sec)

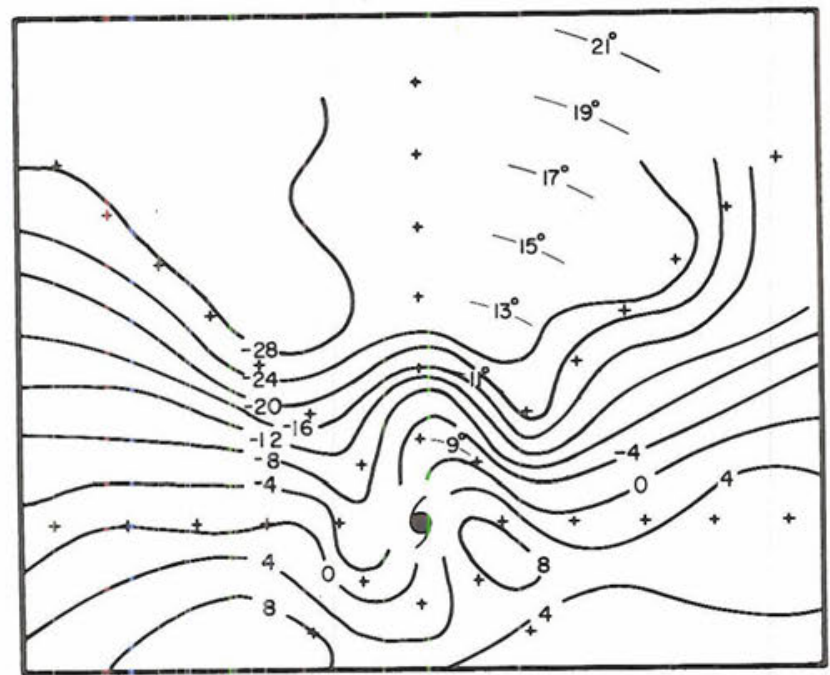

$200 \mathrm{mb}$ Zonal

DIFFERENCE at time

$\mathrm{S}-36 \mathrm{hrs}$. ( $\mathrm{m} / \mathrm{sec})$

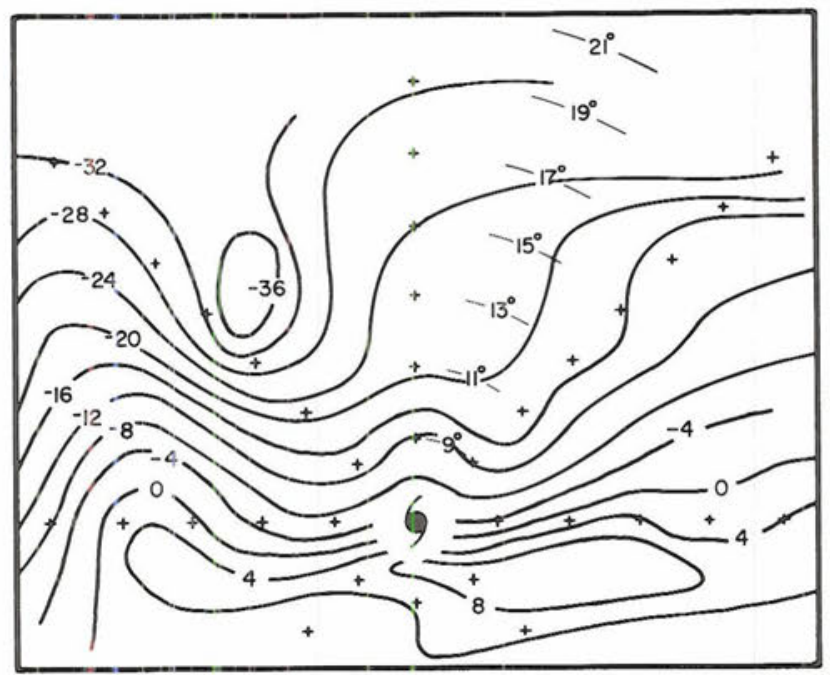

$200 \mathrm{mb}$ Zonal DIFFERENCE at time $\mathrm{S}-12 \mathrm{hrs}$. (m/sec)

Figure 41. Same as Figure 40, except for the $200 \mathrm{mb}$ level. 

$(\sim 4-8 \mathrm{~m} / \mathrm{sec})$ at $8-12^{\circ}$ radii. The differential u fields at $200 \mathrm{mb}$ for the three time periods show the degree of variation of the two stratifications. At 60 hours prior to separation (S), the recurving storms have a westerly u component $24 \mathrm{~m} / \mathrm{sec}$ stronger at $18-20^{\circ}$ radius to the northwest than for the non-recurving storms. At (S-36) the difference is $28 \mathrm{~m} / \mathrm{sec}$, and increases to $36 \mathrm{~m} / \mathrm{sec}$ at the $(\mathrm{S}-12)$ time period. Thus, the upper tropospheric levels appear to be the best levels for the forecasting of recurvature as far as the wind field is concerned.

\subsection{Meridional wind}

Figures 42 and 43 depict the non-recurving minus recurving v component wind differences at 700 and $200 \mathrm{mb}$ for the three mean composite time periods. Negative numbers indicate that recurving storms have stronger southerly components than the non-recurving storms, while positive values are indications of northerly components. At $200 \mathrm{mb}$ for the $(S-60)$ and $(S-36)$ time periods, it is seen that the recurving storms possess positive meridional wind components to the north 12-16 $\mathrm{m} / \mathrm{sec}$ greater than those of the non-recurving storms. This is likely an indication of the typical upper tropospheric trough to the northwest. The $700 \mathrm{mb}$ difference charts for the same time periods indicate a similar differential southerly component to the north and northeast of the storm, but the magnitudes are much less. At (S-12), the $200 \mathrm{mb}$ chart shows 1ittle change from the previous time periods, while at $700 \mathrm{mb}$ the southerly component to the west and northwest diminishes somewhat. Again, it is seen that the upper tropospheric differences are much larger. 


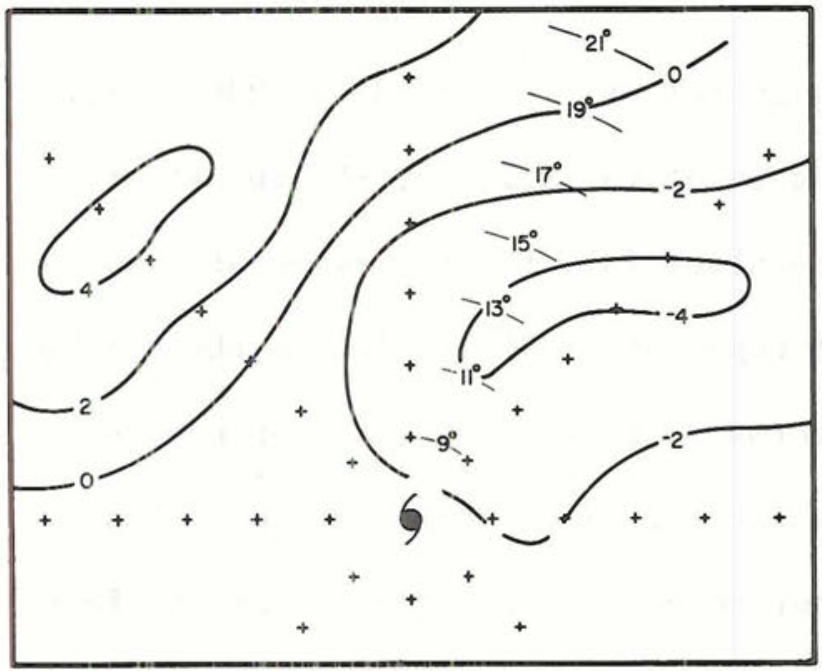

$700 \mathrm{mb}$ Meridional Wind DIFFERENCE at time $\mathrm{S}-60 \mathrm{hrs} .(\mathrm{m} / \mathrm{sec})$

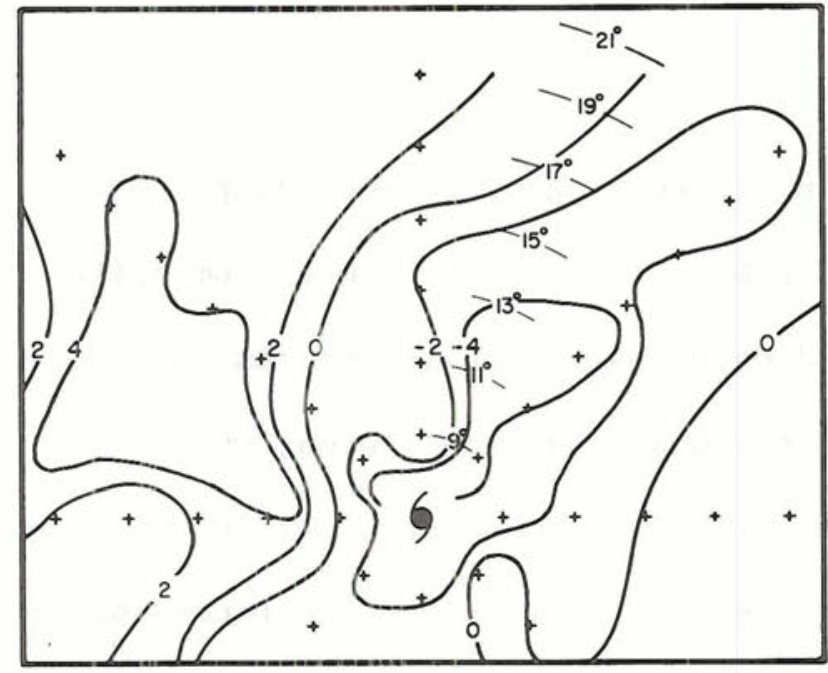

$700 \mathrm{mb}$ Meridional Wind DIFFERENCE at time $\mathrm{S}-36 \mathrm{hrs} .(\mathrm{m} / \mathrm{sec})$

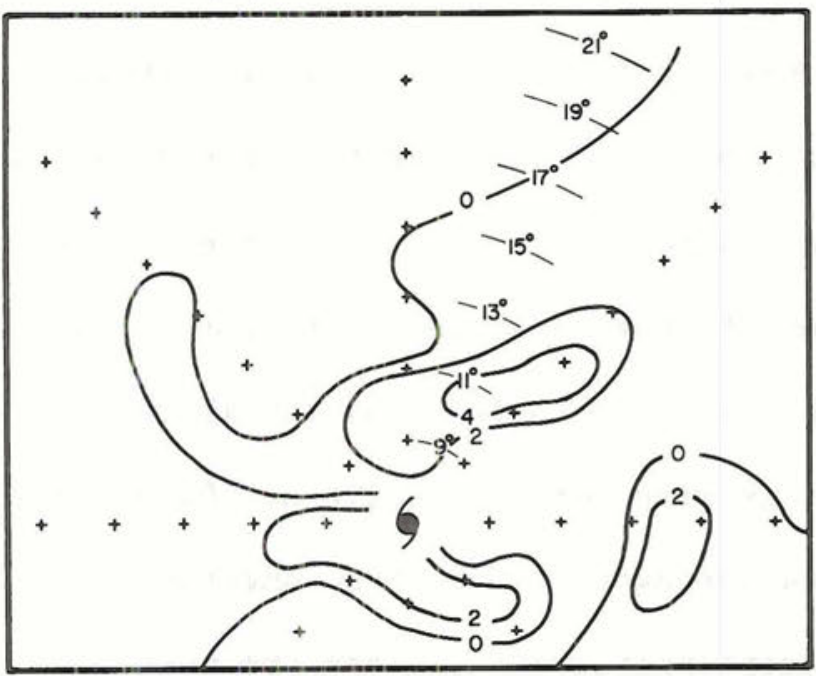

$700 \mathrm{mb}$ Meridional Wind DIFFERENCE at time $\mathrm{S}-12 \mathrm{hrs}$. (m/sec)

Figure 42. $700 \mathrm{mb}$ non-recurving minus recurving storn meridional component difference in meters per second $(\mathrm{m} / \mathrm{sec})$ for the three mean composite time periods. 

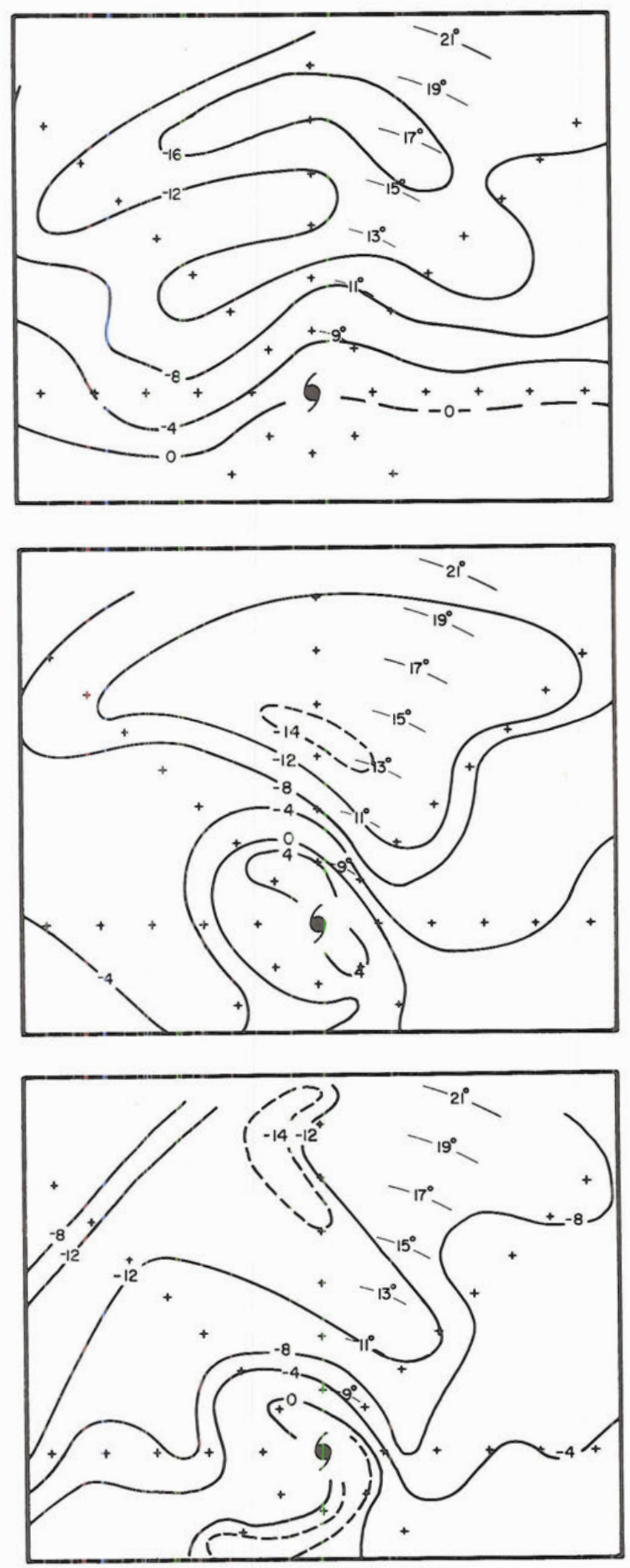

$200 \mathrm{mb}$ Meridional Wind DIFFERENCE at time $\mathrm{S}-60 \mathrm{hrs}$. (m/sec)
$200 \mathrm{mb}$ Meridional Wind DIFFERENCE at time $\mathrm{s}-36 \mathrm{hrs} .(\mathrm{m} / \mathrm{sec})$
$200 \mathrm{mb}$ Meridional Wind DIFFERENCE at time $\mathrm{S}-12 \mathrm{hrs} .(\mathrm{m} / \mathrm{sec})$

Figure 43. Same as Figure 42, except for the $200 \mathrm{mb}$ level. 



\subsection{Height}

The height difference fields for the 700 and $200 \mathrm{mb}$ levels are shown in Figures 44 and 45 . At $200 \mathrm{mb}$ for the (S-60) time period and $18-20^{\circ}$ radius to the north, the non-recurving storms have heights which are over 150 meters greater than the recurving storms. This height difference increases to over 200 meters at (S-36) and to over 300 meters at the (S-12) time period. This striking difference is highly significant. At approximately 24 to 72 hours prior to the separation point for a recurving storm, there is a large height gradient between the storm and $20^{\circ}$ radius to the north of the storm. It would seem that height differences of these magnitudes detected at some prior time period would be a good indication that within 60,36 , or 12 hours, respectively, a tropical storm is likely to begin to recurve. The $700 \mathrm{mb}$ charts show differential gradients of only 40 meters to the north and northeast of the storm center at $16-20^{\circ}$ radii. Generally, both levels and time periods show that for non-recurving storms, the relative heights are significantly higher to the north. Again, the $200 \mathrm{mb}$ difference fields are much more indicative of recurvature.

\subsection{Temperature}

The temperature differences between the two stratifications for the 700 and $200 \mathrm{mb}$ levels at $(\mathrm{S}-60),(\mathrm{S}-36)$, and $(\mathrm{S}-12)$ are depicted in Figures 46 and 47 . At $200 \mathrm{mb}$ it is readily apparent that there is little non-recurving/recurving composite difference $\left(1-2^{\circ}\right)$ in temperature to the north and northwest. However, at $700 \mathrm{mb}(\mathrm{S}-60)$, there is a $4^{\circ}$ differential gradient which increases to $6^{\circ} \mathrm{C}$ at the $(\mathrm{S}-36)$ time period and to $8^{\circ}$ at (S-12). From 12-60 hours before the separation point, 

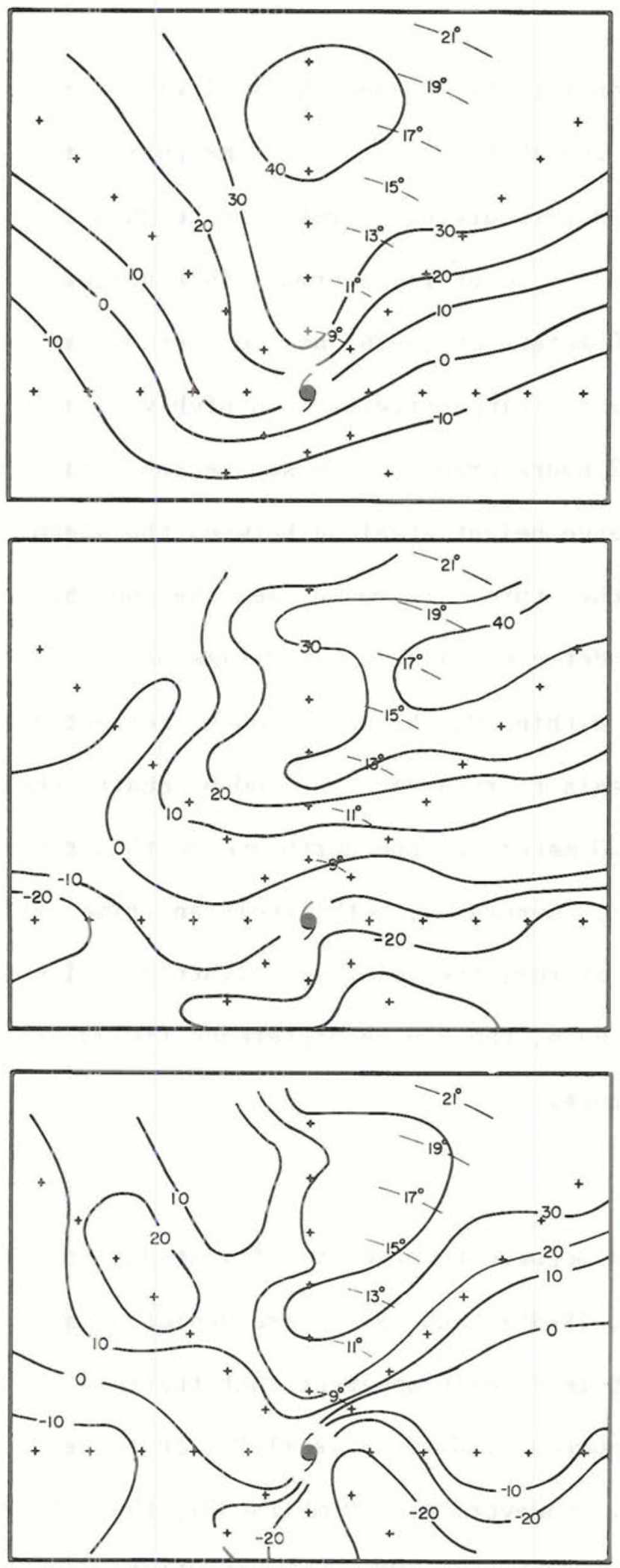

Figure 44. $700 \mathrm{mb}$ non-recurving minus recurving storm height difference in meters (m) for the three mean composite time periods.
$700 \mathrm{mb}$ Height DIFFERENCE in meters at time S-60 hrs.

$700 \mathrm{mb}$ Height DIFFERENCE in meters at time S-36 hrs.

$700 \mathrm{mb}$ Height

DIFFERENCE in meters at time $\mathrm{s}-12 \mathrm{hrs}$. 


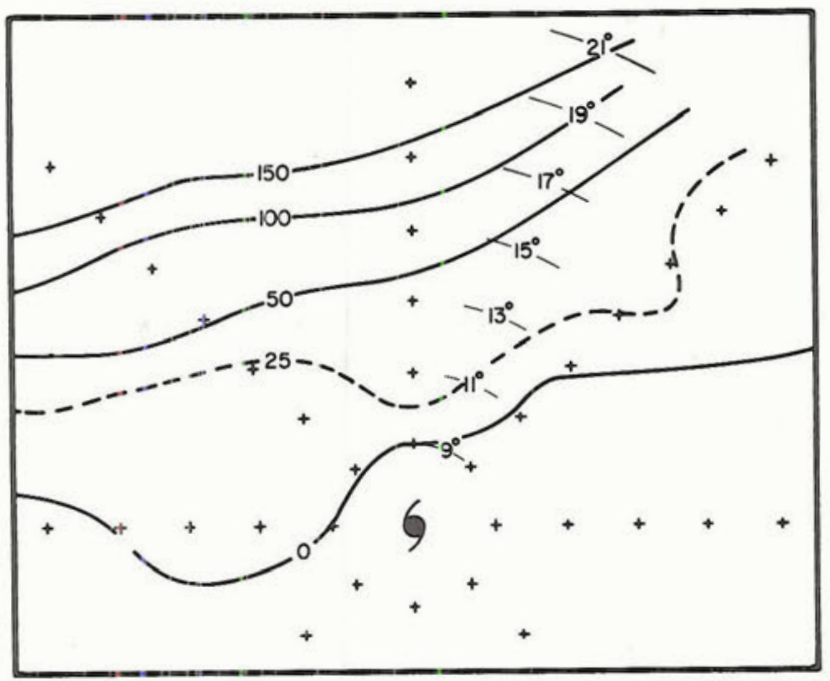

$200 \mathrm{mb}$ Height

DIFFERENCE in meters at time S-60 hrs.

$200 \mathrm{mb}$ Height

DIFFERENCE in meters at time S-36 hrs.

$200 \mathrm{mb}$ Height

DIFFERENCE in meters at time S-12 hrs.

Figure 45. Same as Figure 44, except for the $200 \mathrm{mb}$ leve1. 


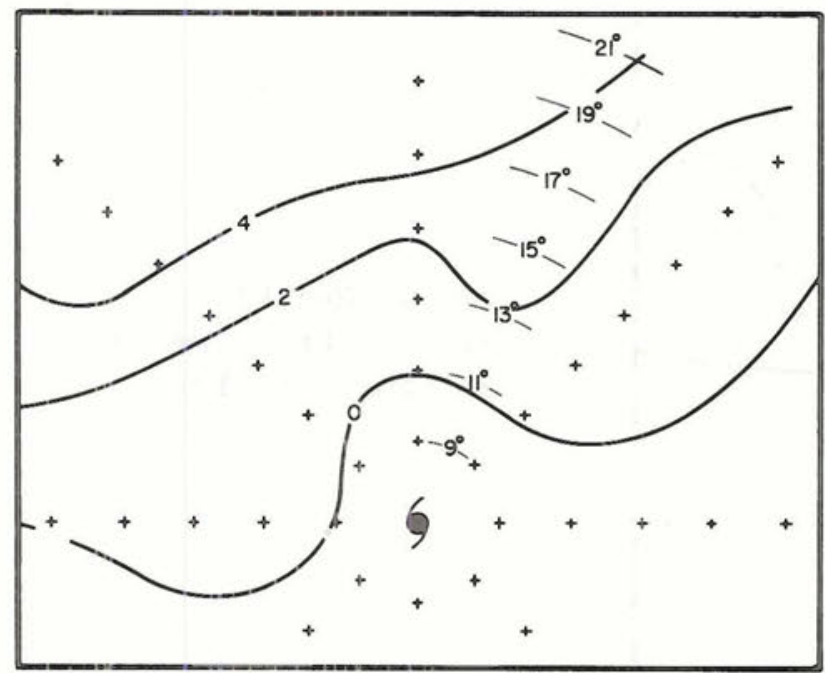

$700 \mathrm{mb}$ Temperature DIFFERENCE in ${ }^{\circ} \mathrm{C}$ at time $\mathrm{S}-60 \mathrm{hrs}$.

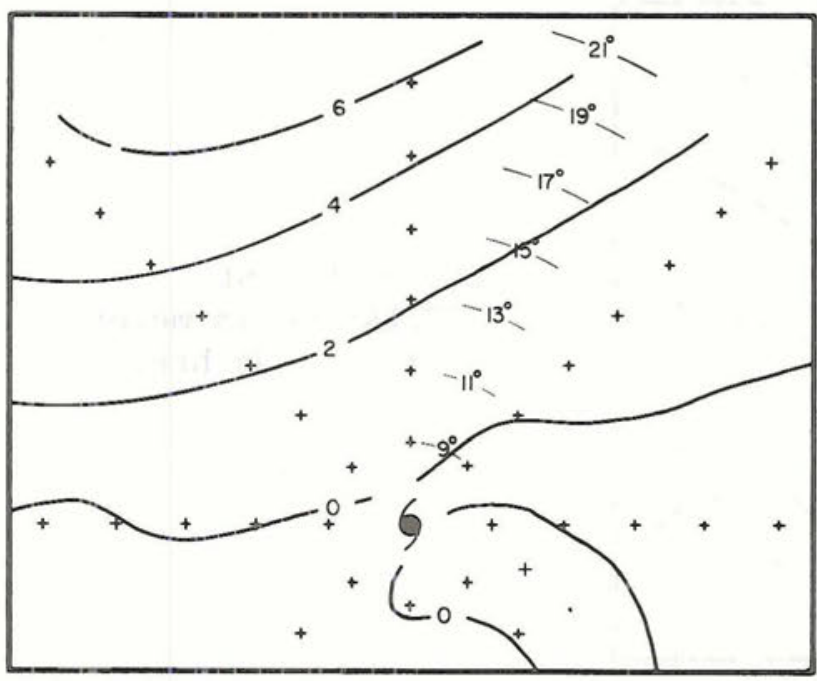

$700 \mathrm{mb}$ Temperature DIFFERENCE in ${ }^{\circ} \mathrm{C}$ at time S-36 hrs.

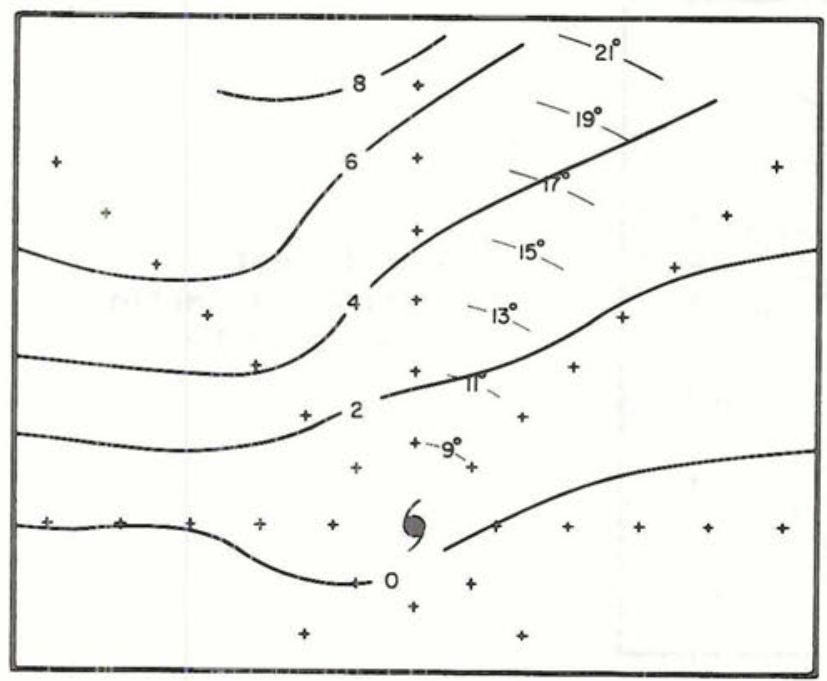

$700 \mathrm{mb}$ Temperature DIFFERENCE in ${ }^{\circ} \mathrm{C}$ at time S-36 hrs.

Figure 46. $700 \mathrm{mb}$ non-recurving minus recurving storm temperature difference in ${ }^{\circ} \mathrm{C}$ for the three mean composite time periods. 


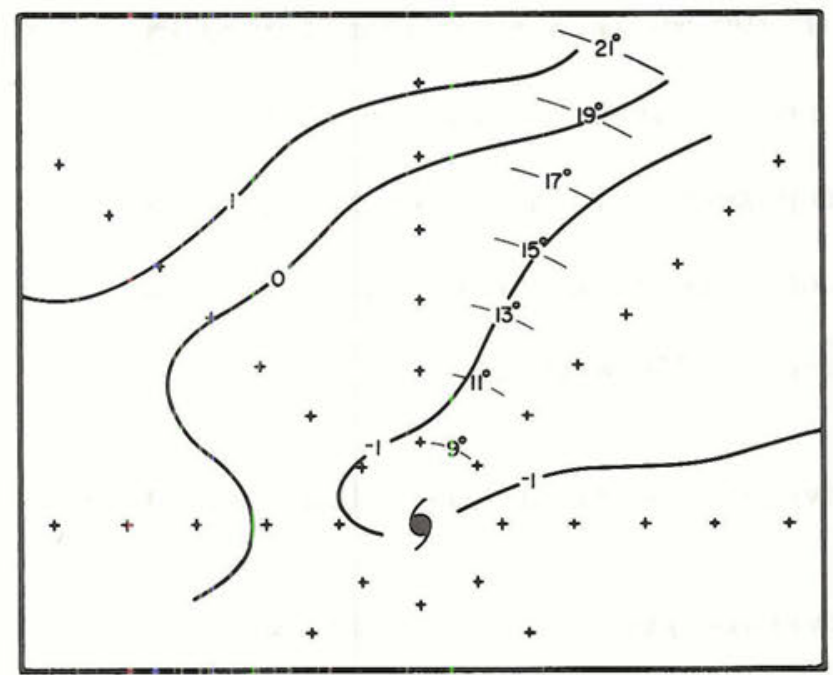

$200 \mathrm{mb}$ Temperature DIFFERENCE in ${ }^{\circ} \mathrm{C}$ at time S $-60 \mathrm{hrs}$.

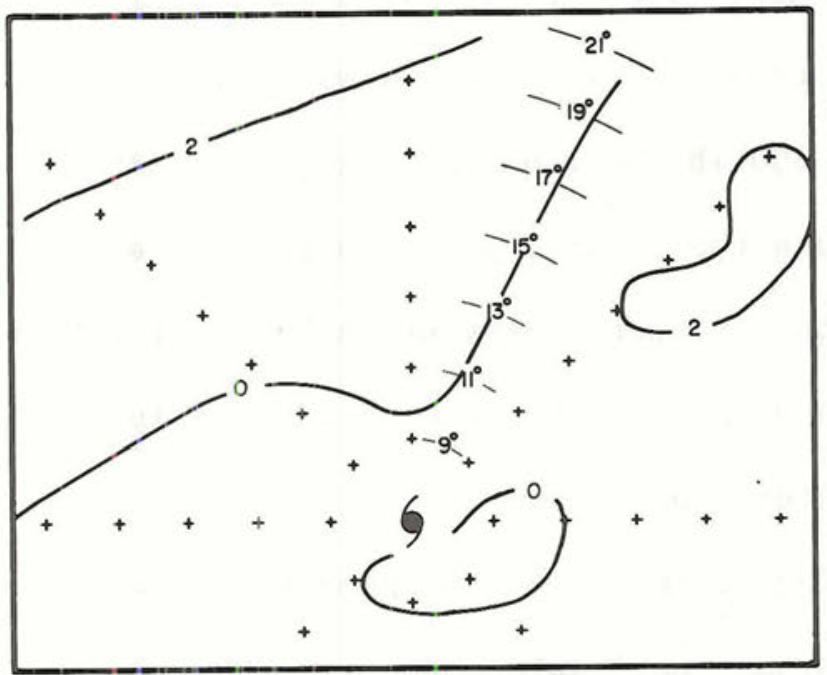

$200 \mathrm{mb}$ Temperature DIFFERENCE in ${ }^{\circ} \mathrm{C}$ at time $\mathrm{s}-36 \mathrm{hrs}$.

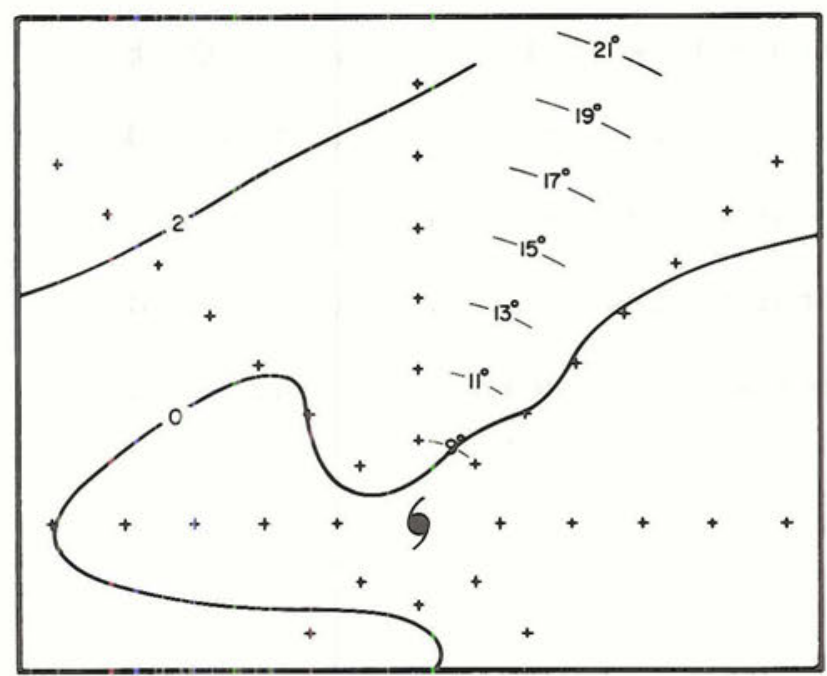

$200 \mathrm{mb}$ Temperature DIFFERENCE in ${ }^{\circ} \mathrm{C}$ at time $\mathrm{S}-12$ hrs.

Figure 47. Same as Figure 46, except for the $200 \mathrm{mb}$ level. 
the outer radii synoptic field at $700 \mathrm{mb}$ is $4-8^{\circ}$ colder for storms that recurve than for storms that do not recurve. Thus, in contrast to the wind field results, the lower troposphere is a better indicator of recurvature as far as the temperature field is concerned. Table 13 summarizes the above discussed parameter differences.

3.7 Recurvature Minus Non-Recurvature Zonal and Meridional Geostrophic Wind Components

Recurvature minus non-recurvature geostrophic zonal and meridional wind components which are calculated from the differential height gradients north to south, and east to west across the storm centers are shown in Figures 48 and 49. At $200 \mathrm{mb}$ the zonal geostrophic environmental flow from $10^{\circ}$ to $20^{\circ}$ across the recurving storms shows a significantly larger component than for the non-recurving storms. At $700 \mathrm{mb}$ these geostrophic zonal differences gradually decrease with radius and are only $1-2 \mathrm{~m} / \mathrm{sec}$ at radii greater than $10^{\circ}$.

Recurving minus non-recurving storm meridional geostrophic wind differences are less pronounced than zonal values, but at $200 \mathrm{mb}$, they still are quite indicative of recurvature at large radii. $700 \mathrm{mb}$ geostrophic flow differences beyond $10^{\circ}$ are near zero. The large $200 \mathrm{mb}$ geostrophic flow differences at large radii indicate a degree of possible forecasting potential. It is apparent that at large radii the $200 \mathrm{mb}$ height field is a much better indicator of recurvature than is the 700 $\mathrm{mb}$ leve1. 
TABLE 13

SUMMARY OF NON-RECURVING MINUS RECURVING PARAMETER DIFFERENCES

Parameter
Data Average 48-72 Hours Data Average 24-48 Hours

Prior to Separation $(S-60)$
Data Average from Time of Separation to 24 Hours Prior to Separation (S-12)

\begin{tabular}{|c|c|c|c|}
\hline $\begin{array}{l}700 \mathrm{mb} \text { zonal wind } \\
\text { field }\end{array}$ & $\begin{array}{l}4-8 \mathrm{~ms}^{-1} \text { at } 8-120 \text { radius } \\
(\mathrm{NW}-\mathrm{NE})\end{array}$ & $\begin{array}{l}4-8 \mathrm{~ms}^{-1} \text { at } 8-120 \text { radius } \\
(\mathrm{NW}-\mathrm{NE})\end{array}$ & $\begin{array}{l}4-8 \mathrm{~ms}^{-1} \text { at } 8-12^{\circ} \text { radius } \\
(\mathrm{NW}-\mathrm{NE})\end{array}$ \\
\hline $\begin{array}{l}200 \mathrm{mb} \text { zonal wind } \\
\text { field }\end{array}$ & $\begin{array}{l}20-24 \mathrm{~ms}^{-1} \text { at } 14-20^{\circ} \\
\text { radius (NW-NE) }\end{array}$ & $\begin{array}{l}24-28 \mathrm{~ms}^{-1} \text { at } 14-20^{\circ} \\
\text { radius (NW-NE) }\end{array}$ & $\begin{array}{l}30-36 \mathrm{~ms}^{-1} \text { at } 14-20^{0} \\
\text { radius }(\mathrm{NW}-\mathrm{NE})\end{array}$ \\
\hline $\begin{array}{l}700 \mathrm{mb} \text { meridional } \\
\text { wind field }\end{array}$ & $\begin{array}{l}2-4 \mathrm{~ms}^{-1} \text { at } 14-20^{\circ} \\
\text { radius }(\mathrm{NW}-\mathrm{N})\end{array}$ & $\begin{array}{l}2-4 \mathrm{~ms}^{-1} \text { at } 8-20^{\circ} \text { radius } \\
(\mathrm{N}-\mathrm{NE})\end{array}$ & $\begin{array}{l}2-4 \mathrm{~ms}^{-1} \text { at } 8-16^{0} \text { radius } \\
(\mathrm{NE})\end{array}$ \\
\hline $\begin{array}{l}200 \mathrm{mb} \text { meridional } \\
\text { wind field }\end{array}$ & $\begin{array}{l}10-12 \mathrm{~ms}^{-1} \text { at } 12-20^{\circ} \\
\text { radius }(\mathrm{NW}-\mathrm{N})\end{array}$ & $\begin{array}{l}12-16 \mathrm{~ms}^{-1} \text { at } 12-20^{\circ} \\
\text { radius (N-NE) }\end{array}$ & $\begin{array}{l}12-14 \mathrm{~ms}^{-1} \text { at } 12-20^{\circ} \\
\text { radius (W-NE) }\end{array}$ \\
\hline $\begin{array}{l}700 \mathrm{mb} \text { height } \\
\text { field }\end{array}$ & $\begin{array}{l}40 \text { meters at } 16-18^{\circ} \\
\text { radius }(\mathrm{N})\end{array}$ & $\begin{array}{l}40 \text { meters at } 16-20^{\circ} \\
\text { radius }(N-N E)\end{array}$ & $\begin{array}{l}30 \text { meters at } 16-20^{\circ} \text { radius } \\
(\mathrm{N}-\mathrm{NE})\end{array}$ \\
\hline $\begin{array}{l}200 \mathrm{mb} \text { height } \\
\text { field }\end{array}$ & $\begin{array}{l}>150 \text { meters at } 18-20^{\circ} \\
\text { radius }(\mathrm{NW}-\mathrm{N})\end{array}$ & $\begin{array}{l}>200 \text { meters at } 18-20^{\circ} \\
\text { radius }(\mathrm{N})\end{array}$ & $\begin{array}{l}>300 \text { meters at } 18-20^{\circ} \\
\text { radius }(\mathrm{N})\end{array}$ \\
\hline $\begin{array}{l}700 \mathrm{mb} \text { tempera- } \\
\text { ture field }\end{array}$ & $\begin{array}{l}4^{\circ} \mathrm{C} \text { at } 18-20^{\circ} \text { radius } \\
(\mathrm{NW}-\mathrm{N})\end{array}$ & $6^{\circ}$ at $18-20^{\circ}$ radius $(\mathrm{NW}-\mathrm{N})$ & $8^{\circ} \mathrm{C}$ at $18-20^{\circ}$ radius $(\mathrm{NW}-\mathrm{N})$ \\
\hline $\begin{array}{l}200 \mathrm{mb} \text { tempera- } \\
\text { ture field }\end{array}$ & $\begin{array}{l}1^{\circ} \mathrm{C} \text { at } 18-20^{\circ} \text { radius } \\
(\mathrm{NW}-\mathrm{N})\end{array}$ & $2^{\circ} \mathrm{C}$ at $18-20^{\circ}$ radius $(\mathrm{NW}-\mathrm{N})$ & $2^{\circ} \mathrm{C}$ at $18-20^{\circ}$ radius $(\mathrm{NW}-\mathrm{N})$ \\
\hline
\end{tabular}




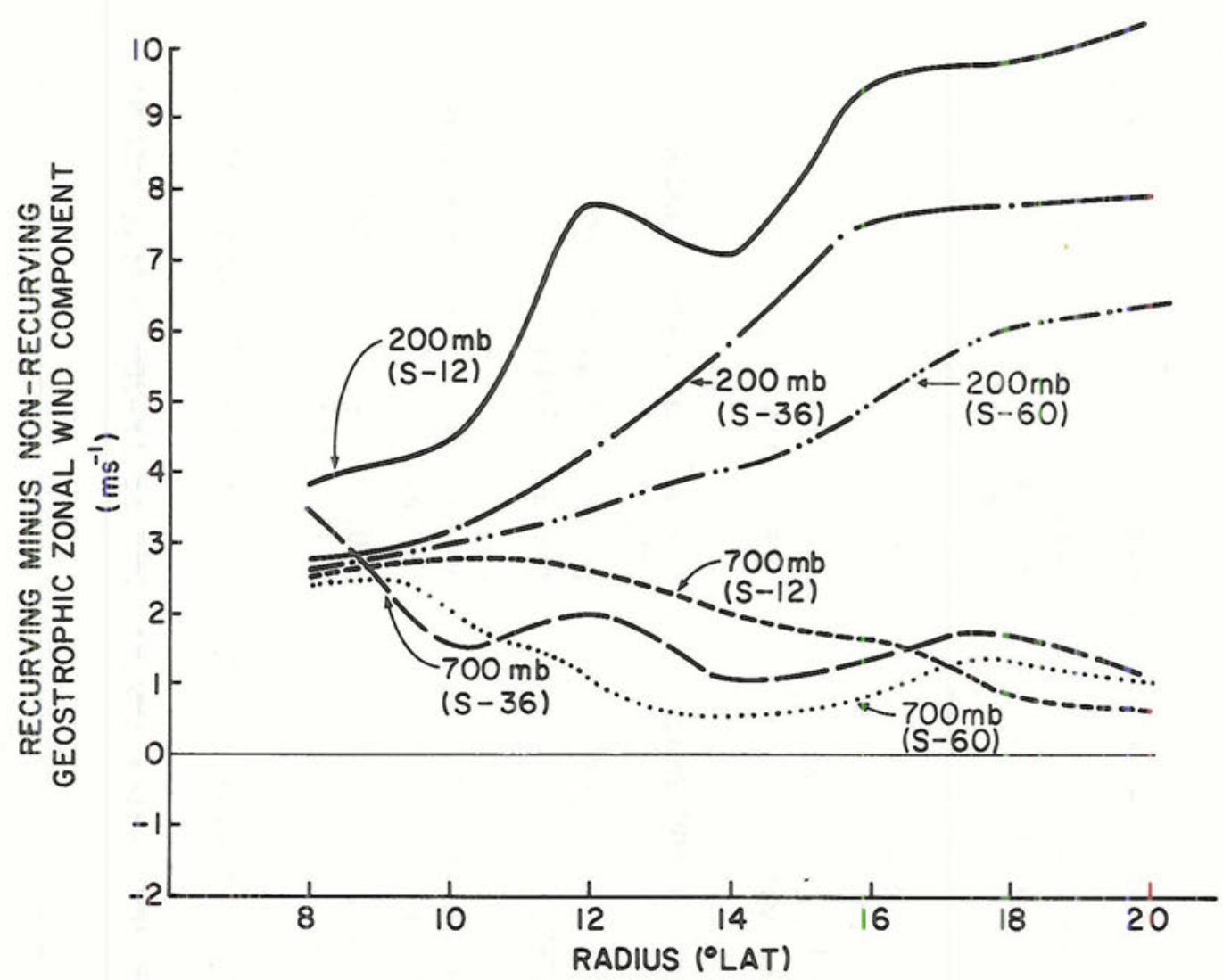

Figure 48. Recurving minus non-recurving geostrophic zonal wind component across the cyclones, based on $700 \mathrm{mb}$ and $200 \mathrm{mb}$ N-S height gradients at various radil.

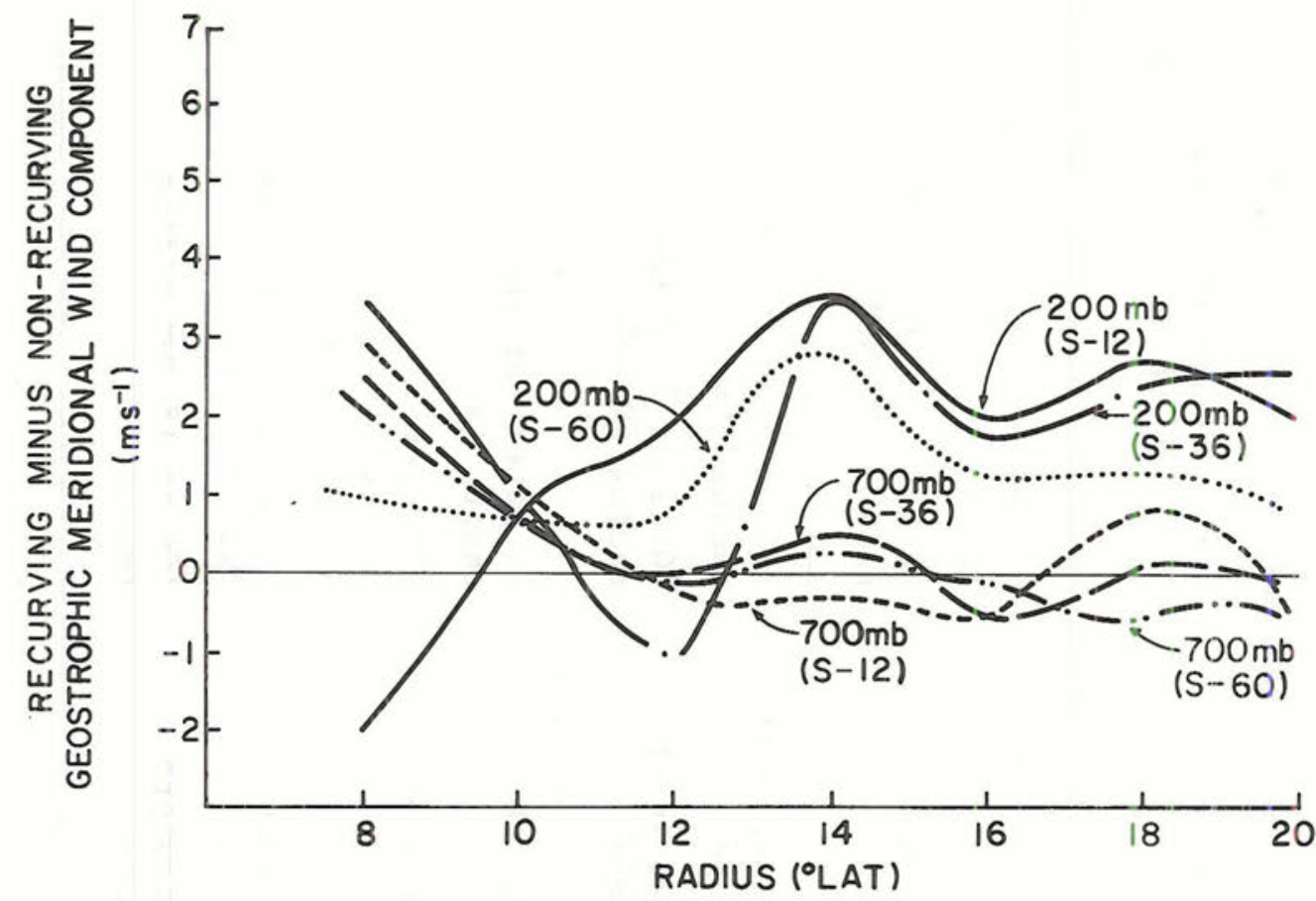

Figure 49. Recurving minus non-recurving geostrophic meridional wind component across the cyclones, based on $700 \mathrm{mb}$ and $200 \mathrm{mb}$ $\mathrm{E}-\mathrm{W}$ height gradients at various radii. 


\section{DISCUSSION}

The results of this recurvature study are encouraging. It seems reasonable that an improved 24 to 72 hour recurvature forecast scheme could be developed using $200 \mathrm{mb}$ level outer radii $\left(16-20^{\circ}\right)$ data. Statistical studies on single cases should now be accomplished to establish the extent to which these average differences can be used in individual situations. These recurvature relationships should also be applicable in the Western Atlantic and other tropical cyclone regions. 
SUMMARY OF PARTS I AND II 


\section{SUMMARY}

As shown by the results in Section I, the best short range steering indicators are found in the lower troposphere and at radii inside $7^{\circ}$. A single level or integrated vertical level in the troposphere was not found to give the best steering results for both direction and speed. However, at short range, storms are best steered by the lower rather than the upper troposphere. The composited data does not show consistent motion-wind relationships at upper levels. Thus, it appears that one should not attempt short range steering with the upper tropospheric data. The comparisons between the composite wind and the geostrophic winds indicate that these pieces of information can be used interchangeably. It appears that the inner convection is not of primary importance in influencing cyclone movement. If the surrounding flow could be better monitored, then the relationships described in this paper could be used to develop an operational forecast scheme. Also, crucial short range forecasts (those where the tropical cyclone is reaching a populated area) might be improved by having aircraft continually monitor the cyclone surrounding height fields at $5-7^{\circ}$ radius.

The recurvature results in Section II indicate that 12 to 60 hours prior to a significant change in cyclone track, there occur large scale parameter differences at upper tropospheric levels and at large radii. The implications of these results for improved recurvature forecasting appear encouraging. With further research, these differences can likely be incorporated into an operational forecasting procedure. Many of the current recurvature forecasting schemes are based on 850-500 mb flow fields. By contrast, this study shows the large benefit that is likely 
to be derived by use of upper troposphere wind-height data at large radii. This has been shown to be a far stronger indicator of recurvature than the lower tropospheric flow. The results of this paper for West Pacific cyclones should be valid in the Western Atlantic and in other tropical regions. 
ACKNOWLEDGEMENTS

The author gratefully acknowledges the guidance, enthusiasm, and encouragement of $\mathrm{Dr}$. William M. Gray who served as his advisor during the course of this research. This study was made possible by the special computer programming expertise of Messrs. Edwin Buzzell and Charles Solonon. Gratitude is extended to Mr. William M. Frank and Major Charles P. Arnold for enlightening discussions. Mrs. Barbara Brumit and Ms. Genevra Metcalf assisted in the data reduction and manuscript preparation.

This research was accomplished while the author was enrolled in the U. S. Air Force Institute of Technology (AFIT) meteorology program at Colorado State University, and has been largely supported by a NOAA research grant (No. 04-5-022-14). The punching of the Japanese rawinsonde data was accomplished through arrangement with the U. S. Navy Environment Prediction Research Facility. 


\section{BIBLIOGRAPHY}

Arakawa, H., 1961: Prediction of movements and surface pressures of typhoon centers in the Far East by statistical methods. Nat'1. Hurr. Res. Proj. Report No. 43, 18 pp. (Available from the U.S. Weather Bureau, Miami, FL).

1963: Studies on statistical prediction of typhoons. Nat'1. Hurr. Res. Proj. Report No. 61, 15 pp. (Available from the U.S. Weather Bureau, Miami, FL).

Birchfield, G. E., 1960: Numerical prediction of hurricane movenent with the use of a fine grid. J. Meteor., 17, 406-414.

Burroughs, I. D. and S. Brand, 1972: Speed of tropical storms and typhoons after recurvature in the western North Pacific ocean. ENVPREDRSCHFAC Tech. Paper No. 7-72, Environmental Prediction Research Facility, Naval Postgraduate School, Monterey CA 93940.

Chin, P. C., 1970: The control point method for the prediction of tropical cyclone movement. Royal Obs. Hong Kong Tech. Note No. 30,25 pp.

Co16n, H. A., 1953: A study of hurricane tracks for forecasting purposes. Mon. Wea. Rev., 81, 53-66.

Dunn, G. E. and B. I. Miller, 1964: Atlantic Hurricanes, Louisiana State Univ. Press, 377 pp.

Gentry, R. C., 1951: Forecasting the formation and movement of the Cedar Keys hurricane, September 1-7, 1950. Mon. Wea. Rev., 79, 107-115.

Gray, W. M., 1971: A climatology of tropical cyclones and disturbances of the Western Pacific with a suggested theory for their genesis/ maintenance. NAVWEARSCHFAC Technical Paper No. 19-70. 225 pp.

Hope, J. R. and C. J. Neumann, 1970: An operational technique for relating the movement of existing tropical cyclones to past tracks. Mon. Wea. Rev., 98, 925-933.

\section{, 1971: Digitized Atlantic tropica1}

cyclone tracks, Technical Memorandum NWS SR-55, National Weather Service, Southern Region, U. S. Department of Comnerce, Miami, FL.

Hubert, L. F., 1956: Numerical weather prediction of hurricane motion. Nat'1. Hurr. Res. Proj. Report No. 2, 29 pp. (Available from the U. S. Weather Bureau, Miami, FL).

1950: An operational test of a numerical prediction method for hurricanes. Mon. Wea. Rev., 87, 222-230.

Hubert, W. E., 1957: Hurricane trajectory forecasts from a nondivergent, non-geostrophic, barotropic model. Mon. Wea. Rev., $85,83-87$. 


\section{BIBLIOGRAPHY (cont'd)}

Japan Meteorological Agency, 1963: Daily Weather Maps, Sept. 3, 1963, and Oct. 9, 1963. Tokyo, Japan.

Jarre11, J. D. and W. L. Somerve11, 1970: A computer technique for using typhoon analogs as a forecast aid. NAVWEARSCHFAC Tech. Paper No. 6-70, Naval Weather Research Facility, Norfolk, VA.

Jordan, E. S., 1952: An observational study of the upper wind circulation around tropical storms. J. Meteor., 9, 340-346.

Kasahara, A., 1957: The numerical prediction of hurricane movement with the barotropic model. J. Meteor., 14, 386-402.

Miller, B. I., 1958a: The use of mean layer winds as a hurricane steering mechanism. Nat'1. Hurr. Res. Proj. Report No. 18, 24 pp.

(Available from the U.S. Weather Bureau, Miami, IL).

, 1958b: The three-dimensional wind structure around a tropical cyclone. Nat'1. Hurr. Res. Proj. Report No. 15, 41 pp.

(Available from the U.S. Weather Bureau, Miami, FL).

and P. L. Moore, 1960: A comparison of hurricane steering

levels. Bull. Amer. Meteor. Soc., 41, 59-63.

and P. P. Chase, 1966: Prediction of hurricane motion by

statistical methods. Mon. Wea. Rev., 94, 399-406.

E. C. Hill and P. P. Chase, 1968: A revised technique

for forecasting hurricane movement by statistical methods. Mon. Wea. Rev., 96, 540-548.

, P. P. Chase and B. R. Jarvinen, 1972: Numerical prediction of tropical weather systems. Mon. Wea. Rev., 100, 825-835.

Neumann, C. J., 1972a: An alternate to the Hurran tropical cyclone forecast system. Technical Memorandum NWS SR-62, National Weather Service, Southern Region, U.S. Department of Commerce, Miami, FL.

, J. R. Hope and B. I. Miller, 1972b: A statistical method of combining synoptic and empirical tropical cyclone prediction systems. Technical Memorandum NWS SR-63, National Weather Service Southern Region, U. S. Department of Commerce, Miami, FL.

and M. B. Lawrence, 1973: Statistical-dynamical prediction of tropical cyclone motion (NHC-73). Technical Memorandum NWS SR-69, National Weather Service, Southern Region. U.S. Department of Commerce, Miami, FL.

Renard, R. J., 1968: Forecasting the motion of tropical cyclones using a numerically derived steering current and its bias. Mon. Wea. Rev., 96, 453-469. 


\section{BIBLIOGRAPHY (cont'd)}

Renard, R. J. and W. H. Levings, 1969: The Navy's numerical hurricane and typhoon forecast scheme: Application to 1967 Atlantic storm data. J. App1. Meteor., 8, 717-725.

et a1., 1973: Forecasting the motion of north Atlantic tropical cyclones by the objective MOHATT scheme. Mon. Wea. Rev., $101,206-214$.

Riehl, H. and R. J. Shafer, 1944: The recurvature of tropical storms. J. Meteor., 1, 42-54.

and N. H. Burgner, 1950: Further studies of the movement and formation of hurricanes and their forecasting. Bull. Amer. Meteor. Soc., 31, 244-253.

W. H. Haggard and R. W. Sanborn, 1956: On the prediction of 24 hour hurricane motion. J. Meteor., 13, 415-420.

Ruprecht, E. and W. M. Gray, 1974: Analysis of satellite-observed tropical cloud clusters. Atmos. Sci. Research Paper No. 219, Colo. State Univ,, Ft. Collins, CO, 91 pp.

Sanders, F. and R. H. Burpee, 1968: Experiments in barotropic hurricane track forecasting. J. App. Meteor., 7, 313-323.

, 1970: Dynamic forecasting of tropical storm tracks. New York Acad. of Sci. Trans., 32, 495-508.

Shea, D. J. and W. M. Gray, 1973: The hurricane's inner core region: I. Symmetric and asymmetric structure. J.A.tmos. Sci, 30, 1544-1564.

Sherman, L., 1950: On the propagation of hurricanes. Trans. Amer. Geophys. Union, 31, 531-535.

Simpson, R. H., 1946: On the movement of tropical cyclones. Trans. Amer. Geophys. Union, 27, 641-655.

Tse, S. Y. W., 1966: A new method for the prediction of typhoon movement using the 700-mb chart. Quart. J. Roy. Meteor. Soc., $92,239-254$.

Vanderman, L. W., 1962: An improved NWP model for forecasting the paths of tropical cyclones. Mon. Wea. Rev., 90, 19-22.

Veigas, K. W., 1961: Prediction of twelve, twenty-four, and thirty-six hour development of hurricanes by statistical methods. Final Report, The Travelers Research Center, Hartford, CT, 39 pp.

, 1962: Development of prediction equations for hurricane movement. Final Report, The Travelers Research Center, Hartford, CT, 59 pp. 


\section{BIBLIOGRAPHY (cont'd)}

Veigas, K.W., R. B. Miller, and G. H. Howe, 1959: Probabilistic prediction of hurricane movements by synoptic climatology. Travelers Weather Research Center, Occasional Papers in Meteorology, No. 2, Hartford, CT, 54 pp.

Wang, G., 1960: A method in regression equations for forecasting the movement of typhoons. Bul1. Amer. Meteor. Soc., 41, 115-124.

Williams, K. T. and W. M. Gray, 1973: Statistical analysis of satelliteobserved trade wind cloud clusters in the western North Pacific. Tellus, 25, 313-336. 


\section{APPENDIX}

Number of Observations per Grid Space

The number of rawinsonde soundings in each grid space (see Figure 3) is shown below in Tables A through $\mathrm{F}$ for each stratified composite data set discussed. The data is presented in matrix form with the columns indicating the radial bands and the rows indicating the 8 octants. 
TABLE A: RAWINSONDE CASE COUNTS FOR LATITUDE STRATIFICATION

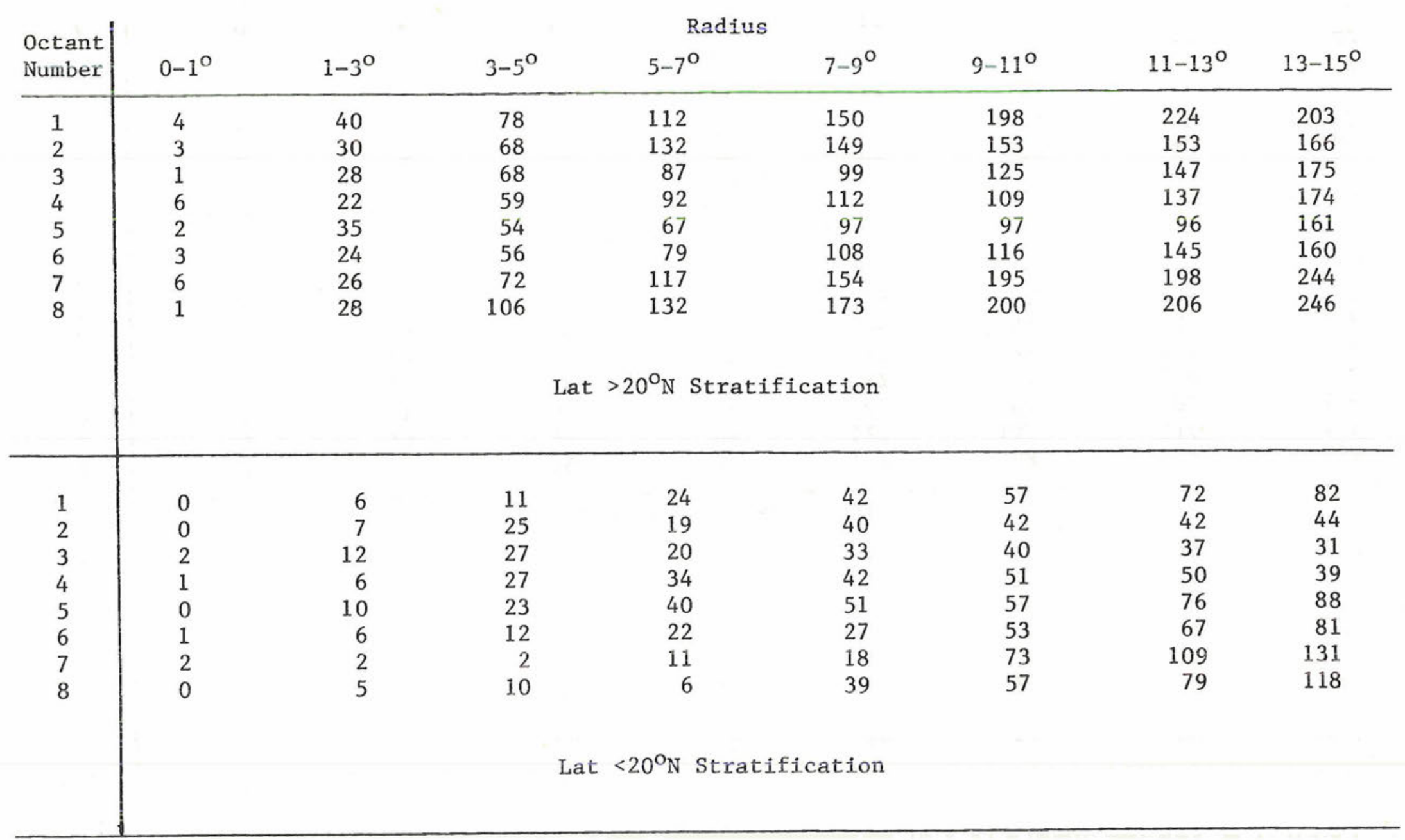


TABLE B: RAWINSONDE CASE COUNTS FOR SPEED STRATIFICATION

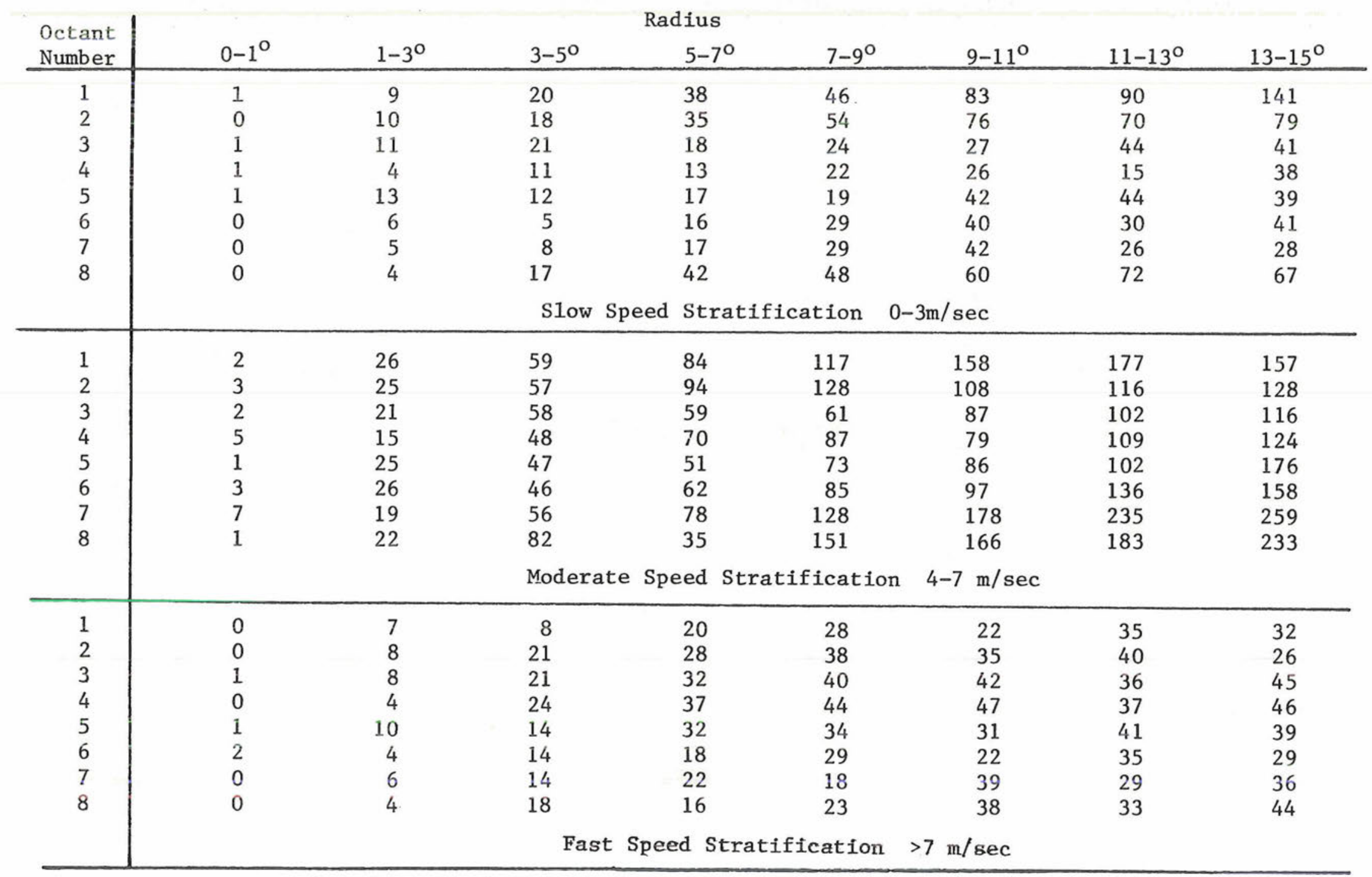


TABLE C: RAWINSONDE CASE COUNTS FOR DIRECTION STRATIFICATION

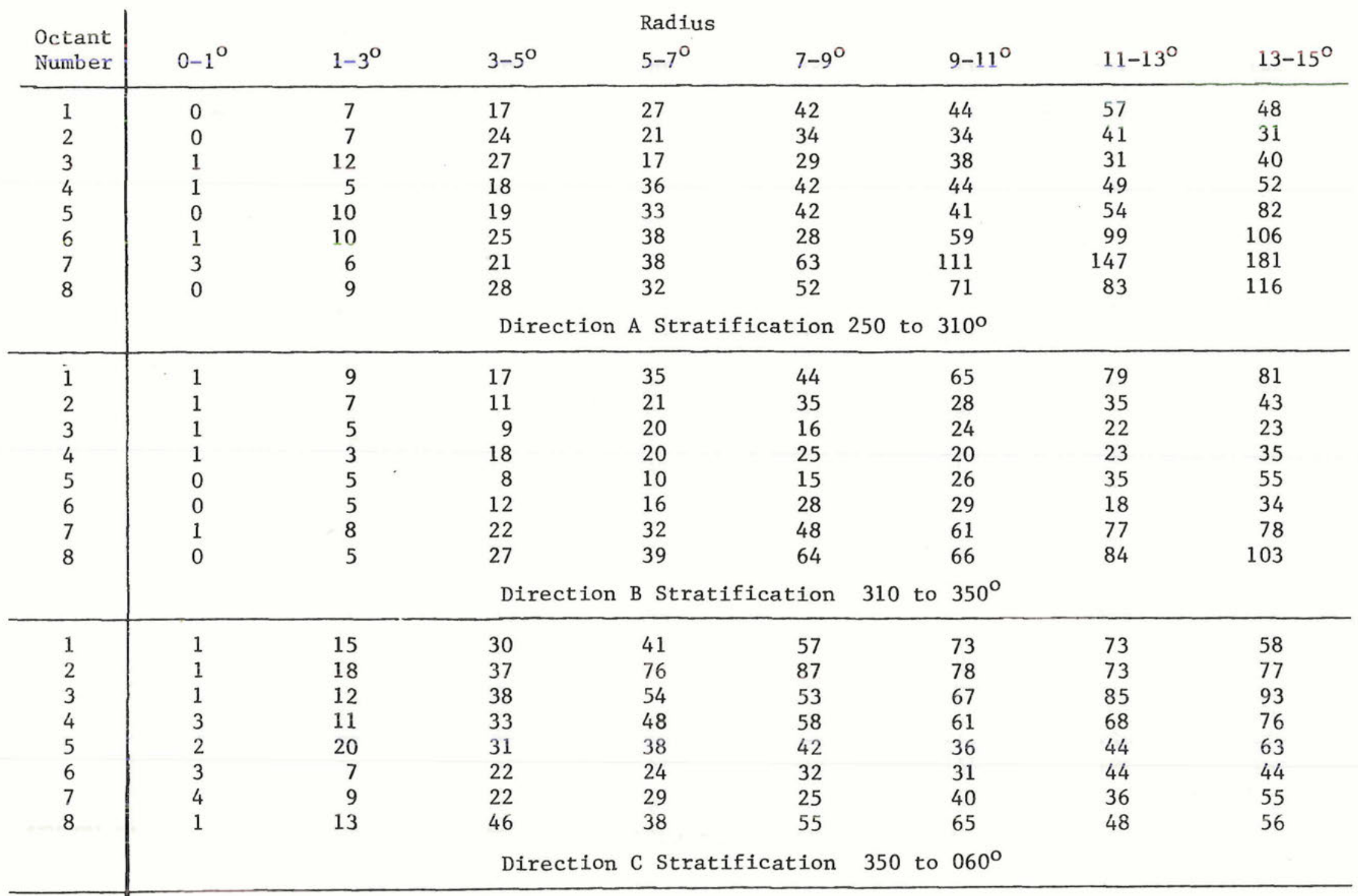


TABLE D: RAWINSONDE CASE COUNTS FOR INTENSITY STRATIFICATION

\begin{tabular}{|c|c|c|c|c|c|c|c|c|}
\hline $\begin{array}{l}\text { Octant } \\
\text { Number }\end{array}$ & $0-1^{\circ}$ & $1-3^{\circ}$ & $3-5^{\circ}$ & $\begin{array}{r}\text { Rad } \\
5-7^{\circ} \\
\end{array}$ & $7-9^{\circ}$ & $9-11^{\circ}$ & $11-13^{\circ}$ & $13-15^{\circ}$ \\
\hline 1 & 3 & 29 & 36 & 91 & 118 & 122 & 164 & 184 \\
\hline 2 & 0 & 30 & 54 & 70 & 92 & 111 & 139 & 146 \\
\hline 3 & 1 & 26 & 35 & 63 & 51 & 77 & 104 & 109 \\
\hline 4 & 2 & 21 & 45 & 55 & 68 & 89 & 76 & 115 \\
\hline 5 & 4 & 21 & 40 & 55 & 83 & 89 & 112 & 133 \\
\hline 6 & 2 & 11 & 42 & 61 & 69 & 93 & 114 & 186 \\
\hline 7 & 3 & 20 & 43 & 66 & 78 & 137 & 189 & 149 \\
\hline \multirow[t]{2}{*}{8} & 1 & 15 & 38 & 70 & 104 & 135 & 187 & 209 \\
\hline & & & \multicolumn{5}{|c|}{ Intensity 1 Stratification $1000-980 \mathrm{mb}$} & \\
\hline 1 & 2 & 12 & 32 & 64 & 110 & 157 & 167 & 175 \\
\hline 2 & 2 & 16 & 40 & 76 & 101 & 110 & 103 & 104 \\
\hline 3 & 2 & 18 & 36 & 51 & 58 & 93 & 94 & 121 \\
\hline 4 & 2 & 11 & 40 & 60 & 55 & 80 & 77 & 91 \\
\hline 5 & 0 & 21 & 32 & 46 & 73 & 76 & 77 & 128 \\
\hline 6 & 3 & 8 & 26 & 51 & 72 & 92 & 115 & 157 \\
\hline 7 & 3 & 6 & 31 & 59 & 80 & 143 & 161 & 221 \\
\hline \multirow[t]{2}{*}{8} & 0 & 10 & 46 & 63 & 103 & 120 & 146 & 207 \\
\hline & & & Intensity 2 & Strat & \multicolumn{2}{|c|}{$980-950 \mathrm{mb}$} & & \\
\hline 1 & 0 & 13 & 30 & 51 & 68 & 88 & 122 & 107 \\
\hline 2 & 0 & 7 & 25 & 37 & 55 & 62 & 80 & 95 \\
\hline 3 & 0 & 8 & 20 & 14 & 30 & 40 & 50 & 61 \\
\hline 4 & 3 & 4 & 14 & 14 & 35 & 43 & 57 & 67 \\
\hline 5 & 0 & 7 & 15 & 25 & 33 & 43 & 65 & 87 \\
\hline 6 & 1 & 6 & 18 & 23 & 24 & 37 & 64 & 69 \\
\hline 7 & 1 & 10 & 16 & 30 & 65 & 93 & 121 & 125 \\
\hline \multirow[t]{2}{*}{8} & 0 & 12 & 36 & 35 & 76 & 119 & 130 & 143 \\
\hline & & & Intensity 3 & Strat & ion & $\mathrm{mb}$ & & \\
\hline
\end{tabular}


TABLE E: RAWINSONDE CASE COUNTS FOR INTENSITY CHANGE STRATIFICATION

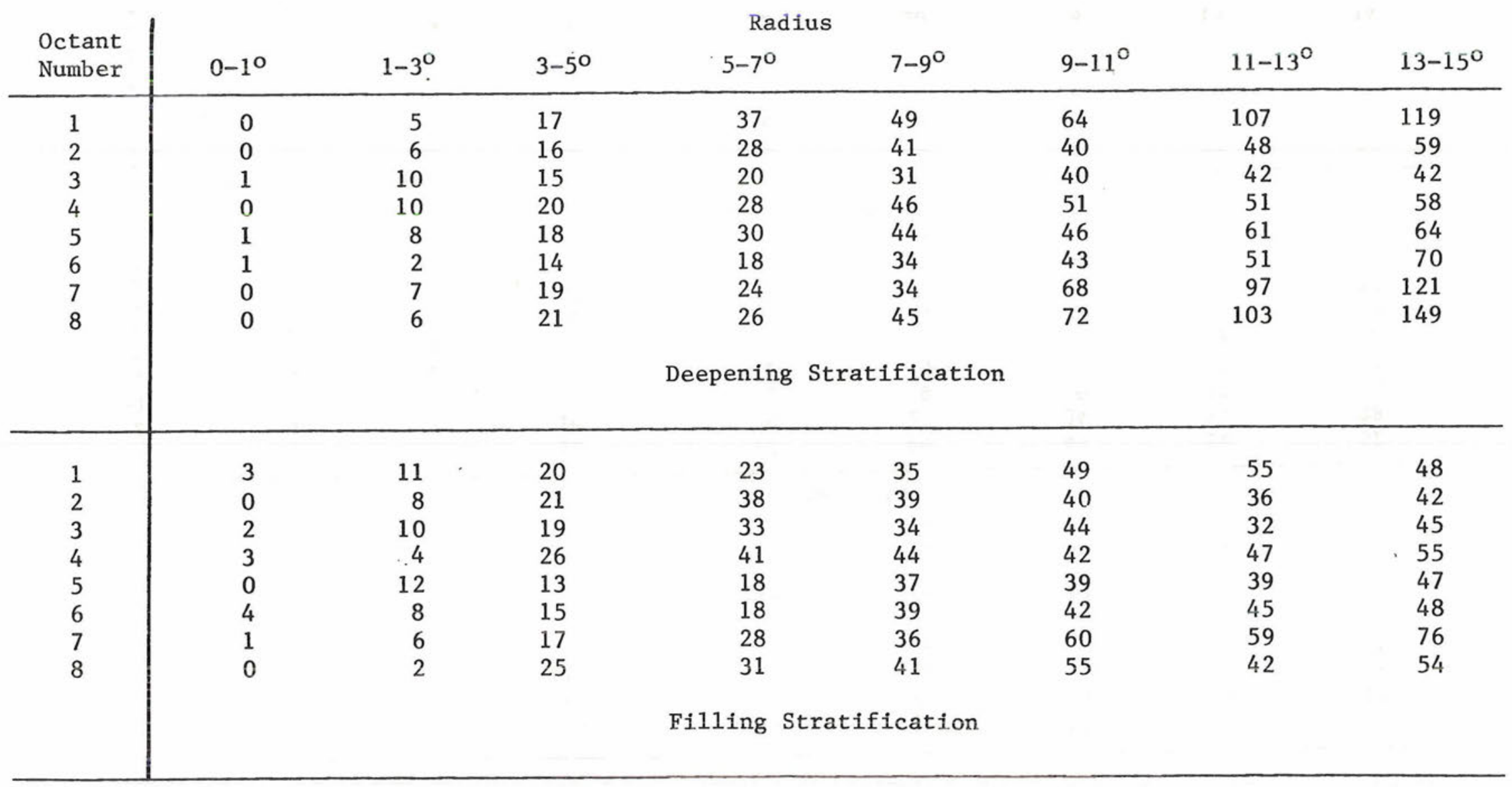


TABLE F. RAWINSONDE CASE COUNTS FOR RECURVATURE STUDIES

\begin{tabular}{lrrrrrrrr}
$\begin{array}{l}\text { Octant } \\
\text { Number }\end{array}$ & $5-7^{\circ}$ & $7-9^{\circ}$ & $9-11^{\circ}$ & $11-13^{\circ}$ & $13-15^{\circ}$ & $15-17^{\circ}$ & $17-19^{\circ}$ & $19-21^{\circ}$ \\
\hline 1 & 17 & 21 & 30 & 43 & 42 & 51 & 73 & 52 \\
2 & 4 & 14 & 20 & 12 & 24 & 14 & 10 & 12 \\
3 & 6 & 7 & 13 & 9 & 12 & 1 & 4 & 1 \\
4 & 0 & 3 & 5 & 5 & 4 & 4 & 1 & 1 \\
5 & 5 & 3 & 8 & 14 & 15 & 13 & 5 & 3 \\
6 & 7 & 9 & 6 & 7 & 7 & 7 & 15 & 8 \\
7 & 5 & 5 & 8 & 18 & 19 & 28 & 28 & 11 \\
8 & 4 & 11 & 13 & & & & & \\
\end{tabular}

(S - 12) Time Period

\begin{tabular}{|c|c|c|c|c|c|c|c|c|}
\hline 1 & 0 & 3 & 11 & 17 & 40 & 45 & 54 & 52 \\
\hline 2 & 4 & 7 & 10 & 20 & 27 & 34 & 34 & 28 \\
\hline 3 & 1 & 3 & 4 & 8 & 9 & 10 & 10 & 5 \\
\hline 4 & 4 & 0 & 3 & 2 & 5 & 3 & 3 & 0 \\
\hline 5 & 5 & 8 & 8 & 4 & 3 & 2 & 2 & 0 \\
\hline 6 & 8 & 7 & 9 & 6 & 5 & 5 & 5 & 9 \\
\hline 7 & 7 & 7 & 7 & 11 & 10 & 11 & 11 & 17 \\
\hline 8 & 4 & 7 & 4 & 9 & 9 & 4 & 4 & 10 \\
\hline
\end{tabular}

(S - 36) Time Period

\begin{tabular}{|c|c|c|c|c|c|c|c|c|}
\hline 1 & 2 & 3 & 8 & 13 & 25 & 24 & 25 & 24 \\
\hline 2 & 4 & 2 & 3 & 6 & 9 & 9 & 12 & 10 \\
\hline 3 & 1 & 2 & 2 & 3 & 5 & 4 & 6 & 0 \\
\hline 4 & 2 & 8 & 4 & 5 & 2 & 5 & 0 & 0 \\
\hline 5 & 5 & 10 & 7 & 4 & 3 & 6 & 6 & 6 \\
\hline 6 & 7 & 5 & 8 & 12 & 10 & 8 & 13 & 14 \\
\hline 7 & 7 & 8 & 9 & 4 & 5 & 9 & 8 & 10 \\
\hline 8 & 5 & 2 & 6 & 16 & 30 & 51 & 46 & 47 \\
\hline
\end{tabular}

(S - 60) Time Period 


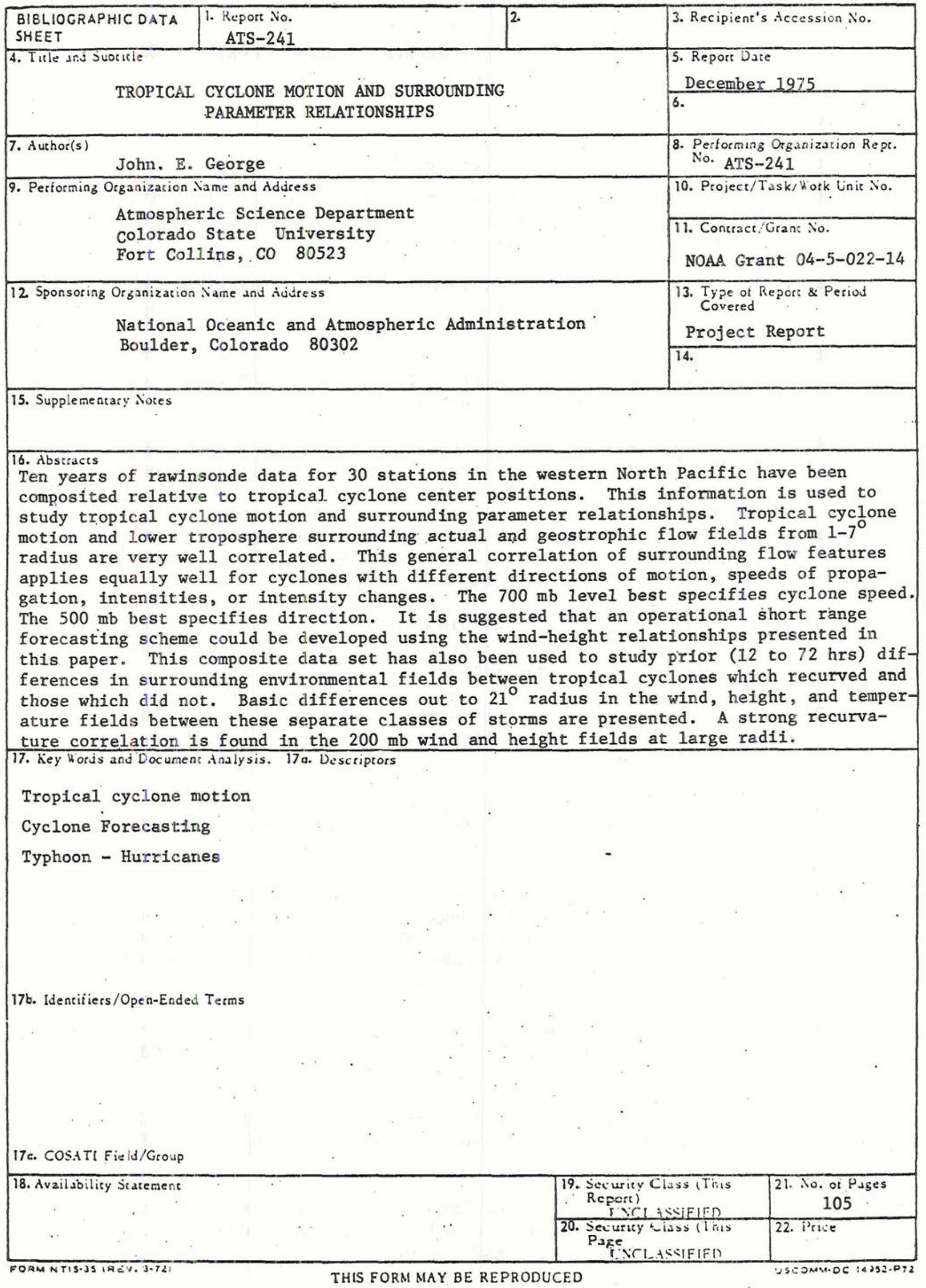


W. M. GRAY'S FEDERALLY SUPPORTED RESEARCH PROJECT REPORTS SINCE 1967

CSU Dept. of

Atmos. Sci.

Report No.

104

114

116

124

Unnumbered

Unnumbered

140

161

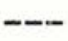

179

182

188

\section{Report Title, Author, Date, Agency Support}

The Mutual Variation of Wind, Shear, and Baroclinicity in the Cumulus Convective Atmosphere of the Hurricane (69pp). W. M. Gray. February 1967. NSF Support.

Global View of the Origin of Tropical Disturbances and Storms (105pp). W. M. Gray. October 1.967. NSF Support.

A Statistical Study of the Frictional Wind Veering in the Planetary Boundary Layer (57pp). B. Mendenhall. December 1967. NSF and ESSA Support.

Investigation of the Importance of Cumulus Convection and Ventilation in Early Tropical Storm Development (88pp). R. Lopez. June 1968. ESSA Satellite Lab. Support.

Role of Angular Momentum Transports in Tropical Storm Dissipation over Tropical Oceans (46pp). R. F. Wachtmann. December 1968. NSF and ESSA Support.

Monthly Climatological Wind Fields Associated with Tropical Storm Genesis in the West Indies (34pp). J. W. Sartor. December 1968. NSF Support.

Characteristics of the Tornado Environment as Deduced from Proximity Soundings (55pp). T. G. Wills. June 1969. NOAA and NSF Support.

Statistical Analysis of Trade Wind Cloud Clusters of the Western North Pacific (80pp). K. Williams. June 1970. ESSA Satellite Lab. Support.

A Climatology of Tropical Cyclones and Disturbances of the Western Pacific with a Suggested Theory for Their Genesis/ Maintenance. W. M. Gray. NAVWEARSCHFAC Technical Paper No. 19-70 (225pp). November 1970. (Available from U.S. Navy, Monterey, CA). U.S. Navy Support.

A Diagnostic Study of the Planetary Boundary Layer over the Oceans (95pp). W. M. Gray. February 1972. Navy and NSF Support.

The Structure and Dynamics of the Hurricane's Inner Core Area (105pp). D. J. Shea. April 1972. NOAA and NSF Support.

Cumulus Convection and Larger-Scale Circulation, Part I: A Parametric Model of Cumulus Convection (100pp). R. E. Lopez. June 1972. NSF Support. 
W. M. GRAY'S FEDERALLY SUPPORTED RESEARCH PROJECT REPORTS SINCE 1967

(Continued)

CSU Dept. of

Atmos. Sci.

Report No.

189

190

195

196

199

200

212

219

224

225

234
Report Title, Author, Date, Agency Support

Cumulus Convection and Larger-Scale Circulations, Part II: Cumulus and Meso-Scale Interactions (63pp). R. E. Lopez. June 1972. NSF Support.

Cumulus Convection and Larger-Scale Circulations, Part III: Broadscale and Meso-Scale Considerations (80pp). W. M. Gray. July 1972. NOAA-NESS.

Characteristics of Carbon Black Dust as a Tropospheric Heat Source for Weather Modification (55pp). W. M. Frank. January 1973. NSF Support.

Feasibility of Beneficial Hurricane Modification by Carbon Black Seeding (130pp). W. M. Gray. April 1973. NOAA Support.

Variability of Planetary Boundary Layer Winds (157pp). L. R. Hoxit. May 1973. NSF Support.

Hurricane Spawned Tornadoes (57pp). D. J. Novlan. May 1973. NOAA and NSF Support.

A Study of Tornado Proximity Data and an Observationally Derived Model of Tornado Genesis (101pp). R. Maddox. November 1973. NOAA Support.

Analysis of Satellite Observed Tropical Cloud Clusters (91 pp). E. Ruprecht and W. M. Gray. May 1974. NOAA-NESS Support.

Precipitation Characteristics in the Northeast Brazil Dry Region (56pp). R. P. L. Ramos. May 1974. NSF

Support.

Weather Modification through Carbon Dust Absorption of Solar Energy (190pp). W. M. Gray, W. M. Frank, M. L. Corrin, and C. A. Stokes. July 1974 .

Tropical Cyclone Genesis (121pp). W. M. Gray. March 1975. NSF Support.

Tropical Cyclone Genesis in the Western North Pacific (66pp). W. M. Gray. March 1975. U.S. Navy Environmental Prediction Research Facility Report. Technical Paper No. 16-75. (Available from the U.S. Navy, Monterey, CA). Navy Support. 
